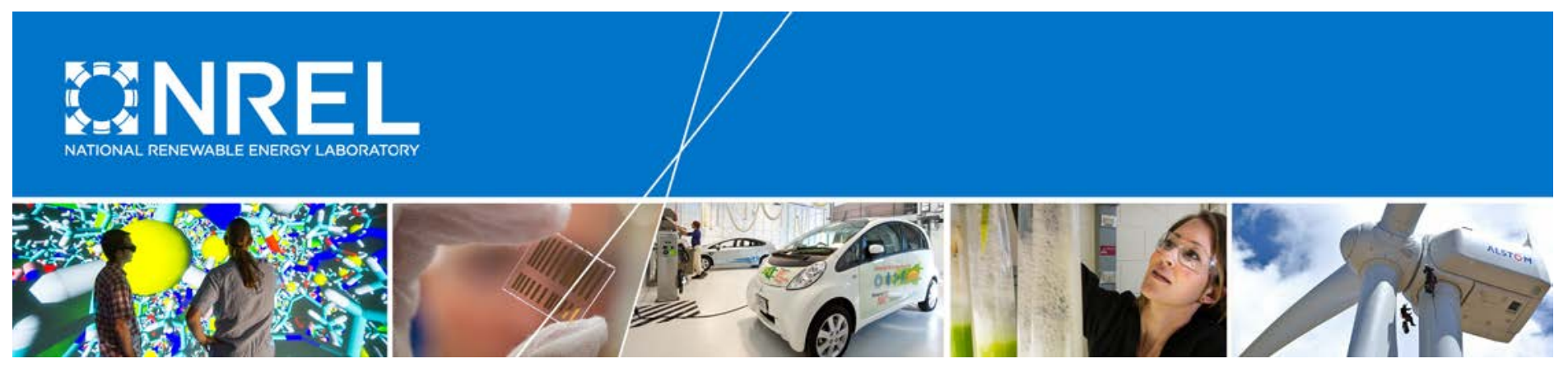

\title{
Methodology to Assess No Touch Audit Software Using Field Data
}

Jie Cai and James E. Braun Purdue University

M. Rois Langner

National Renewable Energy Laboratory

NREL is a national laboratory of the U.S. Department of Energy Office of Energy Efficiency \& Renewable Energy Operated by the Alliance for Sustainable Energy, LLC

This report is available at no cost from the National Renewable Energy Laboratory (NREL) at www.nrel.gov/publications.

Technical Report

NREL/TP-5500-67236

October 2016 


\section{Methodology to Assess No Touch Audit Software Using Field Data}

Jie Cai and James E. Braun

Purdue University

M. Rois Langner

National Renewable Energy Laboratory

Prepared under Task No. BE4C.0201

NREL is a national laboratory of the U.S. Department of Energy Office of Energy Efficiency \& Renewable Energy Operated by the Alliance for Sustainable Energy, LLC

This report is available at no cost from the National Renewable Energy Laboratory (NREL) at www.nrel.gov/publications.

National Renewable Energy Laboratory 15013 Denver West Parkway Golden, CO 80401

303-275-3000 • www.nrel.gov

\section{Technical Report}

NREL/TP-5500-67236

October 2016

Contract No. DE-AC36-08GO28308 


\section{NOTICE}

This report was prepared as an account of work sponsored by an agency of the United States government. Neither the United States government nor any agency thereof, nor any of their employees, makes any warranty, express or implied, or assumes any legal liability or responsibility for the accuracy, completeness, or usefulness of any information, apparatus, product, or process disclosed, or represents that its use would not infringe privately owned rights. Reference herein to any specific commercial product, process, or service by trade name, trademark, manufacturer, or otherwise does not necessarily constitute or imply its endorsement, recommendation, or favoring by the United States government or any agency thereof. The views and opinions of authors expressed herein do not necessarily state or reflect those of the United States government or any agency thereof.

This report is available at no cost from the National Renewable Energy Laboratory (NREL) at www.nrel.gov/publications.

Available electronically at SciTech Connect http:/www.osti.gov/scitech

Available for a processing fee to U.S. Department of Energy and its contractors, in paper, from:

U.S. Department of Energy

Office of Scientific and Technical Information

P.O. Box 62

Oak Ridge, TN 37831-0062

OSTI http://www.osti.gov

Phone: 865.576.8401

Fax: 865.576.5728

Email: reports@osti.gov

Available for sale to the public, in paper, from:

U.S. Department of Commerce

National Technical Information Service

5301 Shawnee Road

Alexandria, VA 22312

NTIS http://www.ntis.gov

Phone: 800.553 .6847 or 703.605 .6000

Fax: 703.605.6900

Email: orders@ntis.gov 


\section{List of Acronyms}

$\begin{array}{ll}\text { ANSI } & \begin{array}{l}\text { American National Standards Institute } \\ \text { BESTEST }\end{array} \\ \text { BOilding Energy Simulation Test } \\ \text { CT } & \begin{array}{l}\text { change of value } \\ \text { current transducer }\end{array} \\ \text { DOE } & \text { U.S. Department of Energy } \\ \text { EMS } & \text { energy management system } \\ \text { FDSI } & \text { Field Diagnostic Services, Inc. } \\ \text { HP } & \text { heat pump } \\ \text { HVAC } & \text { heating, ventilating, and air-conditioning } \\ \text { NREL } & \text { National Renewable Energy Laboratory } \\ \text { Purdue } & \text { Purdue University } \\ \text { RESNET } & \text { Residential Energy Services Network } \\ \text { RMS } & \text { root mean square }\end{array}$




\section{Acknowledgements}

The authors would like to acknowledge the owners and developers of the representative no touch audit tool for generation and discussion of the test sites' audit results that were used for evaluation. The team would also like to acknowledge Pallav Negi and Todd Rossi from Field Diagnostics Services, Inc. for their help in identifying the test sites and providing relevant data sets for the overall evaluation process. 


\section{Executive Summary}

The National Renewable Energy Laboratory (NREL) has a long history of developing analytical and empirical methods to test and diagnose building energy modeling tools and model calibration techniques (Judkoff et al. 1995, 2010, 2016; Neymark et al. 2002, 2008a, 2008b, 2016 ). Some of these methods have become American National Standards Institute (ANSI) Standard Methods of Test (ANSI/ASHRAE Standard 140; ANS BSR/RESNET 1201-2016). This report presents a set of test cases developed for assessing no touch building audit tools using field data, and reports on an assessment of a representative tool that is referred to as "the Tool" throughout this report. This is an empirical approach to assessing the tool. A companion report (Cheung et al. 2016) describes an analytical set of tests based on simulated data as a surrogate for actual building data applied to the same tool. Empirical and analytical validation methods each have advantages and disadvantages. Using both approaches together provides a more complete testing and diagnostic process (Judkoff et al. 1983/2008, 2006).

Building audits are widely adopted by medium to large commercial buildings as an effective means of diagnosing building operational issues and improving building energy performance. However, this technique is seldom used by small commercial buildings because of high labor and instrumentation costs. No- or low-touch audit tools that have been developed in recent years provide a more affordable means for small business owners to take advantage of this technique and improve their buildings' energy performance at a lower cost. This report was developed under the America Saves project, led by the National Trust for Historic Preservation, and aims to provide a set of test cases to assess no touch audit tools, based on real building data. The representative no touch audit tool is evaluated as an example of how to assess no touch audit tools using the empirical test set.

The Tool used for demonstration in this study uses utility bills and high-level building operation information (which can be obtained at a relatively low cost) to generate disaggregated energy end-use data and flag potential causes of high energy use associated with the building. Previous efforts within this multiyear project proposed a methodology to assess no touch audit tools with a simulation-based approach. A report was delivered documenting the detailed assessment for the same representative tool (Cheung et al. 2016). Within the proposed simulation approach, EnergyPlus and OpenStudio energy modeling software was used to develop simulated utility bill data for almost 3,000 cases. The simulations were carried out for a range of typical commercial building types under a variety of vintages, climate zones, and operating issues. The Tool's enduse disaggregation and diagnosis of the imposed operational issues were investigated for performance and reported. The simulation results show that the Tool was able to provide accurate estimates of energy end uses for some, but not all, of the building types tested. Relatively comprehensive analysis was carried out for the simulation results, including investigation of the performance sensitivity with respect to different climate zones, vintages, and building types. However, the previous effort did not consider the effects of uncertainties that would occur with measured data. It only considered the annual energy end use and did not investigate monthly end use, which would be useful in understanding the Tool's performance.

The research presented in this report builds upon these previous efforts and proposes a set of tests to assess no touch audit tools using real utility bill and on-site data. The proposed assessment methodology explicitly investigates the behaviors of the monthly energy end uses 
with respect to outdoor temperature, i.e., the building energy signature, to help understand the Tool's disaggregation accuracy. The project team collaborated with Field Diagnosis Services, Inc. (FDSI) to identify appropriate test sites for the evaluation. It would have been more ideal to install specifically designed monitoring systems on the test sites to provide higher quality benchmark data for the evaluation process. However, such project-specific instrumentation was difficult to accomplish considering time and budget limits, so the project team chose to use existing data and information from FDSI to establish benchmark data, even though it led to elevated uncertainties. From FDSI, the following four data sets were acquired for each site:

- General information about the building type, floor area, location, etc.

- One year of monthly electricity and gas bills

- Heating, ventilating, and air-conditioning equipment inventory data with make and model numbers

- One year of energy management system data.

The team selected 16 test sites initially from the buildings monitored by FDSI. Data for these sites were extracted from FDSI's database. However, two of the sites (Sites 9 and 12) had missing electricity or gas bill information for more than 6 months, and these sites were discarded from the evaluation process. A number of data processing steps were carried out to convert the raw data to meaningful metrics that could be used for evaluation purposes. The detailed processing steps along with some key processing results are documented in this report. Two selfassessment steps were performed prior to the final evaluation process to assure that obtained results were reasonable. The self-assessment steps were particularly helpful in exposing operational issues within the chosen real buildings and understanding certain unexpected behaviors in the final evaluation of the tool.

The overall assessment of the Tool involved investigating the Tool's accuracy in disaggregating energy end uses and its ability to generate appropriate message flags. Disaggregated electricity end uses estimated by the Tool were compared with the submetered energy data per billing cycle per site. Simple prediction error statistics were generated for the different end uses to evaluate overall accuracies. The assessment results show that the Tool was able to estimate cooling electricity with reasonable accuracy for many of the sites. However, the Tool's estimation of heating electricity was not as satisfactory, especially for sites that primarily used gas for heating. The accuracy of the Tool's end-use disaggregation was dependent on the pattern of the baseload electricity use - when the submetered baseload energy was fairly constant throughout the year, the Tool was able to estimate the cooling and heating electricity uses accurately. When the submetered baseload energy showed significant dependence on outdoor temperature, the temperature-dependent portion of the baseload energy was incorrectly counted towards cooling or heating energy. Gas baseload energy was zero or close to zero for all of the chosen sites, so the disaggregation of gas end uses was not conducted in the Tool's analysis. Based on the message flags generated by the Tool, the team shared a list of questions with the building owners to investigate the accuracy of the Tool's message flags. However, the project ended before feedback from individual building managers could be obtained, that was needed to evaluate the accuracy of the message flags. 
The set of tests and data developed during this project could be applicable to assessing other no touch audit tools in the market. It should be noted that the project did not have resources to add instrumentation to the existing sites and therefore a number of assumptions were made in the data processing steps to estimate unmeasured quantities. As a result, significant uncertainties exist in the current benchmark data. In the future, it would be helpful to consider more test sites with additional instrumentation that could provide a cleaner and more definitive validation test suite. Uncertainty in the measured data makes it difficult to determine if disagreements between the tool generated data and the measured data are from problems in the tool or problems in the measurements. 


\section{Table of Contents}

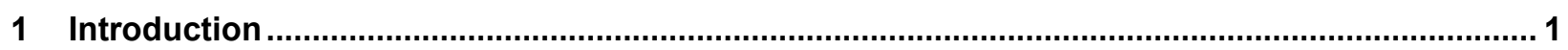

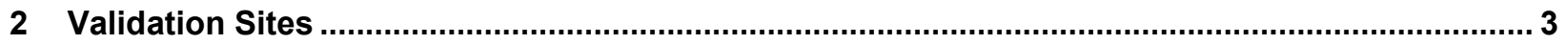

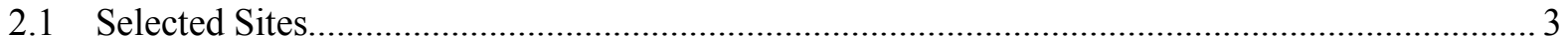

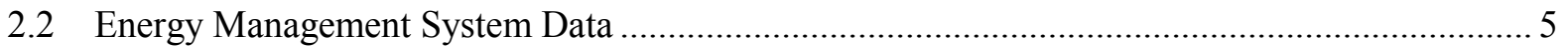

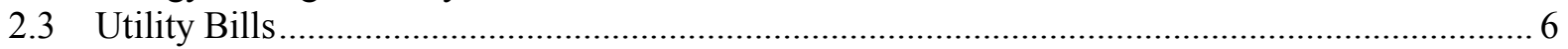

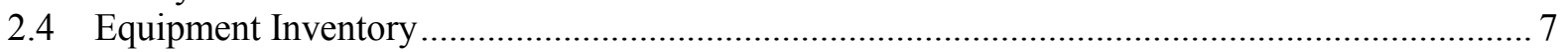

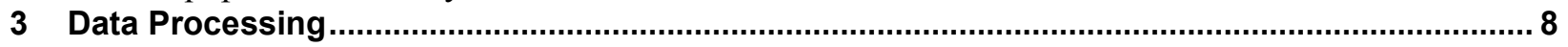

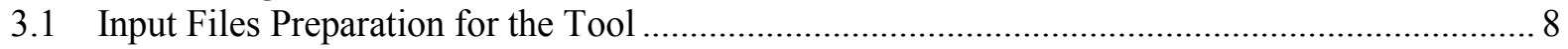

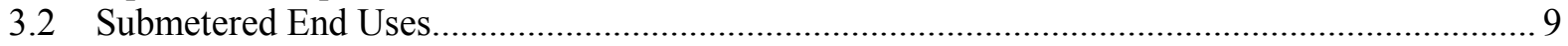

3.3 Metering Instrumentation for Space Cooling and Heating Equipment .................................. 10

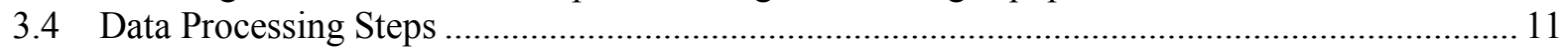

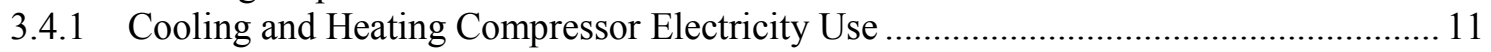

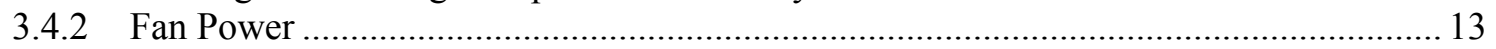

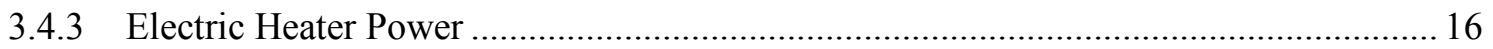

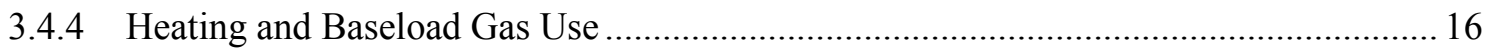

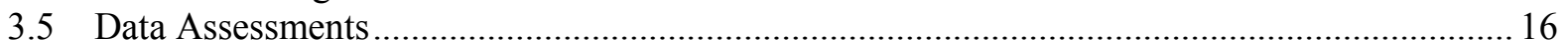

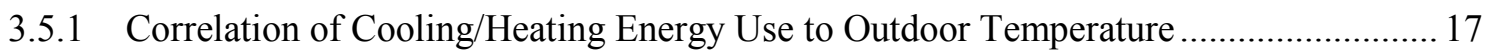

3.5.2 Assessment of Gas Use Data Based on Heating Run Time .......................................... 18

3.6 Summary of Data Processing Steps and Results .................................................................. 20

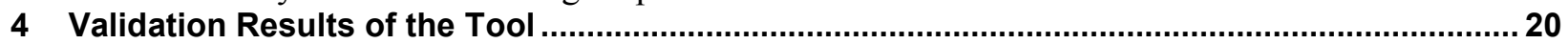

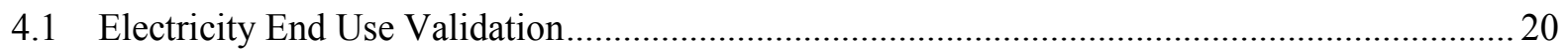

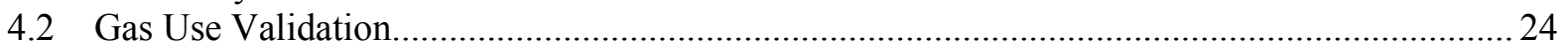

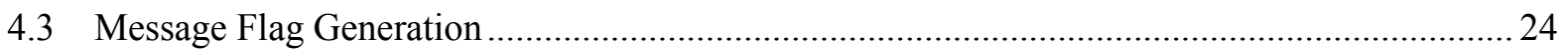

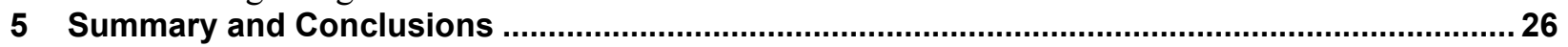

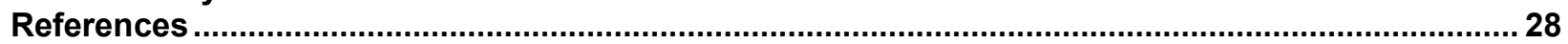

Appendix A .

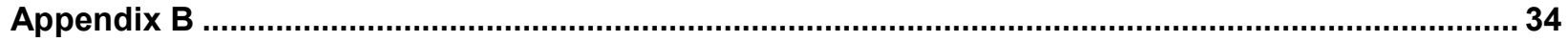

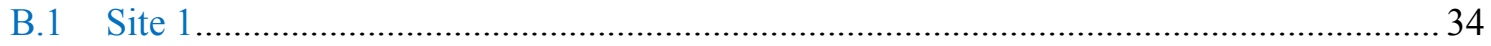

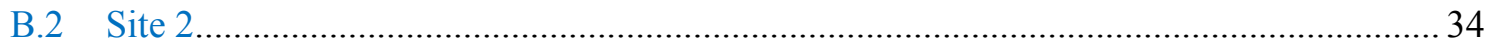

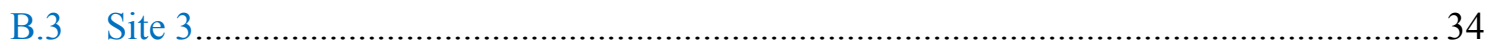

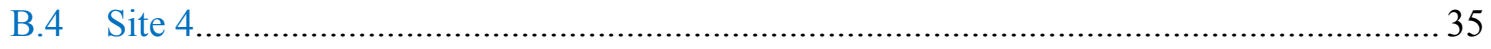

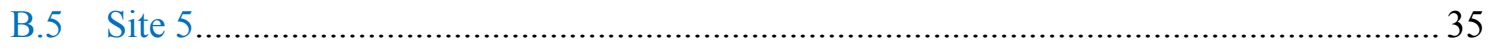

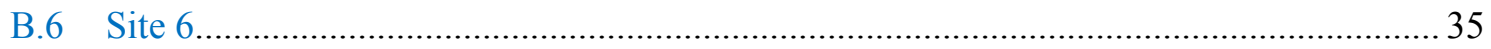

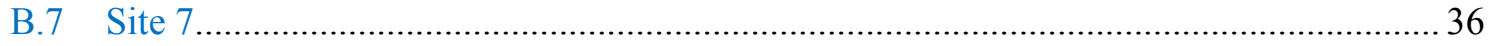

B.8 Site 8

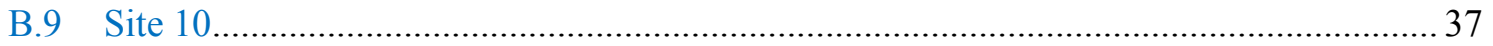

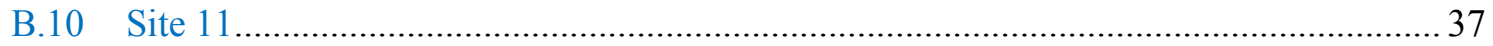

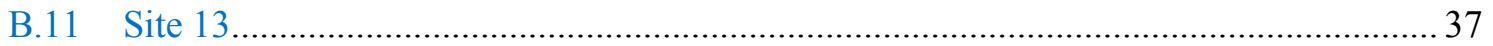

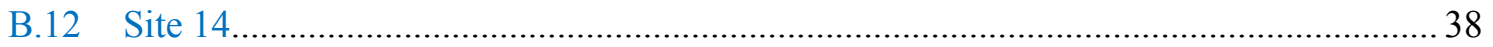

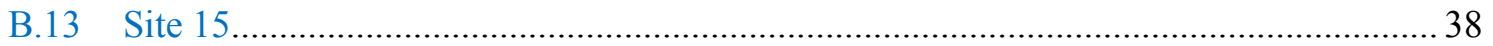

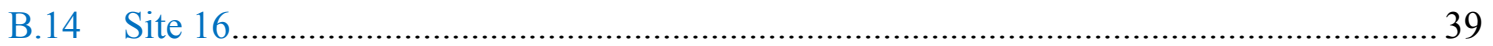

Appendix C .

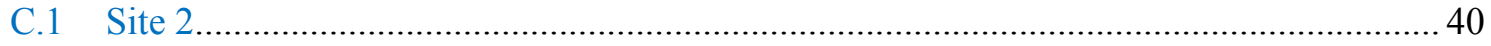

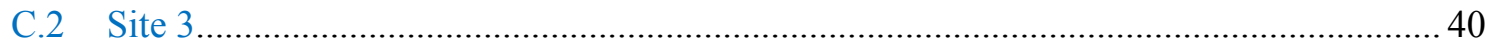

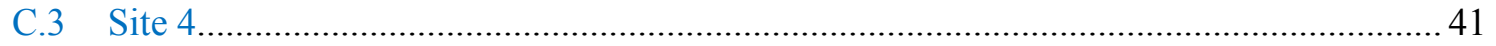

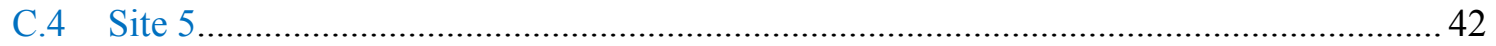

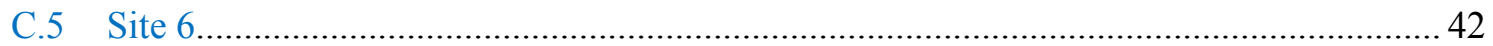

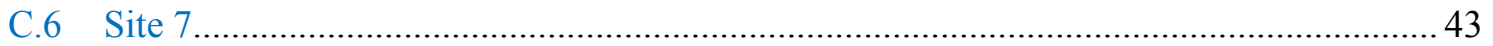

C.7 Site 8

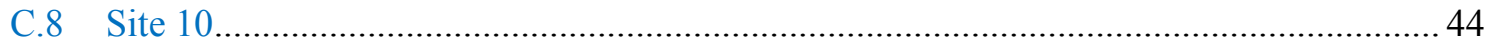




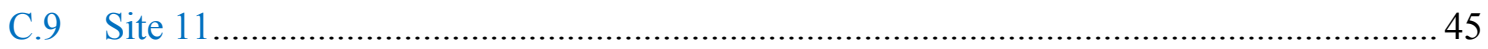

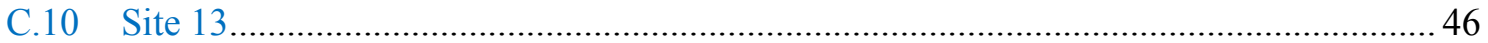

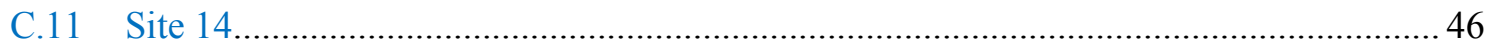

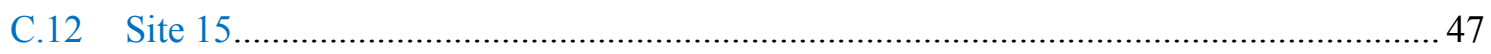

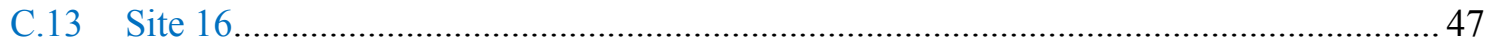

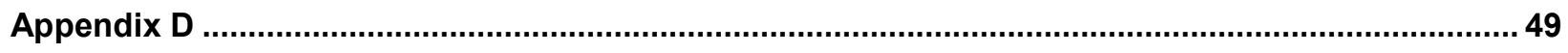




\section{List of Figures}

Figure 1. Flow chart of the overall evaluation procedure (EMS - energy management system, $\mathrm{Cl}$ cooling; Ht - heating) ................................................................................................. 2

Figure 2. Locations and climate zones for the chosen sites (Source: ORNL and PNNL 2010) ................. 5

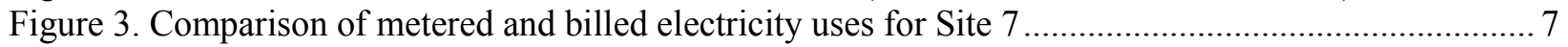

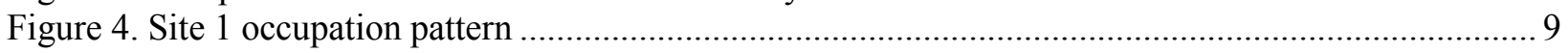

Figure 5. Building energy end uses and their component-level breakdown (S/E - supply and exhaust;

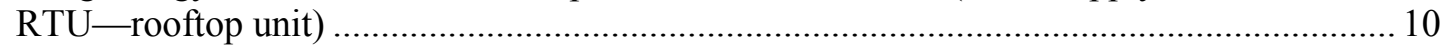

Figure 6. Time plot of condensing unit current and cooling status for the Site 1 air conditioner............... 12

Figure 7. 3-D histogram plot of outdoor unit current versus cooling/heating request ............................. 12

Figure 8. Time plot of the indoor unit current for a heat pump serving Site 1 ......................................... 13

Figure 9. Histogram plot of the indoor unit current for a heat pump serving Site 1 ............................... 14

Figure 10. Time plot of the whole-unit current for a packaged unit serving Site 4 ................................ 14

Figure 11. Time plot of the whole-unit current for a rooftop unit serving Site 3 .................................... 15

Figure 12. Histogram plot of the whole-unit current for a rooftop unit serving Site 3 (Cl-cooling; Ht-

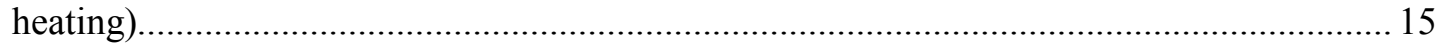

Figure 13. Histogram plot of the whole-unit current for a packaged heat pump serving Site 8 ................ 16

Figure 14. Cooling and heating electricity uses versus outdoor temperature, example 1 (Cl-cooling; Ht-

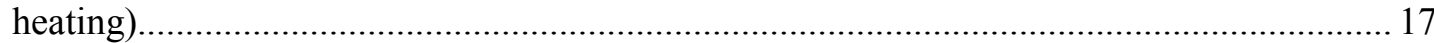

Figure 15. Cooling and heating energy uses versus outdoor temperature, example 2 (Cl-cooling; Ht-

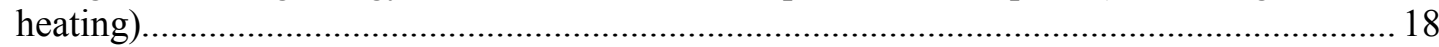

Figure 16. Cooling and heating energy uses versus outdoor temperature, example 3 (Cl-cooling; Ht-

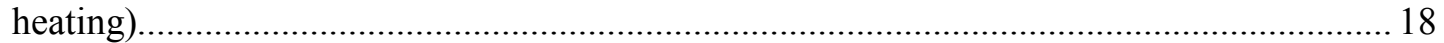

Figure 17. Comparison of submetered and billed gas uses for Site 4 ............................................... 19

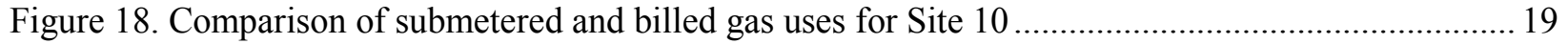

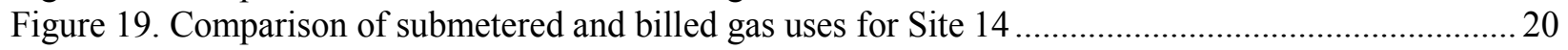

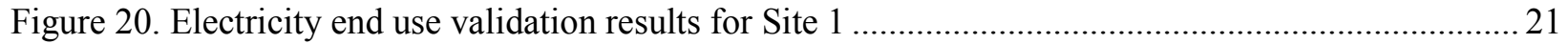

Figure 21. Cooling electricity use prediction errors for the chosen sites (Cl-cooling) ............................ 23

Figure 22. Heating electricity use prediction errors for the chosen sites (Ht-heating) ............................ 23

Figure 23. Comparisons of annual electricity end uses from the estimated and submetered data ............. 24

Figure A-1. Site 6: unit matches between the energy management system and inventory data ................ 31

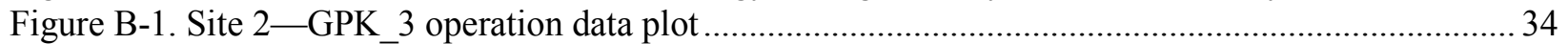

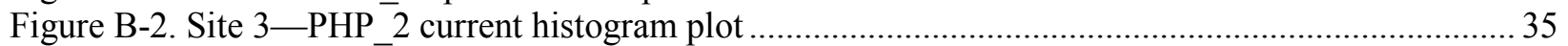

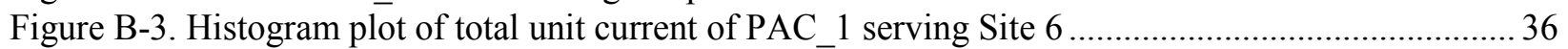

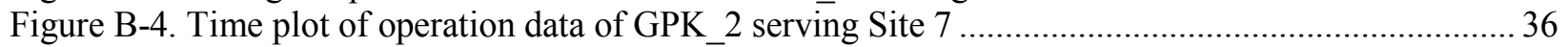

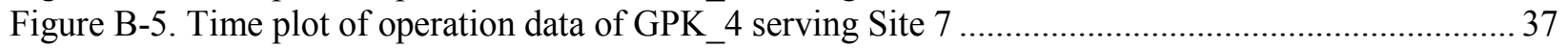

Figure B-6. Time plot of operation data of GPK_4 serving Site 14 .................................................. 38

Figure B-7. Histogram plot of the total unit current of PAC_1 serving Site 15 ....................................... 39

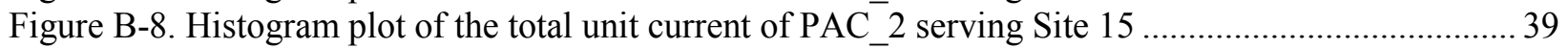

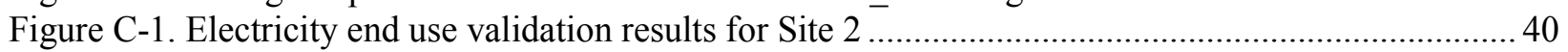

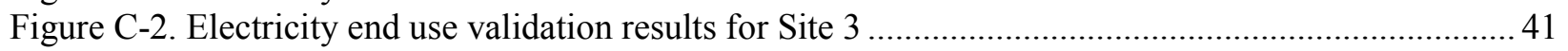

Figure C-3. Electricity signature plot along with the estimated model from the Tool for Site 3............... 41

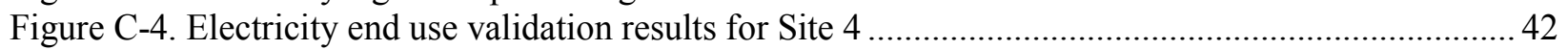

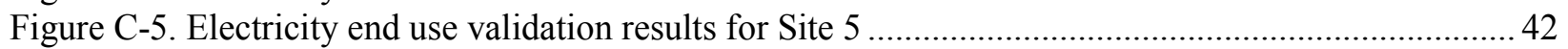

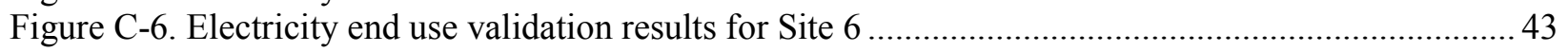

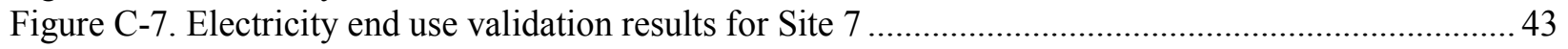

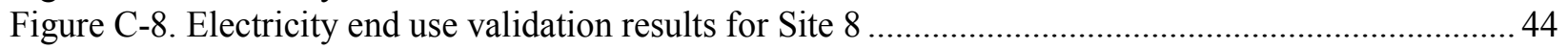

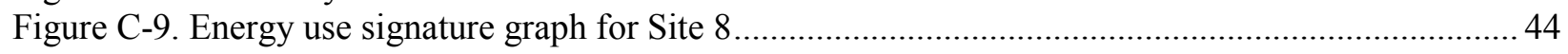

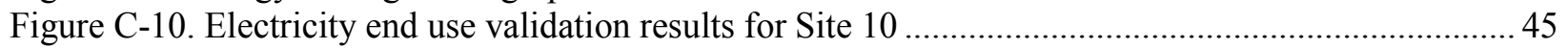

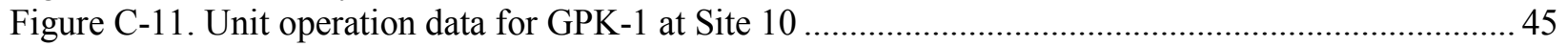


Figure C-12. Electricity end use validation results for Site 11 46

Figure C-13. Electricity end use validation results for Site 13

Figure C-14. Electricity end use validation results for Site 14

Figure C-15. Electricity end use validation results for Site 15

Figure C-16. Electricity end use validation results for Site 16

Figure D-1. Gas use validation results for Site 2 .

Figure D-2. Gas use validation results for Site 4 .

Figure D-3. Gas use validation results for Site 7

Figure D-4. Gas use validation results for Site 8 .....

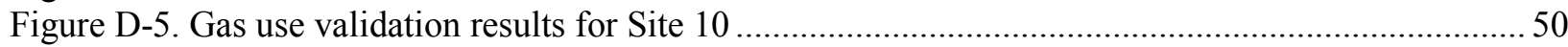

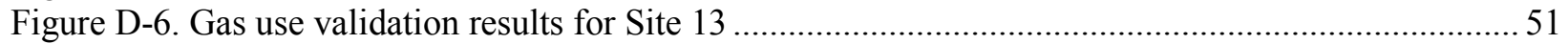

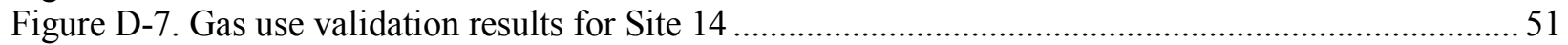

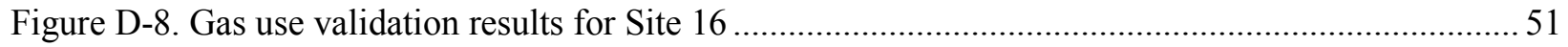

\section{List of Tables}

Table 1. Key Information for Selected Sites ................................................................................... 4

Table 2. Available Points in Energy Management System Data ........................................................ 6

Table 3. Message Flags for the Chosen Sites Generated by the Tool ................................................... 24

Table A-1. Equipment Inventory Information for the Selected Sites ...................................................... 31 


\section{Introduction}

The penetration of energy-efficient building solutions in the small building and small business community has been slow due to the diversity of building types, lack of motivation of small business owners, and few economic incentives for applying the relevant technologies. High instrumentation and labor costs associated with building audit procedures have also presented significant barriers to conducting energy audits in small commercial buildings. In this regard, no touch audit tools offer a more affordable solution for detecting and diagnosing potential causes of high energy use in small commercial buildings. Different from conventional audit procedures, no touch audit tools only rely on utility bill data and rough estimates of building parameters, such as vintage and floor area, to carry out energy efficiency analyses and to provide retrofit recommendations. Thus, such tools have low engineering costs and are best suited for small building and business owners.

As a part of the America Saves project (America Saves 2015), a portion of this multiyear effort has focused on assessing a representative no touch audit tool (referred to as "the Tool" in this report) in two phases - first with a simulation-based approach and secondly by evaluating the Tool using field data. The overall evaluation methodology developed under this project can be applied to other no touch audit tools on the market, even though the project provides a detailed assessment of one representative tool. Previous project efforts assessed the Tool using simulated utility bill data that covered a range of building types, climate zones, vintages, and operational faults (Cheung, et al. 2016). Relatively comprehensive analysis was carried out for the simulation results, including investigation of the performance and sensitivity of different vintages, building types etc. The results show that the Tool generally was able to provide accurate estimates of energy end uses in some, but not all building types depending on size and vintage.. However, the simulation assessment effort did not consider the effects of uncertainties that would occur with measured data and only considered annual energy end use and did not investigate a further breakdown into monthly end use, which is useful in understanding the Tool's overall performance, especially if fault detection is based on monthly, not yearly data. The work done in this report aims to establish a field evaluation methodology and set of benchmark results for evaluating no touch audit tools, as well as to provide an assessment of the representative tool. Specifically, monthly energy end uses are explicitly investigated in this field assessment approach to provide a building energy signature and to better understand the Tool's performance in disaggregating energy end uses.

The Tool (Reichmuth and Turner 2010) uses monthly utility bill data and simple descriptive building information as input, and uses statistical analysis techniques to correlate building energy use with outdoor weather conditions. Various normalized aggregate building parameters such as $\mathrm{UA}$, internal gains in $\mathrm{W} / \mathrm{ft}^{2}$, etc., are identified for each building and are compared to a parameter set within a reference model that has been derived from the analysis of several hundred U.S. Environmental Protection Agency ENERGY STAR ${ }^{\circledR}$ buildings (Reichmuth and Turner 2010). Deviations of building parameter values from those in the reference model are used to generate a list of potential issues causing excessive energy use. The Tool generates a report with the following information for each case: 
- Disaggregated energy end uses including (1) electric space heating energy, (2) electric space cooling energy, (3) electric baseload energy, (4) gas heating energy, and (5) gas baseload energy

- Probable causes of high energy uses within the building

- Post-retrofit energy savings compared to the current building operation.

The tool has some similarities to the Princeton Scorekeeping Method (PRISM) (Fels et al. 1986).

Figure 1 shows a flow chart with the key steps proposed in this field evaluation methodology. The proposed steps are generally applicable for assessing other no touch audit tools with similar functionalities. Four data sets as shown in Figure 1 are needed to obtain the input data required by the Tool and to establish a benchmark data set to be used in the evaluation procedure. Various data processing steps are required to estimate and separate the different component energy uses. Multiple end uses might need to be aggregated to allow comparison with the audit tool's estimated end uses depending on how the audit tool categorizes the different component energy uses. Detailed steps for evaluation of the representative tool are described in Section 3.

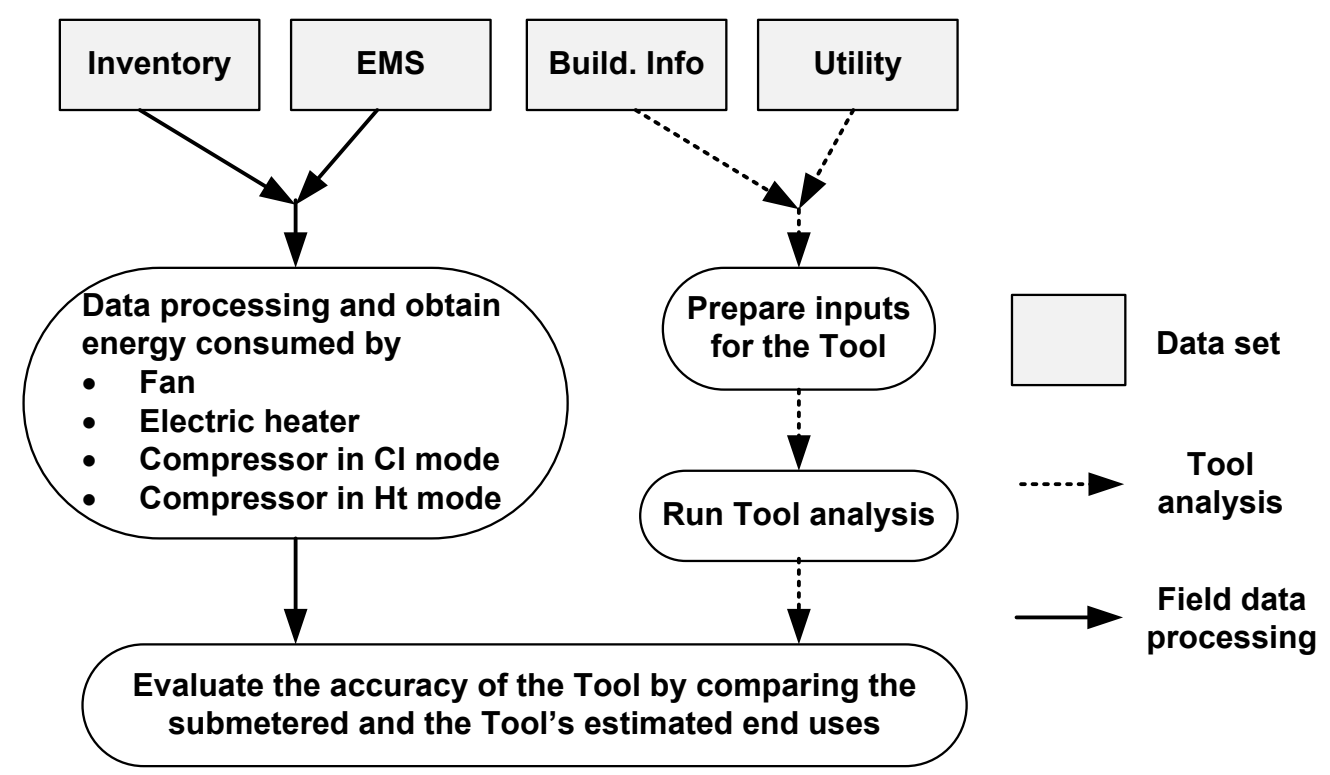

Figure 1. Flow chart of the overall evaluation procedure (EMS-energy management system, Clcooling; Ht-heating)

To collect field data, the project team collaborated with an external contractor, Field Diagnosis Services, Inc. (FDSI) to leverage FDSI's extensive collection of submetered energy data for small commercial buildings across the nation. The team identified 14 small commercial building sites; energy data for the 14 sites were used to evaluate the Tool. The chosen sites cover a variety of locations and climate conditions, and use a range of space heating and cooling equipment that provides a good representation of typical heating, ventilating, and air-conditioning (HVAC) systems found in U.S. small commercial buildings. Disaggregated energy end uses calculated by the Tool were compared to submetered data to assess accuracy. An attempt was made to evaluate message flags identifying possible causes of high energy use generated by the Tool. However, 
this was not successful because the project ended before follow up with the individual building managers could be accomplished.

This report is structured in five sections and includes multiple appendices. Section 2 provides basic information regarding the selected test sites, along with the particular criteria that were used to choose the sites. The data for these sites and associated data structure are also discussed. Section 3 describes the detailed data processing steps used to convert the raw building data to meaningful metrics that could be used in the Tool assessment. Section 4 presents the evaluation results of the 14 sites including an assessment of the disaggregated energy end uses and message flags generated by the Tool. Section 5 wraps up the report with conclusions and a discussion of next steps to pursue in future projects.

\section{Validation Sites}

FDSI monitors and archives electricity and gas uses for about 3,300 branches of a major U.S. bank and for a variety of retail store chains. Most of the monitored sites use energy meters or current transducers (CTs) to measure the whole building and space heating and cooling electricity consumption at intervals of less than an hour. Heating or cooling equipment status and conditioned space temperatures are recorded and stored within on-site energy management systems (EMSs). Other data sets needed for this project included utility bills, equipment inventory information, and general information on the chosen sites.

\subsection{Selected Sites}

Sixteen sites were initially selected from the buildings monitored by FDSI as validation sites for this project. The particular criteria used in choosing the sites were:

- At minimum, one year utility and submetered data

- Relatively comprehensive submetered data

- Dynamic climate conditions (climates that have seasonal changes throughout the year)

- Constant volume air handlers; the project avoided sites with variable-speed fan operation due to difficulties in separating fan power from heating/cooling power

- Mixed sites with different fuel combinations; electricity-only and electricity and gas

- Diversity in climate zones and locations

- Variation in heating and cooling equipment types.

An initial attempt was made to identify sites that cover a range of different building types such as small office, retail stores, and restaurants. However, the sites that met the above-mentioned requirements fell in the category of small office buildings, as other sites had either incomplete submetered data or had less than a year's available utility data. The final sites that were selected were branches of a major U.S. bank across different U.S. climate zones. The lack of building type diversity limits the generalization of the evaluation findings to other building types, but can increase the statistical confidence of any conclusions drawn for this particular building type. 
Table 1 lists the selected sites along with key information. Figure 2 shows the site locations and associated climate zones, where the bubble size is proportional to the corresponding floor area. The sites cover a number of climate zones (ORNL and PNNL 2010), including mixed-humid (Sites 1, 2, 10, and 16), marine (Sites 3 and 4), hot-humid (Sites 5, 6, 11, and 15), cold (Site 7), and hot-dry (Sites 8, 13, and 14). The floor areas of the chosen buildings range from 2,000 to $10,000 \mathrm{ft}^{2}$.

A number of these sites had just shy of 12 months of electricity or gas bills. For example, Site 2 had only 11 valid gas bills due to the existence of a single-day bill, as will be discussed in a later section. For Site 5, the EMS and utility bill data periods were not aligned and had less than an 11-month overlapping period. Communications with the Tool developer confirmed that the Tool would work fine for cases missing 1 or 2 bills, but the evaluation results are not as reliable. Site 9 had gas bill information missing for almost 6 months and Site 12 had incomplete electricity bill information for more than 6 months. These two sites were discarded in the evaluation analysis.

Table 1. Key Information for Selected Sites

\begin{tabular}{|c|c|c|c|c|c|c|}
\hline $\begin{array}{l}\text { Site } \\
\text { ID }\end{array}$ & City, State & $\begin{array}{c}\text { Climate } \\
\text { Zone }\end{array}$ & $\begin{array}{l}\text { Size } \\
\left(\mathrm{ft}^{2}\right)\end{array}$ & $\begin{array}{l}\text { Year } \\
\text { Built }\end{array}$ & $\begin{array}{l}\text { Elec. } \\
\text { Only }\end{array}$ & $\begin{array}{c}\text { Elec. } 8 \\
\text { Gas }\end{array}$ \\
\hline 1 & Riverhead, NY & Mixed-humid & 2,274 & 1978 & $x$ & \\
\hline 2 & Brooklyn, NY & Mixed-humid & 4,537 & 1910 & & $x$ \\
\hline 3 & Seattle, WA & Marine & 6,235 & 1978 & $x$ & \\
\hline 4 & Seattle, WA & Marine & 2,493 & 1978 & & $x$ \\
\hline 5 & San Antonio, TX & Hot-humid & 4,594 & 1978 & $x$ & \\
\hline 6 & Austin, TX & Hot-humid & 4,240 & 1970 & $x$ & \\
\hline 7 & Newton, MA & Cold & 10,000 & 1935 & & $x$ \\
\hline 8 & Los Angeles, CA & Hot-dry & 7,116 & 1950 & & $x$ \\
\hline 9 & \multicolumn{6}{|c|}{ Gas bill missing for 6 months } \\
\hline 10 & Norman, OK & Mixed-humid & 6,990 & 1988 & & $x$ \\
\hline 11 & San Antonio, TX & Hot-humid & 4,496 & 1950 & $x$ & \\
\hline 12 & \multicolumn{6}{|c|}{ Electricity bill missing for 6 months } \\
\hline 13 & Los Angeles, CA & Hot-dry & 8,233 & 1950 & & $x$ \\
\hline 14 & Los Angeles, CA & Hot-dry & 10,425 & 1950 & & $x$ \\
\hline 15 & Austin, TX & Hot-humid & 4,595 & 1974 & $x$ & \\
\hline 16 & Edmond, OK & Mixed-humid & 4,079 & 1995 & & $x$ \\
\hline
\end{tabular}




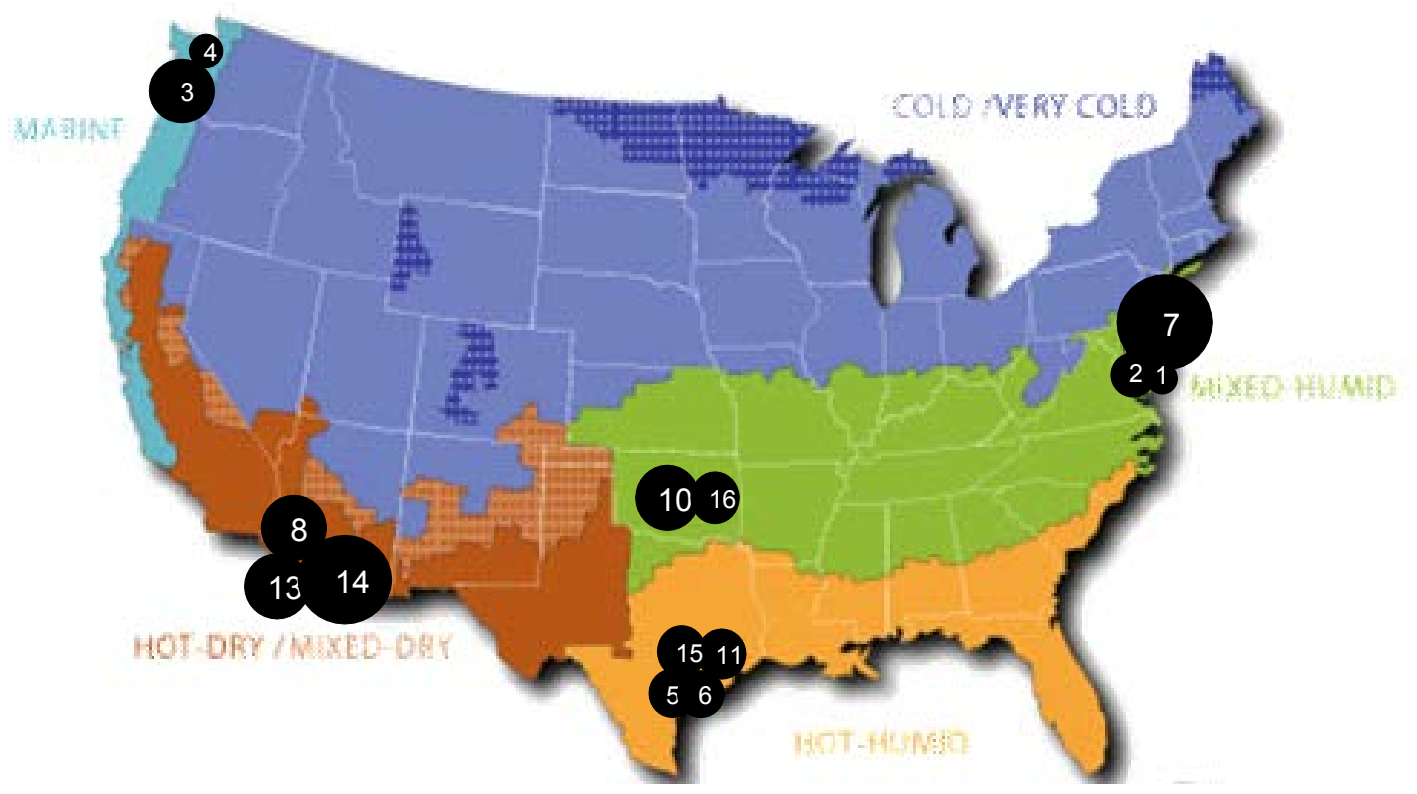

Figure 2. Locations and climate zones for the chosen sites (Source: ORNL and PNNL 2010)

For each site, four data sets were provided by FDSI and used in the evaluation processes:

- General information about the building type, floor area, location, etc.

- One year of monthly utility bills

- HVAC equipment inventory data with make and model numbers

- One year of EMS data.

The subsequent sections elaborate on these data sets.

\subsection{Energy Management System Data}

EMS data were collected by on-site controllers and stored in remote databases managed by FDSI. Three categories of data points were available in the EMS data as listed in Table 2, including weather, building operation, and equipment-related points. Outdoor air temperature, the only weather data point, was collected every hour. Exterior and interior lighting status was recorded as binary values on a change of value (COV) basis. An energy meter was installed at each site to measure the accumulated energy use for the whole building at a sampling interval of 30 minutes. A group of data points were available for each air conditioner and heat pump (HP) unit, which captured the operational status, power consumption, conditioned space temperature, and temperature set point. For packaged units, a single CT was installed on the main power feed measuring the current draw of the whole unit. For split units, two CTs were used to measure the current draws from the indoor and outdoor units separately. Because all of the units used alternating current (AC) power, root mean square (RMS) current readings were recorded at a fixed time interval of either 15 minutes or 1 hour. Cooling and heating requests made from the thermostats were recorded as binary values on a COV basis. For units with two stages of cooling or heating, the stage-2 cooling or heating status was also measured. 
Table 2. Available Points in Energy Management System Data

\begin{tabular}{|c|c|c|c|c|c|}
\hline $\begin{array}{l}\text { Type of } \\
\text { measurements }\end{array}$ & Measurement Name & Unit & Acquisition Time & Value & $\begin{array}{l}\text { Collection } \\
\text { scheme }\end{array}$ \\
\hline Weather & $\begin{array}{l}\text { Outdoor air } \\
\text { temperature }\end{array}$ & ${ }^{\circ} \mathrm{F}$ & Every hr & Float & \\
\hline \multirow{2}{*}{ Operation } & Interior lighting status & - & cov & Binary & \\
\hline & Whole building energy & kWh & Every 30 mins & Float & Cumulative \\
\hline \multirow{7}{*}{ Equipment } & $\begin{array}{l}\text { Air handler current } \\
\text { (split) }\end{array}$ & $A$ & $\begin{array}{l}\text { Fixed interval(15 min or } \\
1 \mathrm{hr})\end{array}$ & Float & RMS \\
\hline & $\begin{array}{l}\text { Condensing unit current } \\
\text { (split) }\end{array}$ & $A$ & $\begin{array}{l}\text { Fixed interval( } 15 \mathrm{~min} \text { or } \\
1 \mathrm{hr})\end{array}$ & Float & RMS \\
\hline & $\begin{array}{l}\text { Total unit current } \\
\text { (packaged) }\end{array}$ & $A$ & $\begin{array}{l}\text { Fixed interval (15 min or } \\
1 \mathrm{hr} \text { ) }\end{array}$ & Float & RMS \\
\hline & $\begin{array}{l}\text { Thermostat } \\
\text { temperature }\end{array}$ & ${ }^{\circ} \mathrm{F}$ & Every 15 min & Float & \\
\hline & Thermostat set point & ${ }^{\circ} \mathrm{F}$ & COV & Float & \\
\hline & Heating $(1,2)$ status & - & cov & Binary & \\
\hline & Cooling $(1,2)$ status & - & COV & Binary & \\
\hline
\end{tabular}

\subsection{Utility Bills}

At least one year of utility bill data was provided by FDSI for each chosen site. This data included:

- Electricity billing start and end dates

- Electricity usage for each billing period

- Gas billing start and end dates

- Gas usage for each billing period.

Based on communications with the Tool developer, non-calendarized bills were preferred to reduce inaccuracies that could be caused by the process of calendarizing the utility bill data. For each site, the electricity and gas billing cycles were not aligned. Because of this, data processing steps were required to align the data sets. This process, which is separate for electricity and gas, is discussed in the following section.

Site 7 had multiple bills that showed zero electricity use; however, the whole building energy meter readings were not zero for those months, as shown in Figure 3. For this site, the metered whole building electricity was calculated within the original billing cycles and used as inputs to the Tool. A similar attempt was made for Site 12 to fill in missing electricity bills, but the energy meter readings are all zero for the site due to the meter malfunctioning. 


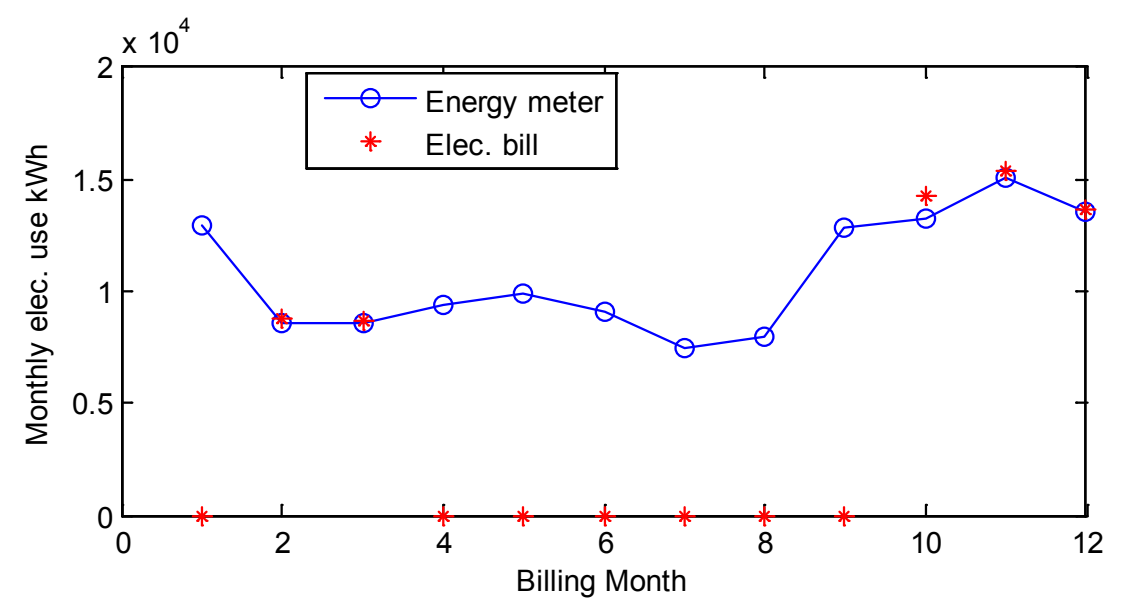

Figure 3. Comparison of metered and billed electricity uses for Site 7

For Sites 13 and 14, gas delivery and supply services were provided by different companies who billed their services with different billing cycles. Taking Site 13 as an example, the delivery service provided by the gas company had a billing period starting April 10, 2014, and ending on May 8, 2014, while the supply service, provided by a different company, started April 2, 2014, and ended on May 1, 2014. Although the gas billing cycles were not aligned, the billed gas uses were the same for the two services. The exact cause of this situation is unknown even after investigating this issue with FDSI. After investigating this issue, FDSI recommended using the set of bills with earlier start dates for the billing cycle.

\subsection{Equipment Inventory}

Data acquired by FDSI on building equipment included the makes and model numbers for each air conditioner and HP unit. Makes and model numbers were used to access the technical specifications of the corresponding units on the manufacturers websites. The technical specifications provide useful information that was used in the data processing steps. For example, gas consumption for space heating was not submetered in any of the chosen sites, but heating requests from thermostats were recorded in the EMS database. Heating request data in combination with the equipment nominal heating capacity can be used to estimate the space heating gas consumption. For the packaged units, only a single-phase current measurement was available. To estimate cooling and heating electricity uses, the single-phase current reading was used in combination with the known line voltage and number of phases of the power supply, which can also be accessible from the equipment technical specifications.

Key information on the air conditioner and HP units is provided in Appendix A. Note that many of the units were installed more than a decade ago, thus technical specifications were no longer accessible in the public domain. For units with missing technical specifications, assumptions were made on the units, which is discussed in subsequent sections. 


\section{Data Processing}

\subsection{Input Files Preparation for the Tool}

Utility bills and high-level descriptive building information is required by the Tool in order for it to run its disaggregation analysis and generate an audit report. The input file prepared for each site contained the following information:

- Building total floor area

- Location

- Percentage of floor area that is occupied

- Percentage of floor area that is cooled and heated

- Number of occupied hours per week

- Year built

- Type of space heating equipment

- Domestic hot water heating source

- Averaged outdoor air temperature for each billing period

- Start and end dates of each billing period

- Electricity and gas consumption for each billing period.

The first four bulleted items in the above list were provided by FDSI. Recorded interior lighting status was used to determine the average occupied hours per week. Because the sites are different branches of the same bank, the occupation patterns are similar. Figure 4 shows an example of the occupation pattern inferred by the interior lighting status for Site 1. On weekdays, the site held regular office hours from 7 a.m. to 7 p.m., and on Saturday, the site was open from 7 a.m. to 3 p.m. The total hours of operation per week are 68 for this site. The exact hours of operation differ from site to site, and range from 52 to 70 per week. 


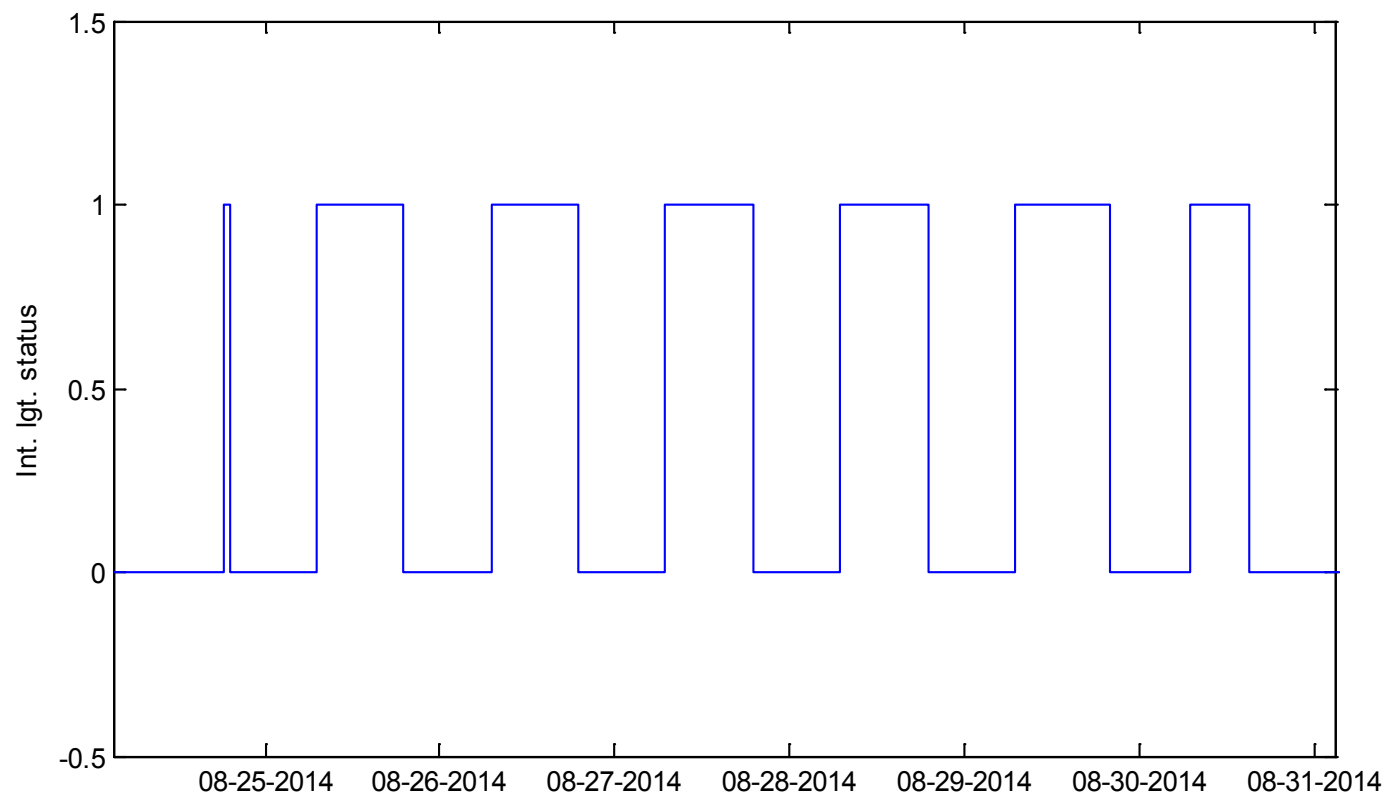

Figure 4. Site 1 occupation pattern

Building vintage was obtained by searching the building's public property record using the building address. Space heating equipment type was obtained from equipment inventory data. The domestic hot water heating type was unknown for all of the sites, but was assumed to be electric for the sites that were all-electric and gas for the sites that had both electricity and gas data. Outdoor air temperature was included in the EMS data and was averaged for each billing period.

\subsection{Submetered End Uses}

The submetered data did not provide disaggregated energy end uses directly, as the meters were originally installed for general monitoring purposes and were not specially designed for this project. Because of this, data processing was required to convert the raw submetered data to meaningful data that could be used to benchmark Tool output.

Figure 5 shows the disaggregated energy end uses that the Tool derives, and a breakdown of HVAC equipment components that fall under each end-use category. Five HVAC equipment components were considered - supply (and exhaust) fan power, compressor power in cooling mode, compressor power in HP mode, electric heat consumption, and gas consumption for space heating. Supply and exhaust fan power is treated as electric baseload energy by the Tool, and that is why this element is separate from the space heating and cooling energy. For HP operation, the compressor power is included in the electric heating consumption. In cooling mode, compressor power is included in the electric space cooling consumption. Energy consumed by electric heaters was considered separately because different power factors were needed in the conversion of current measurement to power, as described shortly. Gas consumption was not submetered in any of the sites and was difficult to validate. However, because the baseload gas consumption was negligible compared to consumption for space heating, the assessment of gas disaggregation was not critical and was not considered in this study. However, the project team did investigate 
total gas consumption behavior in order to evaluate the reasonableness of the data in Section 3.5. In summary, energy associated with these five HVAC components represent the disaggregated energy end uses that the Tool derives.

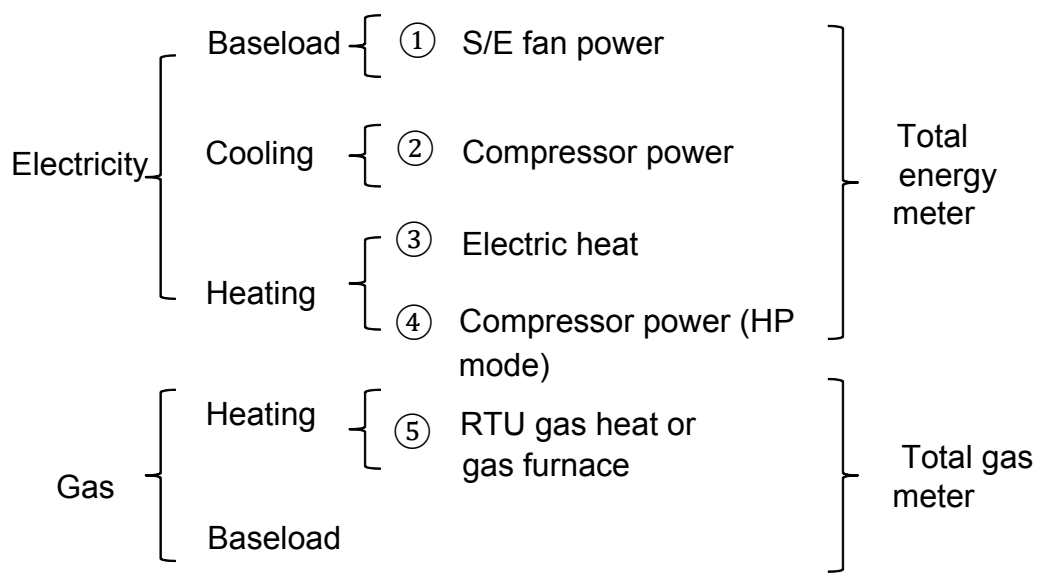

Figure 5. Building energy end uses and their component-level breakdown (S/E-supply and exhaust; RTU-rooftop unit)

Metering instrumentation can be equipment-specific, so data processing steps were required for each piece of equipment depending on the equipment sequence of operation. Each of the building sites were served by a number of space cooling and heating equipment types. These equipment types are reflective of current HVAC equipment stock found in small commercial buildings across the nation. The equipment considered in this analysis included:

- Packaged rooftop units with gas heat

- Packaged rooftop units with electric heat

- Packaged HPs with 2nd stage electric heat

- Split HPs with 2nd stage electric heat

- Split air conditioners with gas heat

- Split air conditioners with cooling only.

The following subsections describe the detailed processing steps for each type of equipment.

\subsection{Metering Instrumentation for Space Cooling and Heating Equipment}

CT data measuring RMS current draw from each site's air conditioners and HPs were used to estimate heating and cooling electricity. For packaged units, a single CT was used to measure the total unit current, which included current draws from compressors, condenser fans, and supply air fans. For split units, two separate CTs were used to measure the current draw from the outdoor and indoor units individually. The outdoor CT measured total current draw from compressors and condenser fans, while the indoor CT captured electricity use of supply fan only. For split systems with electric heat, the indoor CT measured the total current draw for both the supply air fan and electric heater. 
For units with single-phase power, a single CT was installed on the hot wire, and power was calculated by multiplying the nominal line voltage and the RMS current measurement. For units with 3-phase power, current was only measured on one of the three power lines. Assuming power is well-balanced among the three phases, power can be estimated using a similar approach but considering a phase correction factor. Details of these equations are outlined in subsequent sections.

\subsection{Data Processing Steps}

Detailed steps taken to process raw EMS data into five disaggregated energy end uses are described in this section. Some steps are only applicable to certain equipment types. In those cases, specific notes are made describing the particular process. The resultant data were then used to establish a set of benchmark data sets that were used to evaluate the energy end-use disaggregation accuracy of the Tool. These data sets can also be used to assess other no touch audit tools available on the market.

\subsubsection{Cooling and Heating Compressor Electricity Use}

For split air-conditioner units with cooling only, the outdoor unit energy consumption (sum of outdoor fan and compressor power) should be counted towards the cooling electricity. For split HP units, the outdoor unit power should be added to cooling or heating electricity, depending on the thermostat request. For packaged units, the indoor supply fan power needs to be subtracted from the total power to calculate the cooling or heating power, because the Tool categorizes fan energy consumption as baseload energy. Details pertaining to fan power estimation are elaborated in Section 3.4.2.

For HPs, the outdoor unit current measurement should be combined with the cooling and heating status to estimate the corresponding electricity use. However, the current measurement and temperature status have different sampling schemes: CT readings were sampled at 15-minute intervals, while cooling and heating status were recorded on a COV scheme. As an example, Figure 6 shows a time plot of the condensing unit current and cooling status for an air conditioner serving Site 1 . These different sampling schemes caused difficulties estimating the electricity end uses accurately. In addition, there were occasions where the unit power and status did not match due to system anti-cycling control (as explained in detail later in this section).

When calculating the cooling and heating electricity, it was assumed that the most recently called cooling or heating status, at the time of a current measurement, was the status for the sequential sampling interval (zero order hold assumption). CT measurements were converted to unit power using the following equation:

$$
\text { Power }=\text { Amp } \cdot \text { Volt } \cdot f_{\text {phase }} \cdot P F
$$

where $A m p$ is the current reading, Volt is the line voltage ( $208 \mathrm{~V}$ for all units considered in this study), $f_{\text {phase }}$ is a correction factor to account for the number of phases in the power supply, and $P F$ is the power factor. $f_{\text {phase }}$ is equal to 1 for single phase unit and equals 1.732 for units with 3phase power. $P F$ equals 1 for electric heaters, as there is no reactive power. The $P F$ for compressors and fans was assumed to be 0.9 , as recommended by FDSI. Cooling and heating electricity uses were integrated over each billing period respectively. 


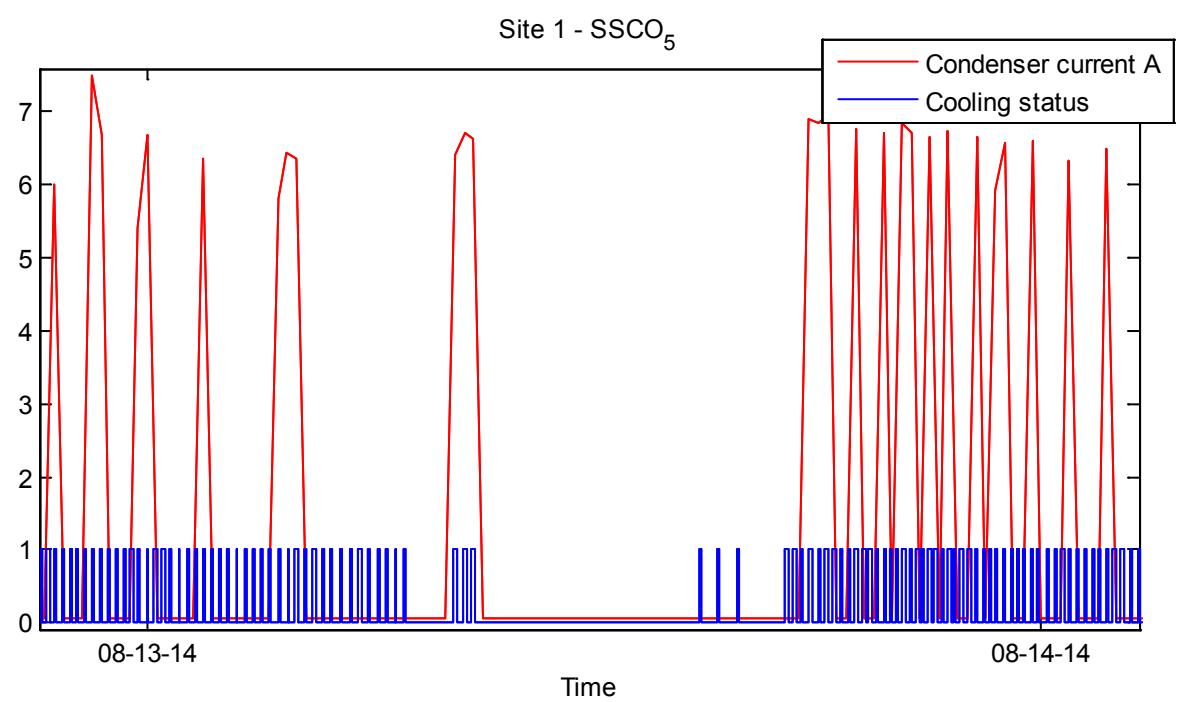

Figure 6. Time plot of condensing unit current and cooling status for the Site 1 air conditioner

For HPs, compressor power was included in heating or cooling electricity use, depending on the thermostat request. However, there were some cases in which the HP did not follow the request because of the unit's anti-cycling protection and other internal control restrictions. To prevent frequent compressor cycling, HPs and air conditioners typically implement a control sequence that maintains the current status (either run or idle) for a minimum period of time, e.g., 5 minutes. For this reason, the outdoor unit power was not perfectly correlated with the operational status. Figure 7 shows a 3-D histogram of the outdoor unit current versus its operational status for Site 1.

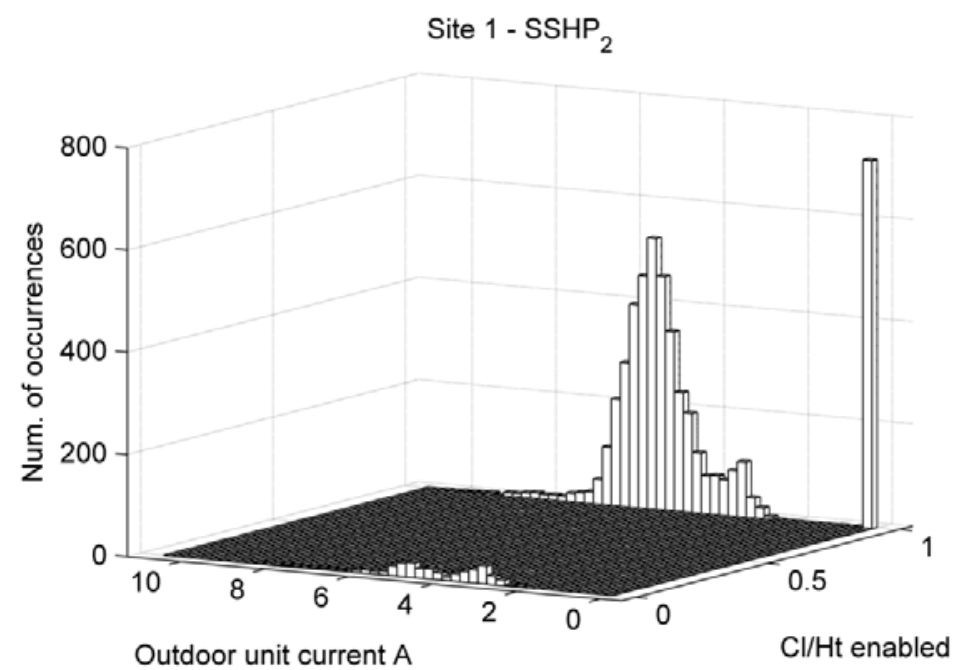

Figure 7. 3-D histogram plot of outdoor unit current versus cooling/heating request

Two types of mismatched data points were discovered in the raw submetered data. When cooling or heating was requested but the measured outdoor unit power was zero, an unexpired idle period prior to the CT sampling instance was assumed. This mismatch in data collection caused a number of "missing" data points, as the compressor could have turned on at any time within the 
sampling interval, but was not recognized by the CT. The second type of mismatched data points correspond to "unclaimed power," which happens when CT readings are nonzero, but there is no heating or cooling request. Thus, this power leads to additional inaccuracies, as it is unclaimed by either the heating or cooling systems. To best account for this mismatched data, the unclaimed power was added to the heating or cooling energy based on the most recent non-idle status, because the nonzero CT reading was caused by a run period associated with a cooling or heating request that occurred prior to the CT sampling instance.

\subsubsection{Fan Power}

Fan current was not measured independently. For a split system, the total current draw from the fan and electric heater was measured together, and, for a packaged unit, only one CT measured the current of the entire unit. Because the Tool allocates fan power to the electric baseload, calculations were needed to separate the fan power from these totals.

\subsubsection{Fan Power in Split Units}

For split units with electric heat, the indoor unit CT captured the power of both the supply fan and electric heater. Figure 8 shows a time plot of the current measurement of a representative split HP with an indoor electric heater. When the outdoor air temperature dropped below a certain threshold, the controller enabled second stage heating that locked out compressor operation. It can be seen from the plot that there are two clusters of values. The lower values correspond to the fan, and because the fan power is relatively constant, it can be easily separated and identified by inspecting the current histogram plot, as shown in Figure 9. For variable-airvolume systems, fan power varies with the cooling and heating loads, making it much harder to detect. For this reason, the team avoided variable-air-volume systems for this assessment. For split units with gas heat, the indoor unit power is fully attributed to the supply fan in colder months.

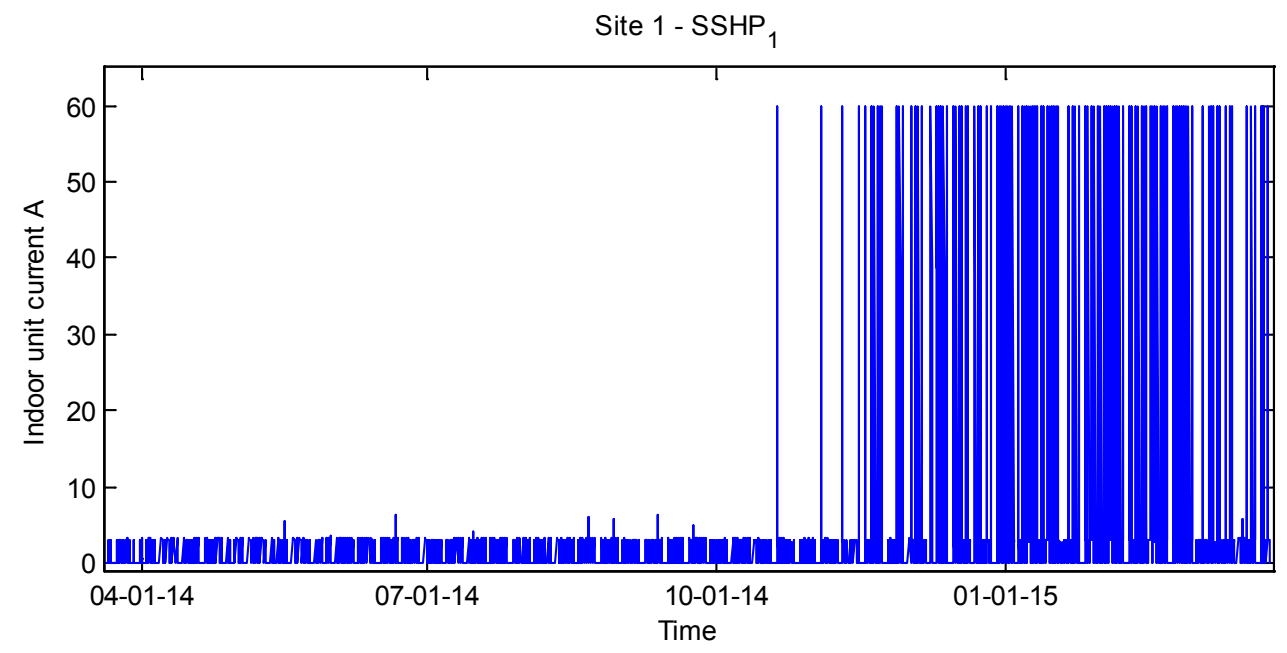

Figure 8. Time plot of the indoor unit current for a heat pump serving Site 1 


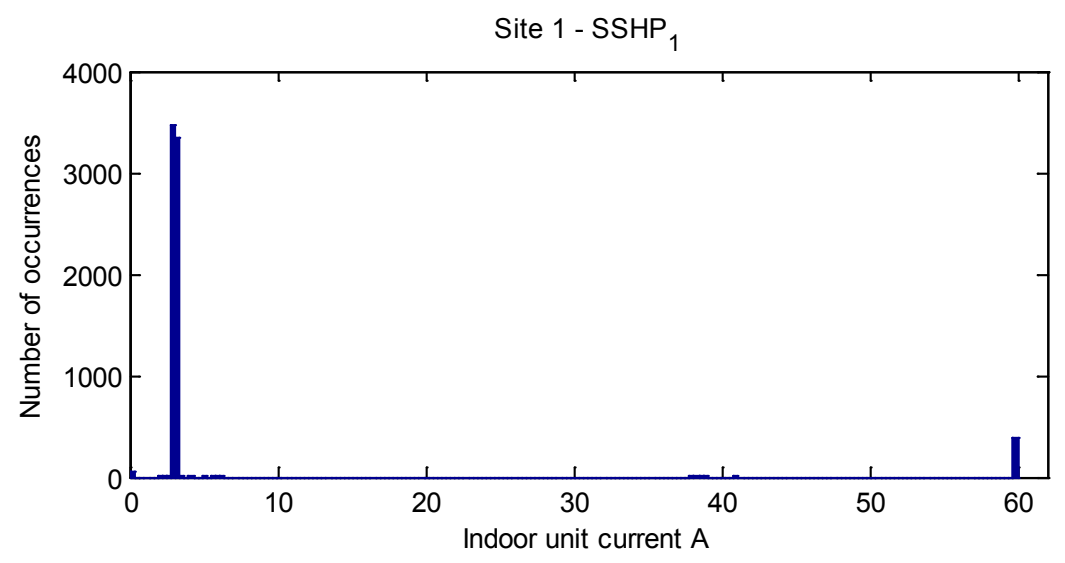

Figure 9. Histogram plot of the indoor unit current for a heat pump serving Site 1

\subsubsection{Fan Power in Packaged Units with Gas Heat}

For packaged units with gas heat, a single CT was instrumented, measuring the cooling and fan power together. However, in heating mode, because gas was the primary heating source, the CT reading directly provides the fan power. Figure 10 shows a time series plot of the whole-unit current measurement for a representative packaged unit with gas heat.

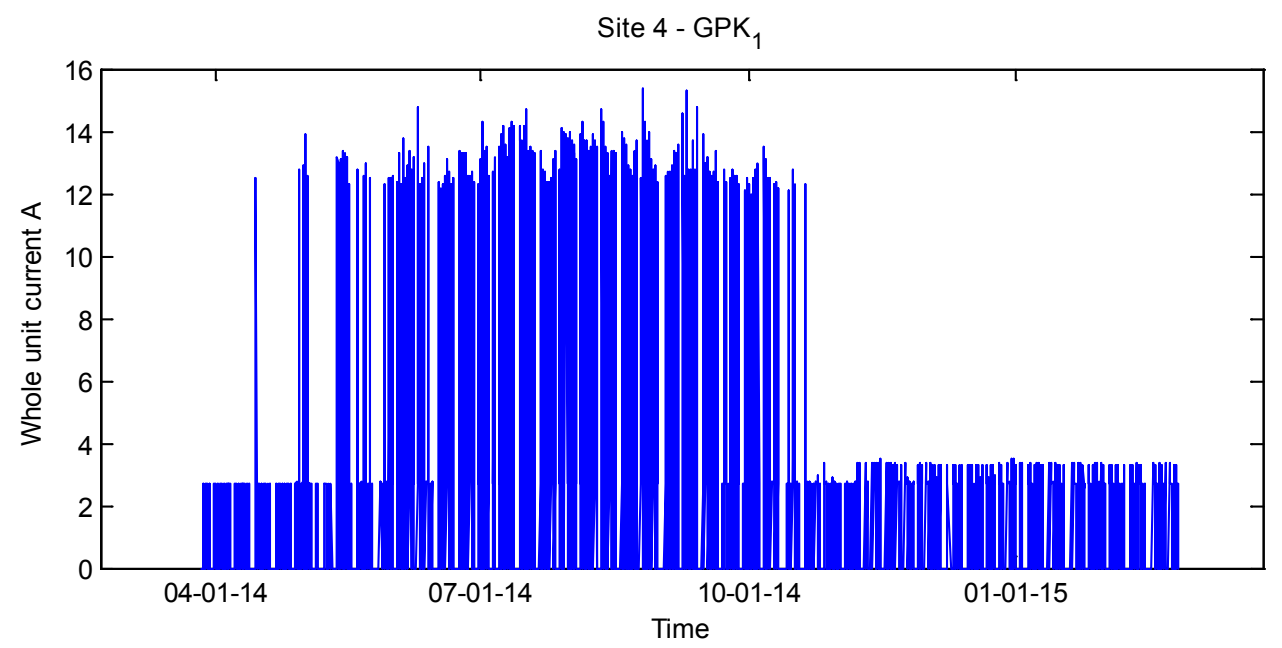

Figure 10. Time plot of the whole-unit current for a packaged unit serving Site 4

\subsubsection{Fan Power in Packaged Units with Electric Heat or Heat Pump}

For packaged units with electric heat or HP operation, it is harder to differentiate electric baseload energy from heating energy. As an example, Figure 11 shows a time plot of the wholeunit current measurement for a unit affiliated with Site 3. In this plot, the fan cycles with the compressor and it is not easy to differentiate the fan power from the total. However, by looking at the current histogram plot in Figure 12, one can easily identify the fan current draw. This unit has a clear separation between the fan and other current draws because the compressor startup is typically delayed by several minutes after the fan turns on. Unfortunately, this useful control sequence was not adopted by all of the units. Figure 13 shows a histogram plot of the unit current 
measurement for a packaged HP affiliated with Site 8 where cooling, heating, and fan energy uses are all mixed together. In such cases, fan power was assumed to be $20 \%$ of maximum power in cooling mode, based on communications with FDSI.

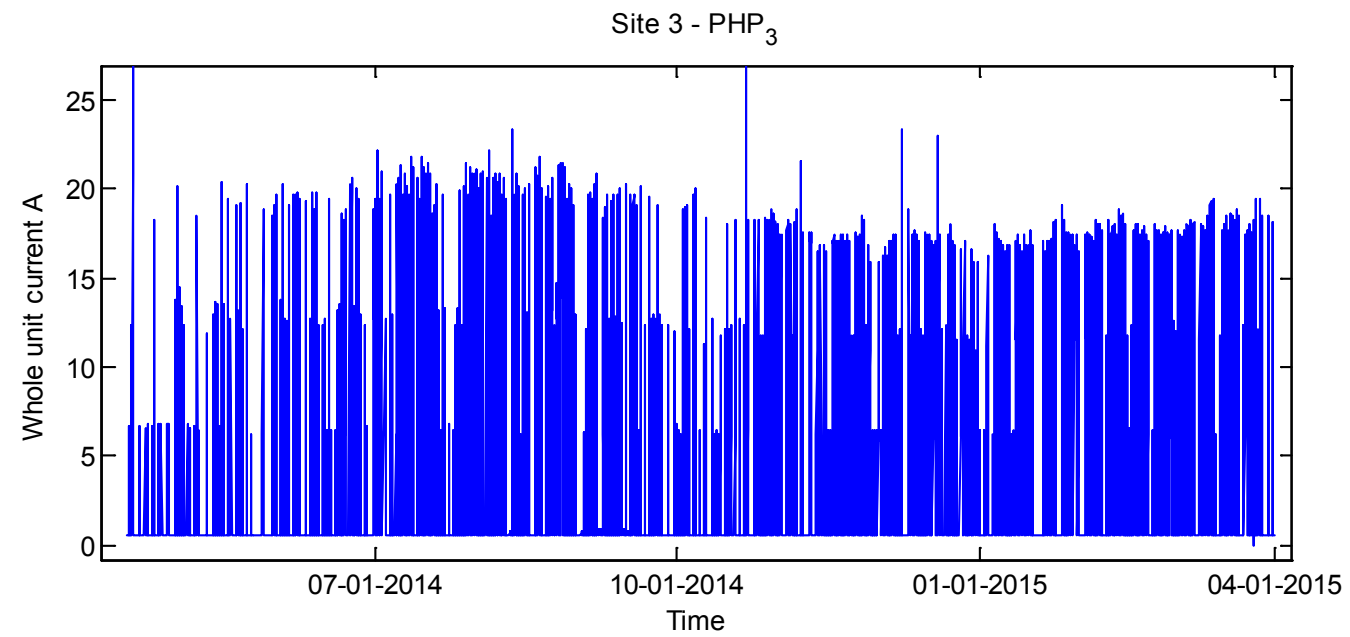

Figure 11. Time plot of the whole-unit current for a rooftop unit serving Site 3

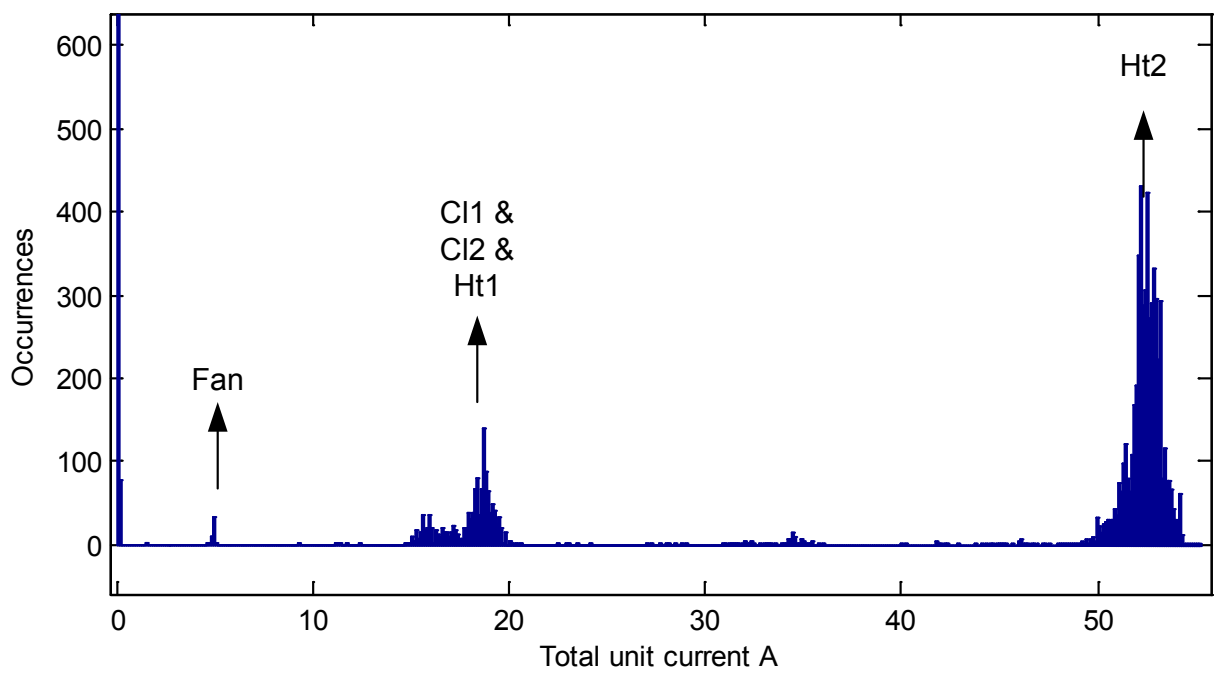

Figure 12. Histogram plot of the whole-unit current for a rooftop unit serving Site 3 (Cl-cooling; Htheating) 


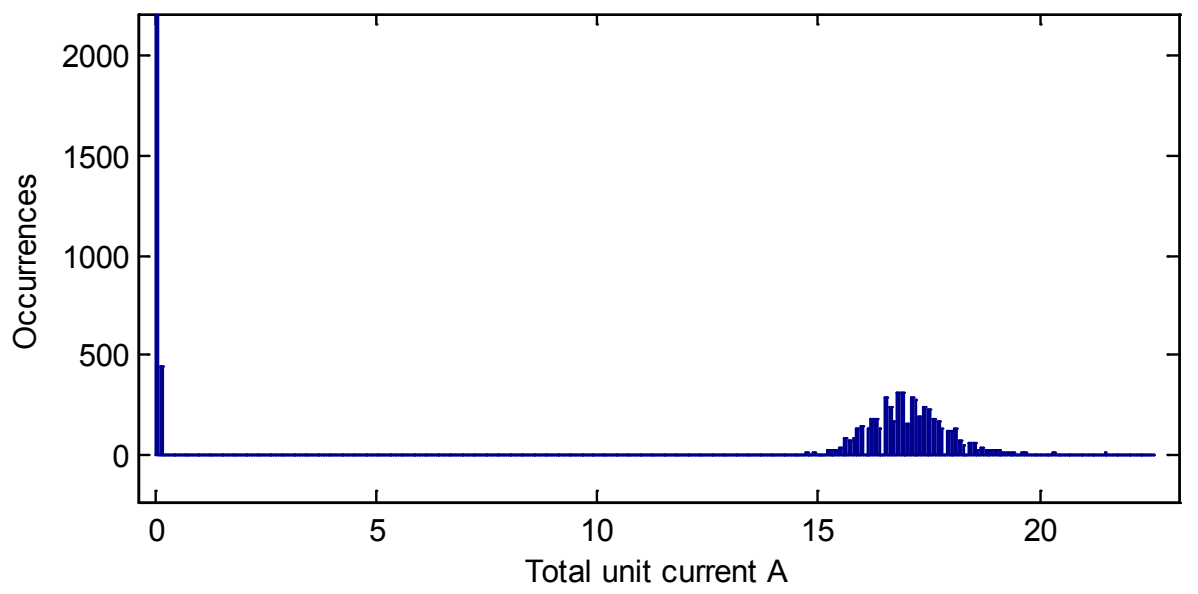

Figure 13. Histogram plot of the whole-unit current for a packaged heat pump serving Site 8

\subsubsection{Electric Heater Power}

Heating electricity includes the compressor energy in HP mode and the energy consumption of electric heaters. It is necessary to separate these two energy uses because different power factors should be applied to each component to accurately calculate the power. For compressor power, a power factor of 0.9 was applied, and 1.0 was used for electric heaters.

\subsubsection{Electric Heater Power in Split Systems}

Electric heaters are typically installed in the indoor unit of a split system. The indoor unit CT captured the total current draw of the supply fan and electric heater. Subtracting the supply fan current (as described in Section 3.4.2) from the total current provided the current of the electric heater.

\subsubsection{Electric Heater Power in Packaged Units}

As explained in Section 3.4.2.3, power measurements for packaged units include multiple electric components. Typically, the electric heater is more energy-intensive than the compressor operated in HP mode. Thus, the highest power consumption in most cases is associated with electric heaters, as shown in Figure 12.

\subsubsection{Heating and Baseload Gas Use}

As mentioned in previous sections, gas end uses for each building site were not submetered. This caused difficulties in disaggregating the gas heating and baseload consumption. In addition, the gas baseload in these types of small buildings is typically small and negligible. Therefore, the gas end uses were not investigated in this project. However, the gas use was still estimated from the available submetered data, but it was primarily used to evaluate whether the data was reasonable.

\subsection{Data Assessments}

A number of assessment steps were carried out to assure that the processed data was reasonable. These steps were also used to identify potential issues with system operations. 


\subsubsection{Correlation of Cooling/Heating Energy Use to Outdoor Temperature}

The correlation between cooling and heating energy uses and averaged outdoor temperature was investigated as a first step in the data assessment process. The cooling energy use was expected to exhibit a positive correlation, while heating energy use was expected to show a negative correlation with outdoor temperature. Any behavior violating this rule drew special attention to either the data processing steps or the unit operation.

Several examples of the data assessment results are presented in this section. Figure 14 shows the correlation results for an HP associated with Site 1. Both the cooling and heating energy matches the expectations described above. When outdoor temperature decreases, heating energy increases. However, when the outdoor temperature drops below a threshold, HP heating energy decreases while electrical energy use increases. This is reasonable as extremely low outdoor temperatures will trigger stage-2 heating, which enables the electric heating and locks out HP operation. Figure 15 shows results for another HP serving Site 1, which exhibits significantly higher electric heating energy than the unit in Figure 14. To assure that no mistakes were made in the data processing, stage- 2 heating data was carefully inspected, and the project team found that the latter unit had a significantly longer stage- 2 run time. This could be caused by high heating loads (e.g., the unit is located in a perimeter zone), poor unit efficiency, or an aggressive heating set point. Figure 16 shows results for a packaged unit with gas heat serving Site 2. Clean and reasonable relationships are shown in the plot, except for a heating point affiliated with an outdoor temperature of $37^{\circ} \mathrm{F}$. This anomaly was caused by a billing cycle that only lasted one day due to a change in service providers. This observation helped the project team detect the singleday bill, which was then removed from the overall analysis.

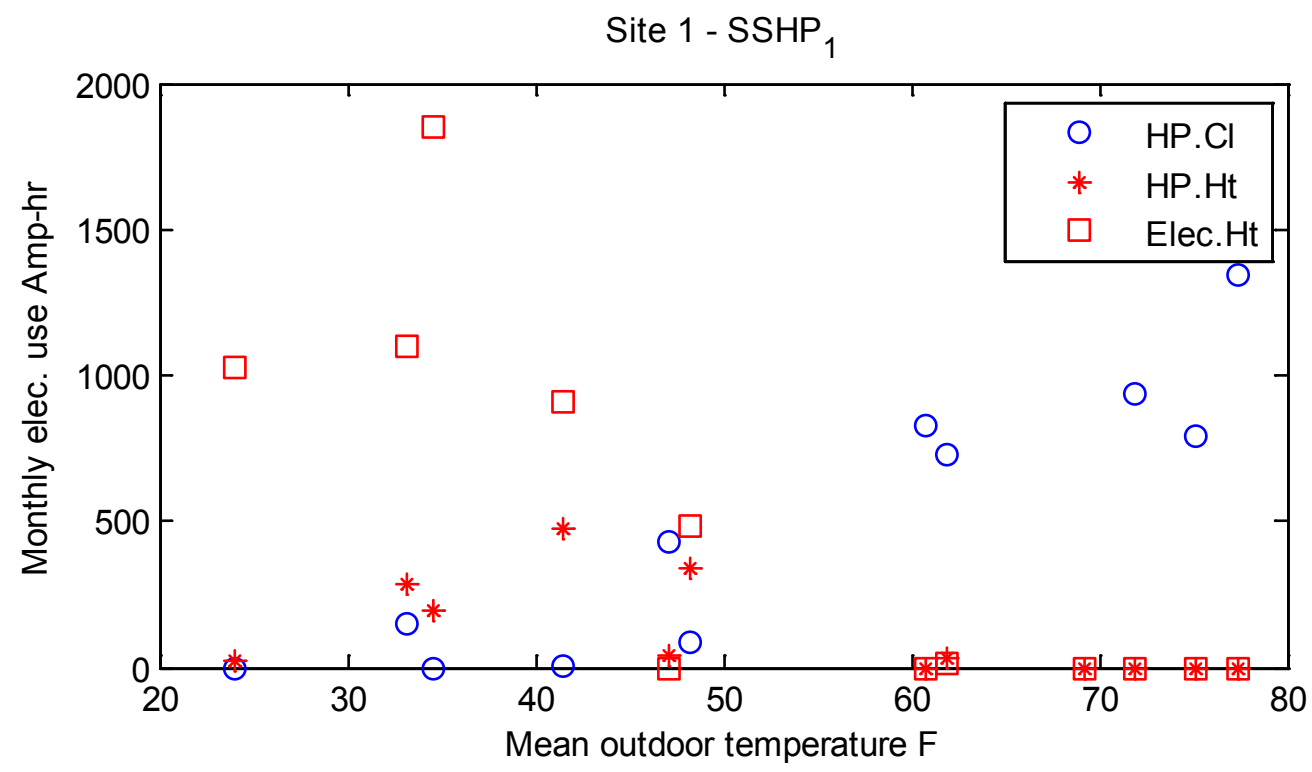

Figure 14. Cooling and heating electricity uses versus outdoor temperature, example 1 (Clcooling; Ht-heating) 


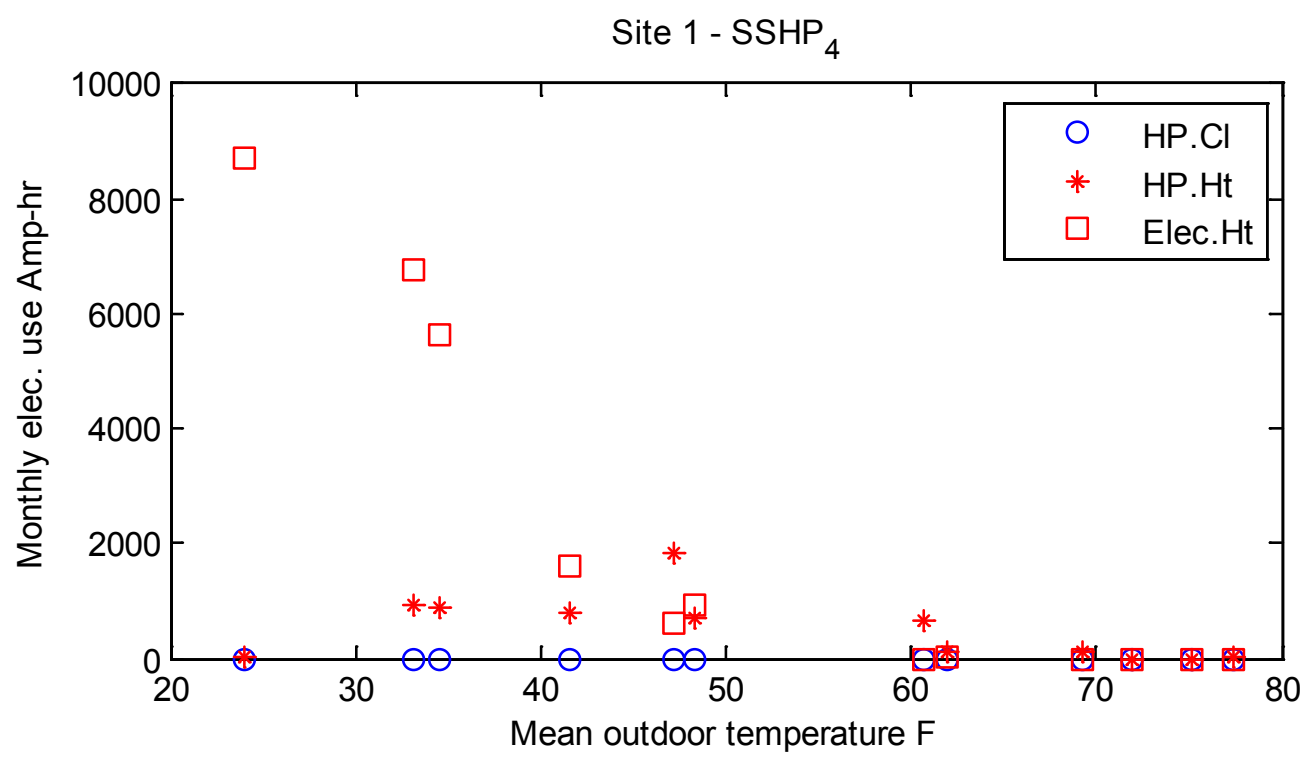

Figure 15. Cooling and heating energy uses versus outdoor temperature, example 2 (Cl-cooling; Ht-heating)

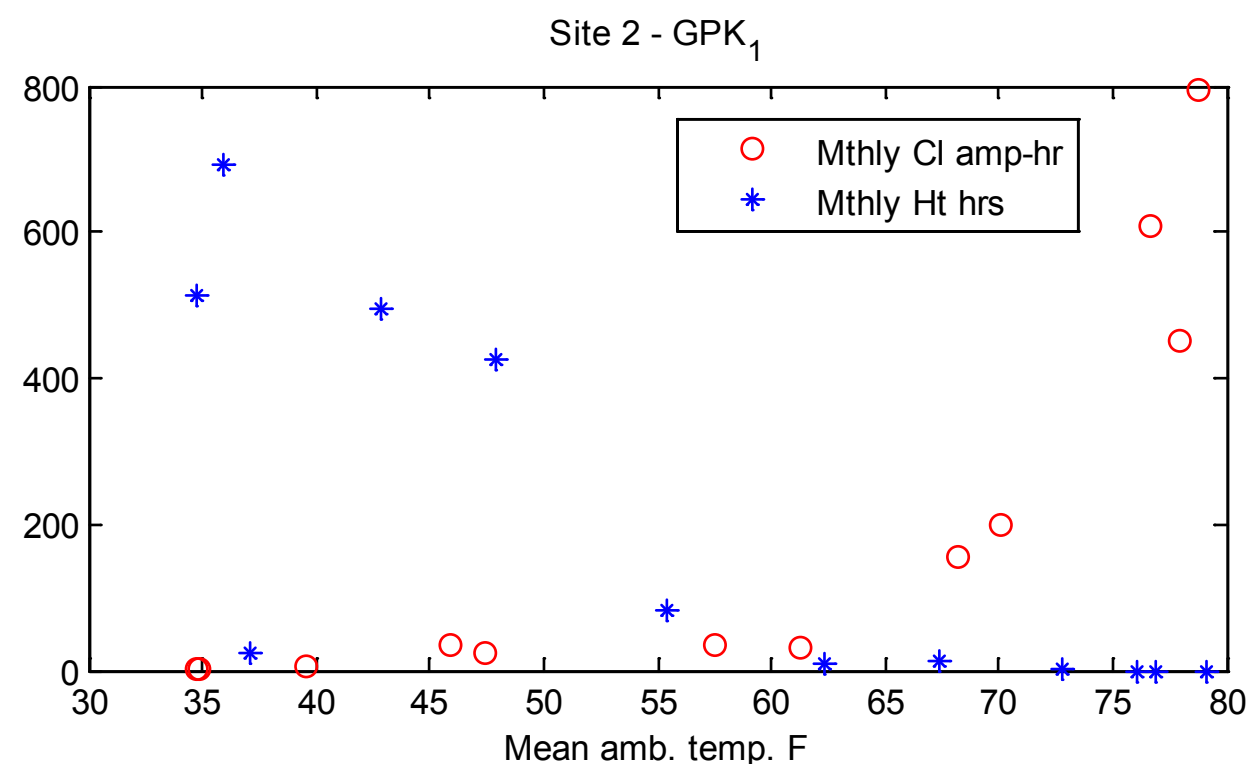

Figure 16. Cooling and heating energy uses versus outdoor temperature, example 3 (Cl-cooling; Ht-heating)

\subsubsection{Assessment of Gas Use Data Based on Heating Run Time}

Gas baseload energy was negligible or zero for all of the studied sites except for one outlier month for Site 14 as discussed shortly. Thus, gas used for space heating should be close to the total gas used in the building. The second data assessment step compared submetered data to billed gas data for each site, even though gas space heating was not directly submetered. For the assessment, gas use was estimated by looking at the integrated run time associated with the heating request from the thermostat and the nominal heating capacity of the equipment. The gas uses from the different units were then summed together to get the total gas use for each site. The 
estimated gas use was compared to billed gas consumption to assure correct system operation and reasonable meter readings.

Sites 4,10 , and 14 were the only sites that had gas heating energy for their units. This data assessment step was carried out for these three sites and results are shown in Figure 17 to Figure 19. As shown in Figure 17, the trends of the submetered and billed gas data for Site 4 show a close match, although the magnitudes differ consistently by a factor of 2.5 . A probable cause of the difference is incorrect estimates of the nominal heating capacities (e.g., due to a gas furnace retrofit). Figure 18 shows that the submetered and billed gas data for Site 10 match well. For Site 14 (shown in Figure 19), the two gas uses are in good agreement for some billing cycles, but have significant differences for others. The submetered gas data exhibit a more reasonable correlation with the outdoor temperature. The billed gas data, however, seem to have some random fluctuation for several billing cycles, which could be caused by meter misreads or some high, non-heating gas uses for those particular months.

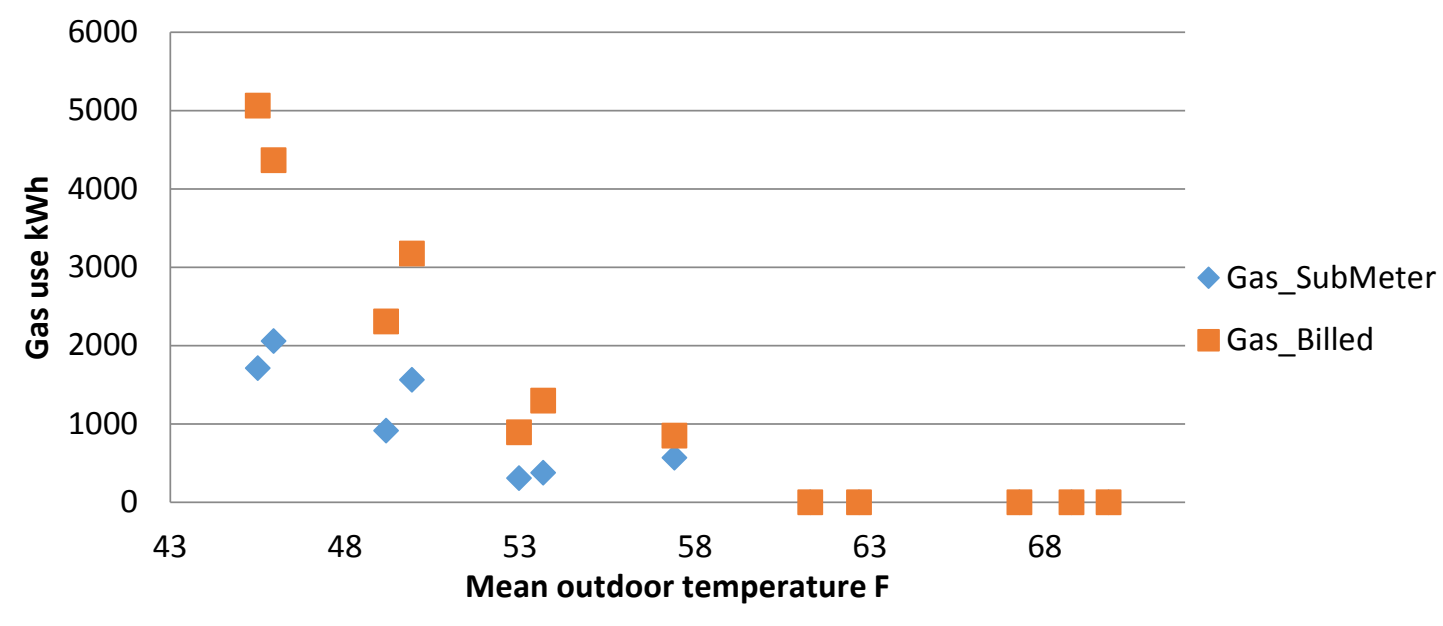

Figure 17. Comparison of submetered and billed gas uses for Site 4

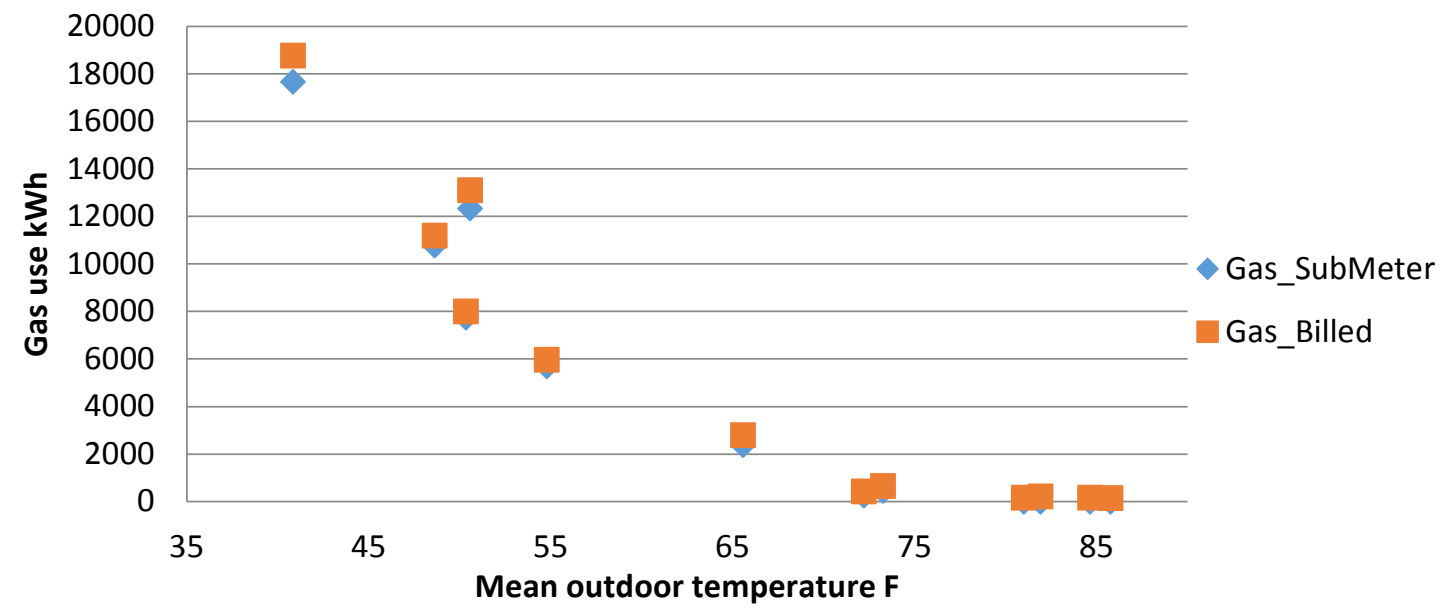

Figure 18. Comparison of submetered and billed gas uses for Site 10 


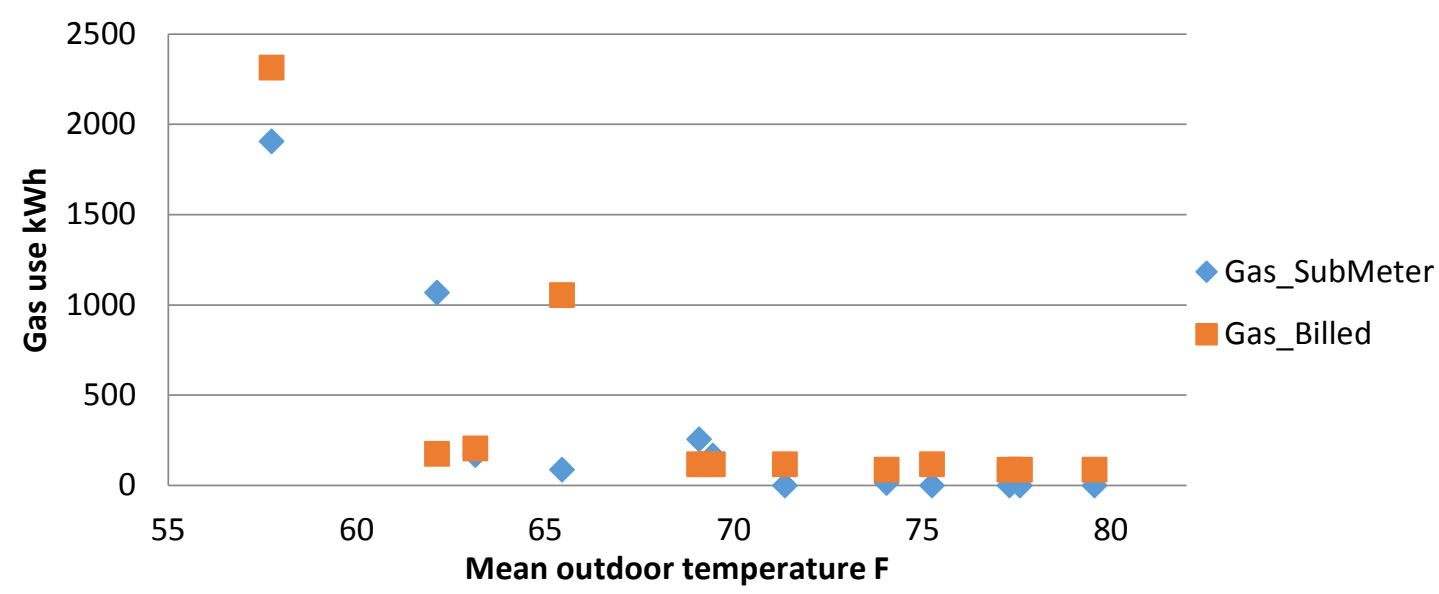

Figure 19. Comparison of submetered and billed gas uses for Site 14

\subsection{Summary of Data Processing Steps and Results}

This section describes a number of raw data processing steps that need to be taken to obtain benchmark data sets for assessing no touch audit tools. Appendix B summarizes some of the key processed results, identifies system operational issues, and highlights difficulties within the data processing steps. It may be difficult to streamline the proposed steps and apply them to larger or more complicated buildings, because the HVAC equipment and metering instrumentation was limited to the data collection setup implemented by FDSI for other purposes. However, the general ideas behind the processing steps can be applied when dealing with other building cases.

The established benchmark data sets are key contributions to the current project as they can be used to assess other no touch audit tools that have similar functionalities. The subsequent section presents validation results of the representative tool using these benchmark data sets.

\section{Validation Results of the Tool}

The input data files prepared in the processing steps were fed into the Tool for energy performance analysis. The Tool disaggregated total energy into the five different end uses for each billing month. The energy end uses were then compared to end-use estimates determined by the audit tool using a reference model, and an audit report was generated that highlighted potential high-energy issues within the target building. The accuracy of the Tool's disaggregation algorithm was then assessed by comparing the output results to the benchmark data sets. Iterations were also made with the site managers via FDSI to qualitatively validate the message flags generated by the Tool.

\subsection{Electricity End Use Validation}

Electricity end uses generated by the Tool were compared to the benchmark data sets to assess the Tool's performance in disaggregating electric end use. This section presents the assessment results for Site 1 as an example illustrating the approach. Assessment results for the other sites are documented in Appendix C. 
Figure 20 shows the monthly end use comparison of the Tool's results to submetered data for Site 1. Square, triangle, and diamond markers are used to represent the space heating, space cooling, and baseload electricity uses, respectively. Red and blue marker colors indicate the correspondence to the results generated by the Tool and those from the benchmark data sets. The monthly end uses are plotted with respect to the mean outdoor temperature to provide an energy signature graph. Note that the electricity baseload was not directly submetered, but obtained by subtracting the cooling and heating electricity from the total billed energy consumption.

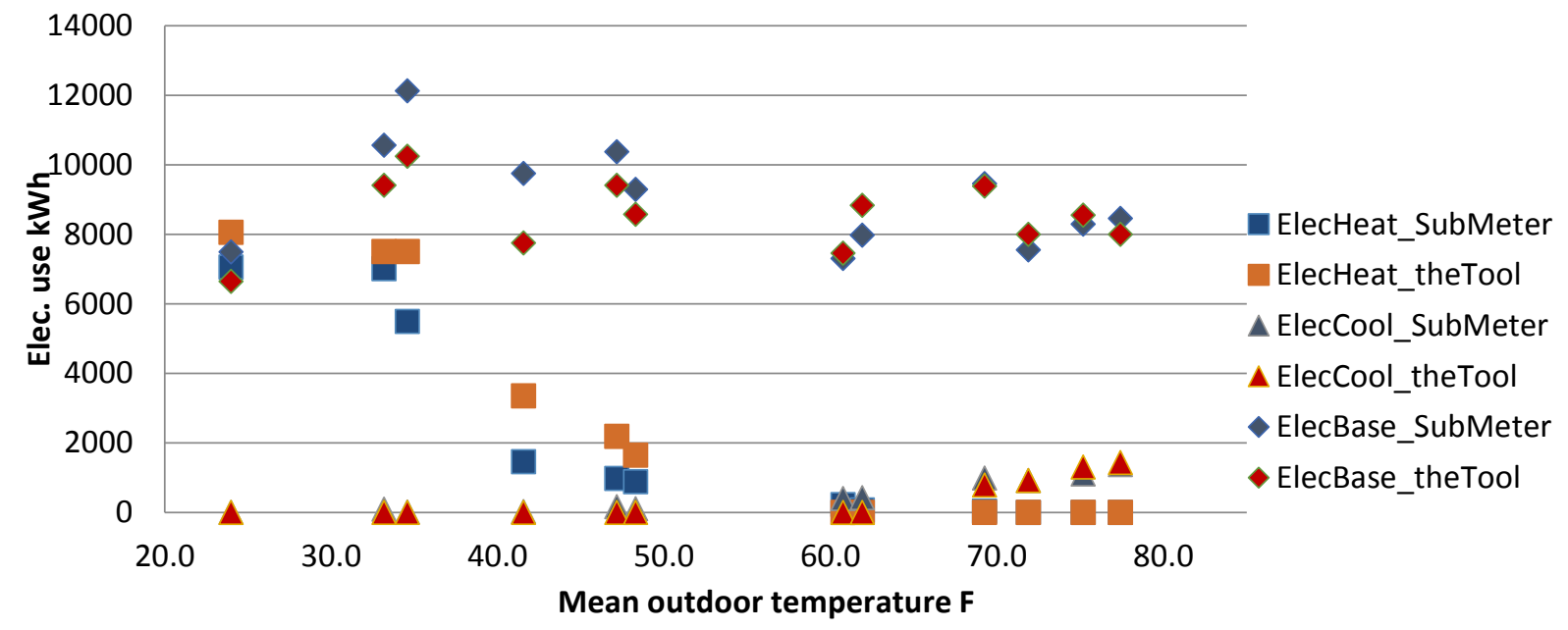

Figure 20. Electricity end use validation results for Site 1

Site 1 is located in Riverhead, New York, which has a relatively cold climate. Because the site did not use any gas, electricity for space heating is dominant. In this example, the Tool is able to provide an accurate estimation of the cooling electricity and slightly overestimates the heating use. Similarly, reasonable agreement can be observed when comparing the estimated and submetered baseload energy. However, the submetered baseload energy shows a dependence on the outdoor temperature in the lower temperature range. That is believed to be the cause of the Tool's overprediction of heating, because the Tool tends to count the temperature-dependent portion of the baseload towards heating electricity consumption.

Similar behaviors can be observed in the validation results of the other sites. Because the Tool assumes a constant energy baseload in its disaggregation algorithm, when the actual baseload of a building depends in part on the outdoor temperature, the Tool will incorrectly treat the temperature-dependent portion of the baseload use as heating or cooling. Thus, the disaggregation accuracy of the Tool is highly dependent on the baseload use profile. Because the baseload was not directly submetered but inferred from other end-use measurements, significant uncertainties existed. A critical step to pursue in future projects is to install baseload meters to investigate the actual baseload behavior with respect to outdoor temperature.

Errors between the estimated and submetered electricity end uses for each month were calculated to quantify the accuracy of the Tool's disaggregation algorithm. For each site, the relative errors for the cooling electricity estimation were calculated using the following equation: 


$$
C I E r[m t h]=\frac{C l U s e_{\text {Tool }}[m t h]-C / U s e_{\text {Submeter }}[m t h]}{C l U s e_{\text {Submeter,mean }}},
$$

where $\mathrm{ClEr}$ is the cooling error, $\mathrm{ClUse}$ is the cooling use, the subscripts Tool and Submeter indicate the data source, the variable $m$ th indexes the different billing periods, and the normalization reference ClUsesubmeter,mean is the averaged submetered cooling uses for the months with nonzero cooling.

When the submetered maximum heating electricity is nonzero, the relative heating errors are defined as:

$$
H t E r[m t h]=\frac{H t U s e_{\text {Tool }}[m t h]-H t U s e_{\text {Submeter }}[m t h]}{H t U s e_{\text {Submeter,mean }}} .
$$

where $\mathrm{HtEr}$ is the heating error, $\mathrm{HtUse}$ is the heating use, and $H t U$ sesubmeter,mean is the averaged submetered heating uses for the heating months. The maximum cooling electricity was nonzero for each site in this assessment. However, the submetered maximum heating electricity was zero for the sites that used gas as the primary heating source, e.g., Site 8 . There are cases where the submetered heating is zero but the Tool's estimation is not. However, the relative errors defined above are not able to capture errors coming from this special type of "overestimation".

Figure 21 and Figure 22 show estimation error box plots of the cooling and heating electricity, respectively. These were obtained by using Equations (2) and (3). The boxes and line segments represent the $25 \%$ and $75 \%$ quantiles, respectively. It can be seen that reasonably good accuracies are achieved in the Tool's estimation of the cooling electricity for seven of the sites, where the 75 percentiles of errors are within plus or minus $50 \%$. For the heating electricity, only Sites 1, 3, and 5 show good accuracies. Errors are significant for the other sites. Sites 6 and 7 used electricity for heating, but significant errors are present in the heating estimation. Sites 2, 4, 10, and 16 did not use electricity for heating at all but the Tool estimated a nonzero electric heating use. The error calculations shown in Equation (3) were skipped for these sites as the errors were not well-defined, with a zero normalizing reference. Sites 8, 13, and 14 have zero heating use in both submetered and the Tool's estimated results. Detailed assessment results and the probable error sources are presented in Appendix C. 


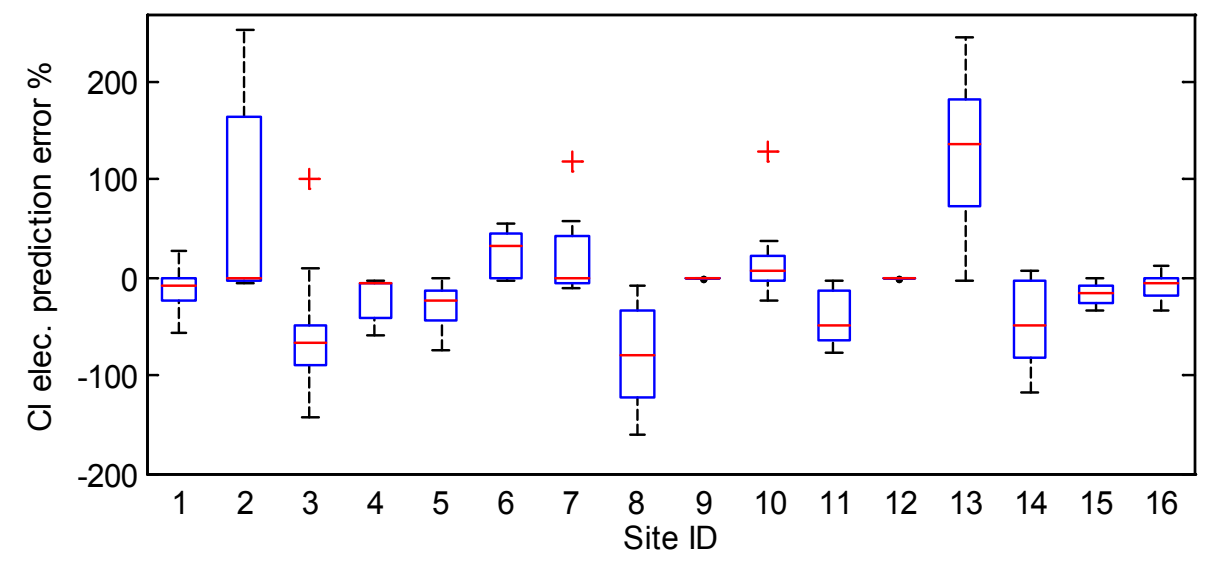

Figure 21. Cooling electricity use prediction errors for the chosen sites (Cl-cooling)

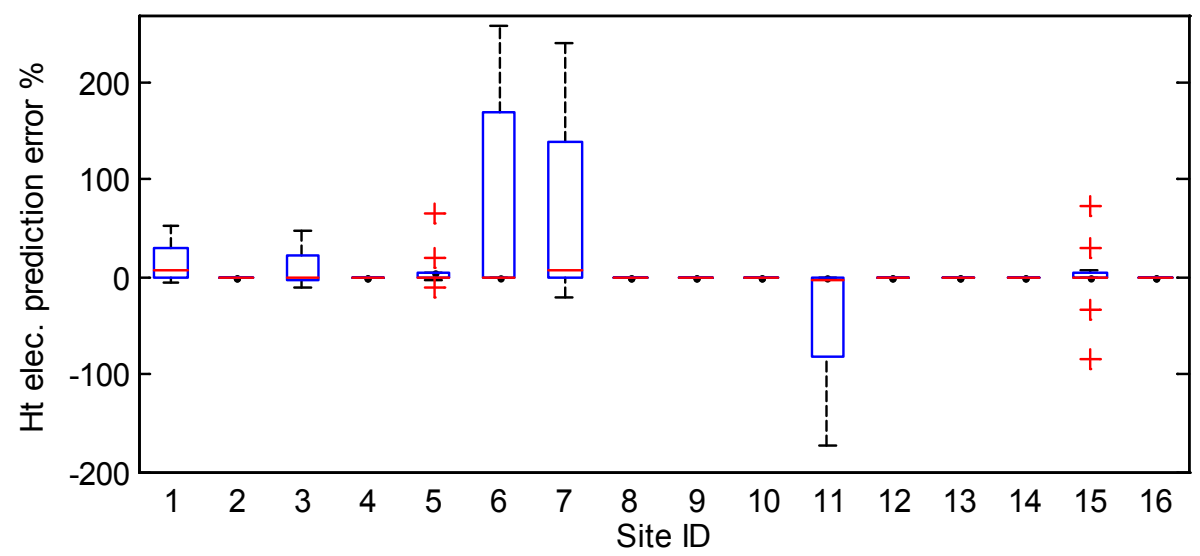

Figure 22. Heating electricity use prediction errors for the chosen sites (Ht-heating)

The Tool's disaggregation accuracy for the monthly end uses shown in Figure 21 and Figure 22 is an important metric to evaluate the Tool's overall performance because the Tool relies on monthly end use patterns with respect to outdoor temperature (i.e., a building's energy signature) to infer potential causes of high energy use.

Figure 23 shows comparisons of annual electricity end uses from the submetered and Tool's estimated results. The demonstrated accuracies for heating and cooling electricity use are similar to those plotted in Figure 21 and Figure 22. However, the annual cooling and heating end uses are plotted together with baseload to present a more comprehensive visualization of the Tool performance. For example, the Tool generated significant underestimation of cooling energy for Site 3 as shown in both Figure 21 and Figure 23. However, it can be observed from Figure 23 that cooling only accounts for a small portion of the total electricity use and the cooling underestimation would not affect the Tool's overall performance much. In addition, Figure 23 shows the Tool is able to capture building baseload use reasonably well. 


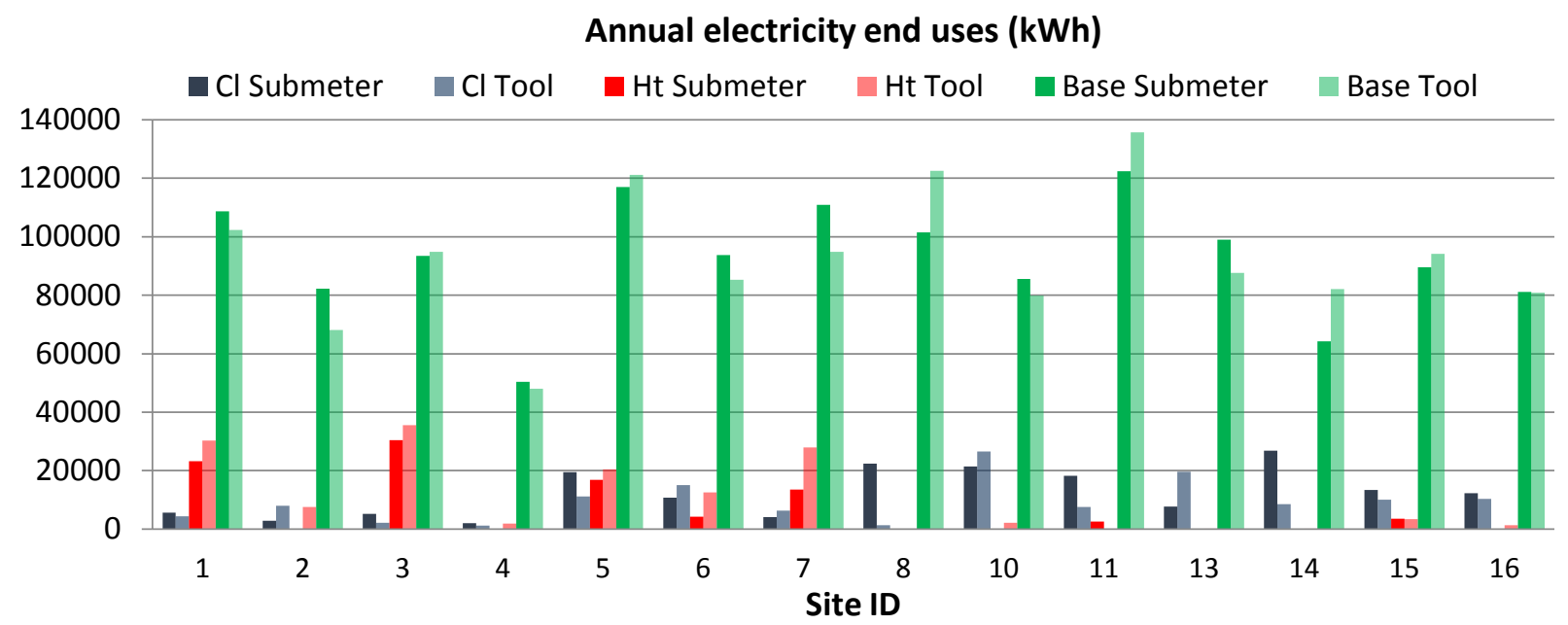

Figure 23. Comparisons of annual electricity end uses from the estimated and submetered data

\subsection{Gas Use Validation}

As previously discussed, gas end-use disaggregation was not investigated in this study as (1) gas was not submetered and (2) gas use was close to zero for all of the sites in this assessment. Gas use data assessment steps were considered in Section 3.5.2, and the final gas assessment compared billed gas data to the Tool's estimated total gas consumption. As this step is essentially a sanity check of the Tool's regression performance, the gas validation results are documented in Appendix D.

\subsection{Message Flag Generation}

Based on the disaggregated energy end uses and comparison of the target building's energy signature with that of a reference building, the Tool provides a report with message flags pointing out potential building construction and operational issues that cause high energy use. Table 3 lists the Tool's message flags along with brief descriptions of each flag. Some sitespecific notes, made by the Tool's developer, are also included to highlight some nonstandard issues and to provide guidance for the project team to investigate specific problems.

Table 3. Message Flags for the Chosen Sites Generated by the Tool

\begin{tabular}{c|c|c|c}
\hline $\begin{array}{c}\text { Site } \\
\text { ID }\end{array}$ & $\begin{array}{c}\text { Flag } \\
\text { ID }\end{array}$ & Category & Message description \\
\hline \multirow{2}{*}{1} & P & Occupancy energy intensity & Very high gain due to probable external load \\
\cline { 2 - 4 } & D & Shell and systems efficiency & Inefficient shell and ventilation \\
\hline \multirow{2}{*}{2} & B & Occupancy energy intensity & Occupant loads moderate \\
\cline { 2 - 5 } & D & Shell and systems efficiency & Inefficient shell and ventilation \\
\hline \multirow{2}{*}{3} & B & Occupancy energy intensity & Occupant loads moderate \\
\cline { 2 - 5 } & D & Shell and systems efficiency & Inefficient shell and ventilation \\
\cline { 2 - 5 } & E & Shell and systems efficiency & Inefficient cooling (coefficient of performance) \\
\hline
\end{tabular}




\begin{tabular}{|c|c|c|c|}
\hline & $\mathrm{N}$ & Other & R-squared $<0.85$ erratic operation \\
\hline & - & Note & Possible meter misreads \\
\hline \multirow{2}{*}{4} & C & Occupancy energy intensity & Occupant loads are much higher than typical \\
\hline & $\mathrm{D}$ & Shell and systems efficiency & Inefficient shell and ventilation \\
\hline \multirow{3}{*}{5} & $\mathrm{P}$ & Occupancy energy intensity & Very high gain due to probable external load \\
\hline & $\mathrm{D}$ & Shell and systems efficiency & Inefficient shell and ventilation \\
\hline & M & Shell and systems efficiency & Possible low heating efficiency \\
\hline \multirow{3}{*}{6} & $\mathrm{C}$ & Occupancy energy intensity & Occupant loads are much higher than typical \\
\hline & $\mathrm{D}$ & Shell and systems efficiency & Inefficient shell and ventilation \\
\hline & M & Shell and systems efficiency & Possible low heating efficiency \\
\hline \multirow{3}{*}{7} & $\mathrm{~B}$ & Occupancy energy intensity & Occupant loads moderate \\
\hline & $\mathrm{D}$ & Shell and systems efficiency & Inefficient shell and ventilation \\
\hline & - & Note & Both gas and electric heating used \\
\hline \multirow[b]{2}{*}{8} & $\mathrm{C}$ & Occupancy energy intensity & Occupant loads much higher than typical \\
\hline & - & Note & $\begin{array}{l}\text { Minimal gas baseload, no evident heating or cooling } \\
\text { Very atypical—probably missing electric meter }\end{array}$ \\
\hline 9 & - & - & - \\
\hline \multirow{2}{*}{10} & $\mathrm{~B}$ & Occupancy energy intensity & Occupant loads moderate \\
\hline & $\mathrm{D}$ & Shell and systems efficiency & Inefficient shell and ventilation \\
\hline 11 & $\mathrm{O}$ & Occupancy energy intensity & Very high gain-may be due to building self-heating \\
\hline 12 & - & - & - \\
\hline \multirow{2}{*}{13} & $\mathrm{~B}$ & Occupancy energy intensity & Occupant loads moderate \\
\hline & $\mathrm{D}$ & Shell and systems efficiency & Inefficient shell and ventilation \\
\hline \multirow{3}{*}{14} & B & Occupancy Energy Intensity & Occupant loads moderate \\
\hline & $\mathrm{D}$ & Shell and systems efficiency & Inefficient shell and ventilation \\
\hline & - & Note & Probably missing electric meter \\
\hline \multirow{3}{*}{15} & $\mathrm{C}$ & Occupancy energy intensity & Occupant loads much higher than typical \\
\hline & $\mathrm{D}$ & Shell and systems efficiency & Inefficient shell and ventilation \\
\hline & M & Shell and systems efficiency & Possible low heating efficiency \\
\hline \multirow{2}{*}{16} & $\mathrm{C}$ & Occupancy energy intensity & Occupant loads much higher than typical \\
\hline & $\mathrm{D}$ & Shell and systems efficiency & Inefficient shell and ventilation \\
\hline
\end{tabular}


A list of survey questions were composed for each site based on the generated message flags and an attempt was made by the project team and FDSI to distribute the surveys to the building managers to assess the accuracy of the message flags. However, the project did not have direct communication or time to work with the individual building managers to truly determine whether the flags were accurate or not.

Message flags statistics for the validation sites are summarized below. The list shows how many sites, out of the total (14), triggered each flag:

- D (inefficient shell and ventilation) occurrences: $12 / 14$

- B (occupant loads moderate) occurrences: 6/14

- $\mathrm{C}$ (occupant loads much higher than typical) occurrences: 5/14

- $\mathrm{M}$ (possible low heating efficiency) occurrences: $3 / 14$

- $\quad \mathrm{P}$ (very high gain probable external load) occurrences: 2/14.

Message flag D is present for most of the validation sites indicating inefficient shell and ventilation. This message flag is triggered by excessively high sensitivity of energy use to external weather conditions. Because the project sites are bank branches, message flag D could represent poor construction quality and high infiltration due to customers entering and leaving the building at a high frequency. Another possibility is a faulty diagnosis, due to the Tool's reference model not capturing the specific characteristics of a bank, and assuming its operation is more like that of an office building.

\section{Summary and Conclusions}

This project developed a set of test cases for assessing no touch audit tools based on data from real buildings.. The assessment methodology used four sets of building data, including site information, monthly utility bill data, equipment inventory data, and data from the building's EMS. The building data sets came from an extensive database monitored by FDSI. Fourteen sites were chosen for the study, which covers a range of climate zones, vintages, and HVAC equipment. A number of data processing steps were proposed to convert the raw building data into five different energy end uses, and to establish a set of benchmark data. This benchmark data was used to assess the representative Tool's accuracy in energy end-use disaggregation and to identify possible causes of high energy use.

The validation results show that the Tool was able to provide reasonably accurate estimations of cooling electricity for many of the sites. The accuracy for the heating electricity was not as satisfactory, especially for the sites with gas heat. The results also show that the accuracy of the Tool's disaggregation algorithm was highly dependent on the correlation of the electric baseload to outdoor temperature. The Tool assumes a flat baseload in the disaggregation algorithm, so temperature-dependent portions of a baseload are inaccurately counted towards cooling or heating electricity use. This means that when the electric baseload responds to changes in outdoor temperature, the Tool is less accurate. When the electric baseload is consistent and independent of outdoor temperature, the Tool is more accurate. The electric baseload was not directly submetered (only estimated by subtracting the other uses from the total billed electricity 
use), therefore, the temperature dependence of the benchmarked baseload could hold temperature inaccuracies as well. Thus, a critical step to pursue in future projects is to install submeters to capture the actual baseload characteristics. If the actual baseload varies with outdoor temperature, the Tool would need to improve its current disaggregation algorithm to incorporate temperature-dependent baseload use estimation.

The gas baseload was zero or close to zero in all of the sites, thus there was no need to disaggregate the gas end uses (except for the outlier month for Site 14). The Tool simply performs a curve fit of the billed gas data with respect to ambient temperature. In small commercial buildings, the gas baseload use, which is mostly attributed to domestic hot water, is typically small compared to that for space heating. Thus, the Tool's gas disaggregation accuracy does not have a significant impact on its overall performance.

The Tool generated message flag D for 12 out of the 14 sites, indicating inefficient shell construction and infiltration. An excessively steep slope shown in the heating or cooling energy consumption with respect to outdoor air temperature triggers the flag. Because the sites are banks, it may be that this message is due to the fact that bank facilities experience relatively frequent door openings, caused by a larger customer volume than a typical office building. This action introduces intensive air and heat exchange with outdoor air temperatures, causing a significant sensitivity of the heating and cooling energy use to the outdoor temperature. If this explanation is correct, a recommended improvement to the Tool would be to expand its current building categories to include finer granularity in capturing the characteristics of more building types.

The proposed methodology is generally applicable for evaluating no touch audit tools with similar functionalities. However, specific data processing steps and energy end-use groupings might need to be designed on a case-by-case basis to accommodate evaluation of different audit tools and for test sites that are instrumented differently. Some key issues that require special attention for assessing alternative audit tools are summarized below:

- The representative tool evaluated in this project treats distribution fan energy as baseload and fan power needs to be separated from cooling or heating energy uses. Other audit tools, however, could involve other types of end uses and have a different grouping. The energy end-use calculation and aggregation would need to be modified accordingly.

- The representative tool relies on the energy signature of the different end uses to analyze the building performance and identify probable causes of higher energy use. For such cases, monthly energy end uses are particularly useful in investigating the Tool's performance. For audit tools using other analysis approaches, however, more suitable forms of data organization and temporal discretization might need to be identified.

- The sensing and data acquisition system could be different when dealing with additional test sites. For example, energy meters instead of CTs could be used to measure component power consumption. Data acquisition systems could take averaged instead of snapshot readings. Data processing steps need to be designed to accommodate such sitespecific instrumentation. 


\section{References}

America Saves. 2015. "Saving Energy + Money Together." Accessed September 2015.

www.americasavesenergy.org.

ANS BSR/RESNET 1201-2016, Standard Method of Test for the Evaluation of Building Energy Analysis

Model Calibration Methods. American National Standards Institute/Residential Energy Services Network.

ANSI/ASHRAE Standard 140-2014, Standard Method of Test for the Evaluation of Building

Energy Analysis Computer Programs. American Society of Heating, Refrigerating and Air-

Conditioning Engineers, Inc., Atlanta, GA.

Fels, M. 1986. PRISM: An Introduction. Center for Energy and Environmental Studies, Princeton University. Energy and Buidings, 9 (1986) 5 - 18.

Howard Cheung, James E. Braun, and Rois Langner. 2016. Methodology to Assess No Touch Audit Software Using Simulated Building Utility Data. Golden, CO: NREL. Technical Report. National Renewable Energy Laboratory . NREL/TP-5500-66001 (tk To appear).

Judkoff, R., Wortman, D., and O’Doherty, B. 1983/2008. A Methodology for Validating Building Energy Analysis Simulations. NREL/TP-550-42059.

Judkoff, R., and Neymark, J. 1995. International Energy Agency Building Energy Simulation Test (BESTEST) and Diagnostic Method. NREL/TP-472-6231.

Judkoff, R., and Neymark, J. 2006. Model Validation and Testing: The Methodological Foundation of ASHRAE Standard 140. ASHRAE Annual Meeting, Quebec City, Canada. Preprint NREL/CP-550-40360.

Judkoff, R., Polly, B., Bianchi, M., and Neymark, J. 2010. Building Energy Simulation Test for Existing Homes (BESTEST-EX). NREL/TP-550-47427.

Judkoff, R., Polly, B., Bianchi, M., Neymark, J., Kennedy,M. 2011. Building Energy Simulation Test for Existing Homes (BESTEST-EX): Instructions for Implementing the Test Procedure, Calibration Test Reference Results, and Example Acceptance-Range Criteria. NREL/TP-550052414.

Judkoff, R., Polly, B., and Neymark, J. 2016. "A Method to Test Model Calibration Techniques." Proceedings of the ACEEE Summer Study on Energy Efficiency in Buildings, Pacific Grove California. Preprint, NREL/CP-5500-65981.

Neymark, J., and Judkoff, R. 2002. International Energy Agency Building Energy Simulation Test and Diagnostic Method for Heating, Ventilating, and Air-Conditioning Equipment Models (HVAC BESTEST); Volume 1: Cases E100-E200. NREL/TP-550-30152.

Neymark, J., Judkoff, R., Beausoleil-Morrison, I., Ben-Nakhi, A., Crowley M., Deru, M., Henninger, R.,Ribberink, H., Thornton, J., Wijsman, A., Witte, M. 2008a. International Energy Agency Building Energy Simulation Test and Diagnostic Method (IEA BESTEST): In-Depth 
Diagnostic Cases for Ground Coupled Heat Transfer Related to Slab-on-Grade Construction. NREL/TP-550-43388.

Neymark, J., Judkoff, R., Alexander, D., Felsmann, C., Strachan,P., Wijsman, A. 2008b. International Energy Agency Building Energy Simulation Test and Diagnostic Method (IEA BESTEST) Multi-Zone Non-Airflow In-Depth Diagnostic Cases: MZ320 -- MZ360. NREL/TP$550-43827$.

Neymark, J., Kennedy, M., Judkoff, R., Gall, J., Knebel,D., Henninger, R., Witte, M., Hong, T., McDowell, T., Yan, D., Zhou, X. 2016. Airside HVAC BESTEST: Adaptation of ASHRAE RP 865 Airside HVAC Equipment Modeling Test Cases for ASHRAE Standard 140. Volume 1, Cases AE101-AE445. NREL/TP-5500-66000.

PNNL and ORNL (Pacific Northwest National Laboratory and Oak Ridge National Laboratory). 2010. High-Performance Home Technologies: Guide to Determining Climate Regions by County, Volume 7.1. https://basc.pnnl.gov/resources/high-performance-home-technologiesguide-determining-climate-regions-county-volume-71.

Reichmuth, Howard, and Cathy Turner. 2010. "A Tool for Efficient First Views of Commercial Building Energy Performance." 2010 ACEEE Summer Study on Energy Efficiency in Buildings Proceedings 325-338. http://aceee.org/files/proceedings/2010/data/papers/1986.pdf. 


\section{Appendix A}

Table A-1 lists the key equipment inventory information for the selected sites. As explained in Section 2, gas heat rates and unit tonnage are needed from equipment catalog data in the selfvalidation steps. Line voltage and number of phases for the power supply are required to infer unit electricity usage from CT readings. Model numbers for all units were extracted from the equipment inventory data provided by FDSI, which were used to identify the correct tech sheets from the public domain. Most of the tabulated information was extracted from the obtained tech sheets. However, tech sheets for some obsolete units are not available and some assumptions have to be made for those units. Three-phase power was assumed for the units lacking power information as that is the most commonly used power setup in the involved units.

The inventory database was not well-maintained and a portion of the inventory data provided by FDSI is outdated. For example, the EMS data shows Site 2 has three packaged rooftop units, although the inventory data for this site includes five air-conditioning units where the two additional units were replaced in a retrofit. Such replaced units were identified and removed from the inventory data based on iterations with FDSI.

Unit identifiers used in the inventory data do not match those in the EMS data. For example, Site 3 uses "RF-HP-1" to "RF-HP-4" but the EMS data uses "PHP1" to "PHP4" to identify the four units serving this site, and the last digits in the unit identifiers do not match when comparing the nominal and estimated cooling capacities from EMS data. To map the units correctly across the two data sets, model numbers in the inventory data were matched to the units in the EMS data by matching the cooling tonnage in the self-validation step. Figure A-1 shows the calculated and nominal tonnage values for the four units serving Site 6 and the unit matching across the two data sets.

Tech sheets were not available for some of the units, which created difficulties in obtaining the correct cooling tonnage and mapping the corresponding units. This situation occurred for Sites 7 and 8 most severely, which elevated the uncertainty levels in the analysis results. For Site 7, three of the five units do not have tech sheets or nominal tonnage values, and unit mapping was not possible. For Site 8, the team was able to obtain the tech sheets for all three units but they do not match the actual unit operation observed from the EMS data. The tech sheets indicate one unit is a split system with cooling only but all three units seem to be packaged systems with heat pump operation observed from the EMS data. The tech sheets also show the largest unit is a 15ton HP but the maximum cooling tonnage calculated from the EMS data is 7. Again, for these units, 3-phase power was assumed and the self-validation step for the gas heating uses was skipped. 


\begin{tabular}{|c|c|c|c|c|}
\hline \multicolumn{2}{|c|}{ EMS data } & \multicolumn{2}{c|}{ Inventory data } \\
\hline Unit ID & $\begin{array}{c}\text { Calculated } \\
\text { Tonage }\end{array}$ & & Unit ID & $\begin{array}{c}\text { Nominal } \\
\text { Tonage }\end{array}$ \\
\hline PAC1 & 2.7 \\
\hline PAC2 & 3 & & RF-AC-1 & 10 \\
\hline PAC3 & 8 & RF-AC-2 & 3 \\
\hline PAC4 & 2 & RF-AC-3 & 3 \\
\hline & RF-AC-4 & 2 \\
\hline
\end{tabular}

Figure A-1. Site 6: unit matches between the energy management system and inventory data

Table A-1. Equipment Inventory Information for the Selected Sites

\begin{tabular}{|c|c|c|c|c|c|c|c|}
\hline $\begin{array}{l}\text { Site } \\
\text { ID }\end{array}$ & Unit ID & $\begin{array}{c}\text { Package } \\
\text { /Split }\end{array}$ & $\begin{array}{l}\text { Cool } \\
\text { Ton }\end{array}$ & $\begin{array}{l}\text { Heat } \\
\text { Source }\end{array}$ & $\begin{array}{l}\mathrm{CO}^{\mathrm{a}} \\
\mathrm{HP}\end{array}$ & $\begin{array}{l}\text { Tech } \\
\text { Sheet } \\
\text { Avail. }\end{array}$ & $\begin{array}{c}\text { Power } \\
\text { Volt./Phase }\end{array}$ \\
\hline \multirow{5}{*}{1} & SSHP1 & Split & NA & Elec. & HP & $\mathrm{N}$ & NA \\
\hline & SSHP2 & Split & 6 & Elec. & HP & $\mathrm{Y}$ & $208-230 / 3$ \\
\hline & SSHP3 & Split & 2.5 & Elec. & HP & $\mathrm{N}$ & NA \\
\hline & SSHP4 & Split & 3 & Elec. & $\mathrm{HP}$ & $\mathrm{N}$ & NA \\
\hline & SSCO5 & Split & 2 & Elec. & $\mathrm{CO}^{\mathrm{a}}$ & $\mathrm{N}$ & NA \\
\hline \multirow{3}{*}{2} & GPK1 & Package & 5 & Gas & $\mathrm{CO}^{\mathrm{a}}$ & $Y$ & $208-230 / 3$ \\
\hline & GPK2 & Package & 6 & Gas & $\mathrm{CO}^{\mathrm{a}}$ & $\mathrm{N}$ & NA \\
\hline & GPK3 & Package & 10 & Gas & $\mathrm{CO}^{\mathrm{a}}$ & $Y$ & $208-230 / 3$ \\
\hline \multirow{4}{*}{3} & PHP1 & Package & 6.5 & Elec. & HP & $Y$ & $208-230 / 3$ \\
\hline & PHP2 & Package & 5 & Elec. & HP & $Y$ & $208-230 / 3$ \\
\hline & PHP3 & Package & 6.5 & Elec. & HP & $Y$ & $208-230 / 3$ \\
\hline & PHP4 & Package & 3 & Elec. & HP & $Y$ & $208-230 / 3$ \\
\hline \multirow{3}{*}{4} & GPK1 & Package & 4 & Gas & $\mathrm{CO}^{\mathrm{a}}$ & $Y$ & $208-230 / 3$ \\
\hline & GPK2 & Package & 3 & Gas & $\mathrm{CO}^{\mathrm{a}}$ & Y & $208-230 / 3$ \\
\hline & GPK3 & Package & 3 & Gas & $\mathrm{CO}^{\mathrm{a}}$ & Y & $208-230 / 3$ \\
\hline \multirow{5}{*}{5} & PAC1 & Package & 6 & Elec. & $\mathrm{CO}^{\mathrm{a}}$ & $Y$ & $208-230 / 3$ \\
\hline & PAC2 & Package & 6 & Elec. & $\mathrm{CO}^{\mathrm{a}}$ & $Y$ & $208-230 / 3$ \\
\hline & PAC3 & Package & 5 & Elec. & $\mathrm{CO}^{\mathrm{a}}$ & Y & $208-230 / 3$ \\
\hline & PAC4 & Package & 5 & Elec. & $\mathrm{CO}^{\mathrm{a}}$ & $\mathrm{Y}$ & $208-230 / 1$ \\
\hline & PCO5 & Package & 5 & No Heat & $\mathrm{CO}^{\mathrm{a}}$ & $Y$ & $208-230 / 1$ \\
\hline
\end{tabular}




\begin{tabular}{|c|c|c|c|c|c|c|c|}
\hline & PAC6 & Package & 5 & Elec. & $\mathrm{CO}^{\mathrm{a}}$ & $\mathrm{Y}$ & $208-230 / 1$ \\
\hline & PAC7 & Package & 5 & Elec. & $\mathrm{CO}^{\mathrm{a}}$ & $Y$ & $208-230 / 1$ \\
\hline \multirow{4}{*}{6} & PAC1 & Package & 10 & Elec. & $\mathrm{CO}^{\mathrm{a}}$ & $\mathrm{Y}$ & $208-230 / 3$ \\
\hline & PAC2 & Package & 3 & Elec. & $\mathrm{CO}^{\mathrm{a}}$ & $Y$ & $208-230 / 3$ \\
\hline & PAC3 & Package & 3 & Elec. & $\mathrm{CO}^{\mathrm{a}}$ & $\mathrm{Y}$ & $208-230 / 3$ \\
\hline & PAC4 & Package & 2 & Elec. & $\mathrm{CO}^{\mathrm{a}}$ & $\mathrm{Y}$ & $208-230 / 1$ \\
\hline \multirow{5}{*}{7} & GPK1 & Package & 8.5 & Gas & $\mathrm{CO}^{\mathrm{a}}$ & $\mathrm{Y}$ & $208-230 / 1$ \\
\hline & GPK2 & Package & NA & Gas & $\mathrm{CO}^{\mathrm{a}}$ & $\mathrm{N}$ & NA \\
\hline & GPK3 & Package & 6 & Gas & $\mathrm{CO}^{\mathrm{a}}$ & $\mathrm{Y}$ & $208-230 / 3$ \\
\hline & GPK4 & Package & NA & Gas & $\mathrm{CO}^{\mathrm{a}}$ & $\mathrm{N}$ & NA \\
\hline & SSEL5 & Split & NA & Elec. & $\mathrm{CO}^{\mathrm{a}}$ & $\mathrm{N}$ & NA \\
\hline \multirow{3}{*}{8} & PHP1 & Package & NA & Elec. & $\mathrm{HP}$ & $\mathrm{N}$ & NA \\
\hline & PHP2 & Package & NA & Elec. & $\mathrm{HP}$ & $\mathrm{N}$ & NA \\
\hline & PHP3 & Package & NA & Elec. & $\mathrm{HP}$ & $\mathrm{N}$ & NA \\
\hline 9 & - & - & - & - & - & - & - \\
\hline \multirow{3}{*}{10} & GPK1 & Package & 12.5 & Gas & $\mathrm{CO}^{\mathrm{a}}$ & $\mathrm{Y}$ & $208-230 / 3$ \\
\hline & GPK2 & Package & 12.5 & Gas & $\mathrm{CO}^{\mathrm{a}}$ & $\mathrm{Y}$ & $208-230 / 3$ \\
\hline & GPK3 & Package & 5 & Gas & $\mathrm{CO}^{\mathrm{a}}$ & $\mathrm{Y}$ & $208-230 / 3$ \\
\hline \multirow{4}{*}{11} & PAC1 & Package & 10 & Elec. & $\mathrm{CO}^{\mathrm{a}}$ & $\mathrm{Y}$ & $208-230 / 3$ \\
\hline & PAC2 & Package & 4 & Elec. & $\mathrm{CO}^{\mathrm{a}}$ & $\mathrm{Y}$ & $208-230 / 3$ \\
\hline & PAC3 & Package & 6 & Elec. & $\mathrm{CO}^{\mathrm{a}}$ & $\mathrm{Y}$ & $208-230 / 3$ \\
\hline & PAC4 & Package & 3 & Elec. & $\mathrm{CO}^{\mathrm{a}}$ & $\mathrm{Y}$ & $208-230 / 3$ \\
\hline 12 & - & - & - & - & - & - & - \\
\hline \multirow{3}{*}{13} & GPK1 & Package & 12 & Gas & $\mathrm{CO}^{\mathrm{a}}$ & $\mathrm{N}$ & $208-230 / 3$ \\
\hline & GPK2 & Package & 4 & Gas & $\mathrm{CO}^{\mathrm{a}}$ & $\mathrm{Y}$ & $208-230 / 3$ \\
\hline & GPK3 & Package & 7 & Gas & $\mathrm{CO}^{\mathrm{a}}$ & $\mathrm{N}$ & $208-230 / 3$ \\
\hline \multirow{4}{*}{14} & GPK1 & Package & 3 & Gas & $\mathrm{CO}^{\mathrm{a}}$ & $\mathrm{Y}$ & $208-230 / 3$ \\
\hline & GPK2 & Package & 4 & Gas & $\mathrm{CO}^{\mathrm{a}}$ & $\mathrm{Y}$ & $208-230 / 3$ \\
\hline & GPK3 & Package & 10 & Gas & $\mathrm{CO}^{\mathrm{a}}$ & $\mathrm{Y}$ & $208-230 / 3$ \\
\hline & GPK4 & Package & 10 & Gas & $\mathrm{CO}^{\mathrm{a}}$ & $\mathrm{Y}$ & $208-230 / 3$ \\
\hline
\end{tabular}




\begin{tabular}{|c|c|c|c|c|c|c|c|}
\hline & GPK5 & Package & 10 & Gas & $\mathrm{CO}^{\mathrm{a}}$ & $\mathrm{Y}$ & $208-230 / 3$ \\
\hline \multirow{4}{*}{15} & PAC1 & Package & $\mathrm{NA}$ & Elec. & $\mathrm{CO}^{\mathrm{a}}$ & $\mathrm{N}$ & $\mathrm{NA}$ \\
\cline { 2 - 8 } & PAC2 & Package & 5 & Elec. & $\mathrm{CO}^{\mathrm{a}}$ & $\mathrm{Y}$ & $208-230 / 3$ \\
\cline { 2 - 8 } & PAC3 & Package & 3 & Elec. & $\mathrm{CO}^{\mathrm{a}}$ & $\mathrm{Y}$ & $208-230 / 3$ \\
\cline { 2 - 8 } & PAC4 & Package & $\mathrm{NA}$ & Elec. & $\mathrm{CO}^{\mathrm{a}}$ & $\mathrm{N}$ & $\mathrm{NA}$ \\
\hline \multirow{4}{*}{16} & SAHU1 & Split & 3.5 & Gas & $\mathrm{CO}^{\mathrm{a}}$ & $\mathrm{Y}$ & $208-230 / 1$ \\
\cline { 2 - 8 } & SAHU2 & Split & 6 & Gas & $\mathrm{CO}^{\mathrm{a}}$ & $\mathrm{Y}$ & $208-230 / 1$ \\
\cline { 2 - 8 } & SAHU3 & Split & 4 & Gas & $\mathrm{CO}^{\mathrm{a}}$ & $\mathrm{Y}$ & $208-230 / 1$ \\
\cline { 2 - 8 } & SAHU4 & Split & 4 & Gas & $\mathrm{CO}^{\mathrm{a}}$ & $\mathrm{Y}$ & $208-230 / 1$ \\
\hline
\end{tabular}




\section{Appendix B}

This appendix provides a summary of the equipment information, operational issues identified from the EMS data, and difficulties encountered in the data processing steps for each of the chosen sites.

\section{B.1 Site 1}

Site 1 has five split units. Units SSHP_1 to SSHP 4 are HPs with auxiliary electric heaters in the indoor units. When outdoor air temperature drops below a certain threshold, stage-2 heating is enabled that locks out compressor operation and energizes the electric heater. As pointed out in Section 3.5, SSHP 4 did not make any cooling request for the whole year potentially due to a high cooling setpoint, low heat gains in the conditioned space, or a system malfunction in cooling mode. The 5th unit, SSCO_5, is a split air conditioner with cooling only.

\section{B.2 Site 2}

Site 2 has three packaged rooftop units with gas heat. One of the gas bills has a single day billing cycle caused by a change of service (as pointed out in Section 3.5). This single-day bill was removed from the analysis, so there are only 11 gas bills for this site included in the Tool's analysis.

The EMS data showed that an audit performed in March 2014 resulted in a field adjustment to the supply fan in one of units (GPK_3), leading to increased fan power as shown in Figure B-1.

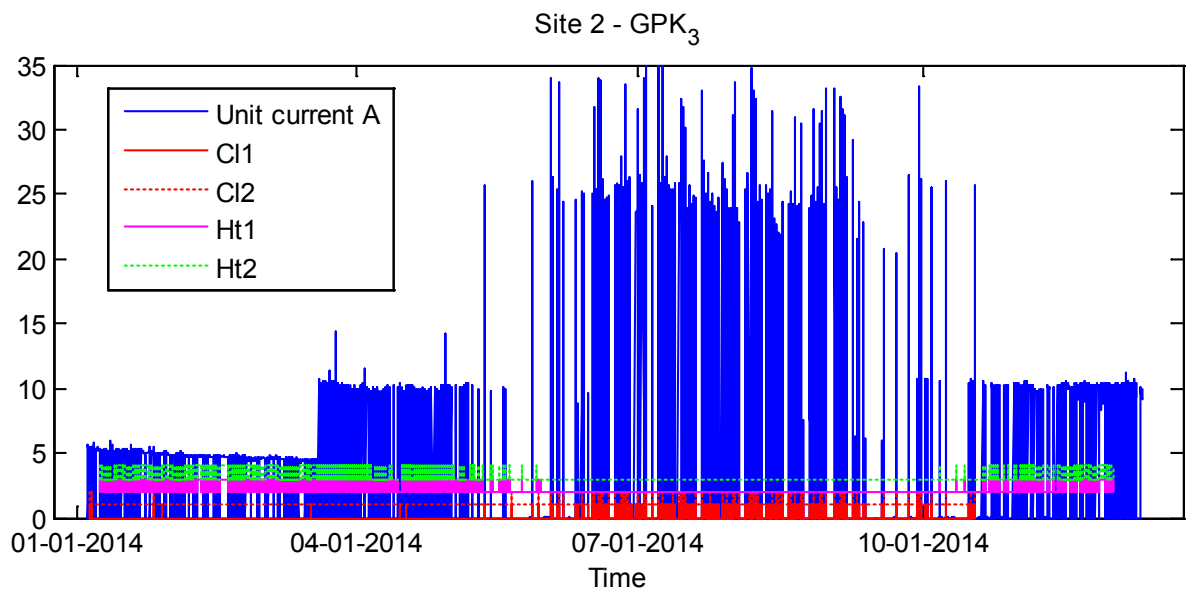

Figure B-1. Site 2-GPK_3 operation data plot

\section{B.3 Site 3}

Site 3 has four package heat pumps, identified as PHP_1 to PHP_4 with field-installed electric heaters. PHP_1 and PHP_3 are identical 6.5-ton units with two compressors and two refrigerant circuits providing two stages of cooling. PHP_2 is a 5-ton unit and PHP_4 is a 3-ton unit, both featuring single compressor operation. For all four units, stage- 2 heating enables the auxiliary electric heater and locks out compressor operation. 
PHP_2 and PHP_4 both involve stage-2 thermostat cooling requests as observed in the EMS data. But only a single cooling stage was available in the two units as they are both configured with a single-stage compressor. This can be seen from the current histogram plot in Figure B-2 where the stage-1 and stage- 2 cooling lead to the same cooling power consumption. Current measurement of PHP_4 has a resolution of 1 amp leading to higher uncertainties in the processed data.

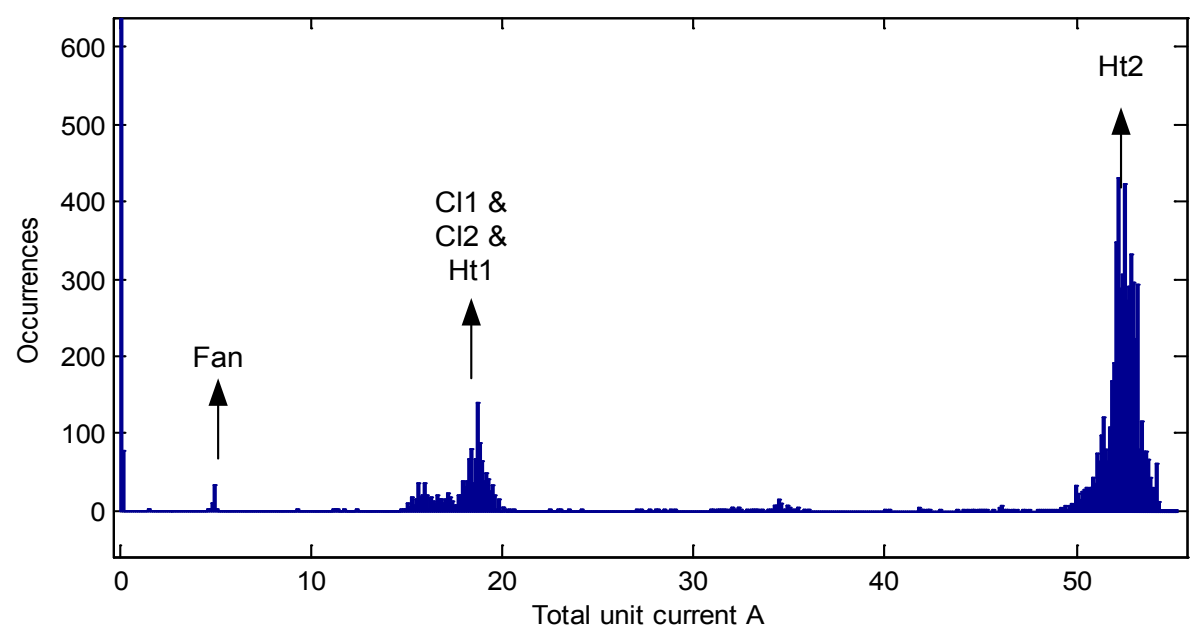

Figure B-2. Site 3-PHP_2 current histogram plot

\section{B.4 Site 4}

Site 4 has a very similar setup to Site 2, as they both have three packaged rooftop units with gas heat. The EMS data shows one of the units (GPK_3) was down for the whole year with no cooling or heating request and zero current measurement for the whole unit.

\section{B.5 Site 5}

Site 5 has seven packaged rooftop units, six of which have electric heat (PAC_1 to PAC_4 and PAC_6 and PAC_7), and one unit that has cooling only (PCO_5). Unit PAC_ 2 did not have any heating request for the whole year, possibly due to a low heating setpoint or it may serve a core zone with a small heating demand. Units PAC_1 to PAC_3 use 3-phase power, while the other four units use single-phase power.

\section{B.6 Site 6}

Site 6 has four packaged rooftop units with electric heat, identified as PAC_1 to PAC_4. As explained in Appendix A, the orders of the four units do not match between the EMS and equipment data. The units and the corresponding tech sheets were correctly mapped by matching the nominal and calculated cooling capacities. From the tech sheet, unit PAC_1 has a tonnage of 10 and features two stages of cooling. However, the EMS data for this unit only includes a stage1 cooling status, but two clusters of current values can be observed in cooling mode, as shown in Figure B-3. For the same unit, stage-1 heating seems to be a dummy status without taking any action as the total stage- 1 heating power is the same as the fan power. In addition, the unit spec sheet indicates a $36-\mathrm{kW}$ electric heat capacity, but the measured stage-2 heating power is only 10 $\mathrm{kW}$. This indicates a potential retrofit was carried out for this unit after its original installation. 
The other three units, PAC_2 to PAC_4, have smaller cooling capacities (2 or 3 tons) and only have single-stage cooling. The measured heating power shows close matches to the rating values for the these units.

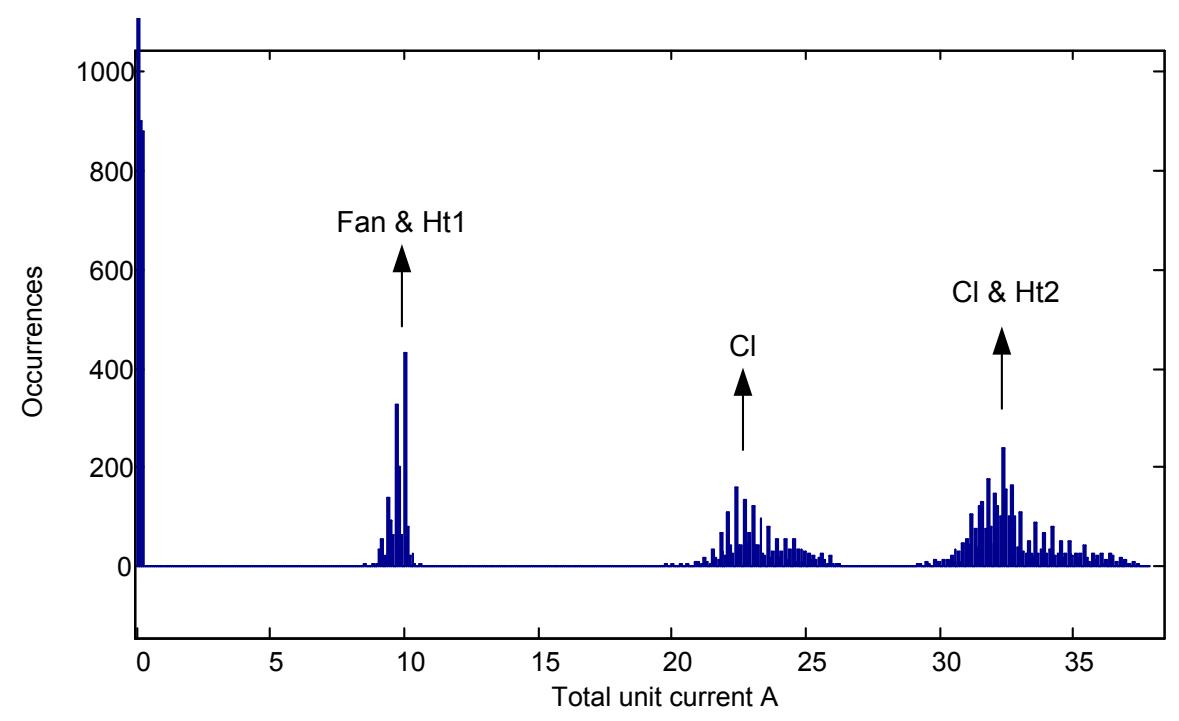

Figure B-3. Histogram plot of total unit current of PAC_1 serving Site 6

\section{B.7 Site 7}

Site 7 has four packaged rooftop units with gas heat (GPK_1 to GPK_4) and a split air conditioner with electric heat (SSEL_5), so this site relies on both electricity and gas for heat. As explained in Appendix A, this site has missing tech sheets for three of the units, which also creates difficulties in mapping the other two units with the correct tech sheets. The EMS data shows changes of operation for the supply fan in unit GPK_2, as can be seen in Figure B-4. The supply fan seemed to work in constant-on mode in May and June, 2014 and it worked in auto mode for the rest of the year. Unit GPK_4 seemed to have faulty operation in March and April, 2014 where the unit consumed significant electricity without any cooling request, as can be seen in Figure B-5. In the cooling electricity use calculation, this chunk of the data was discarded.

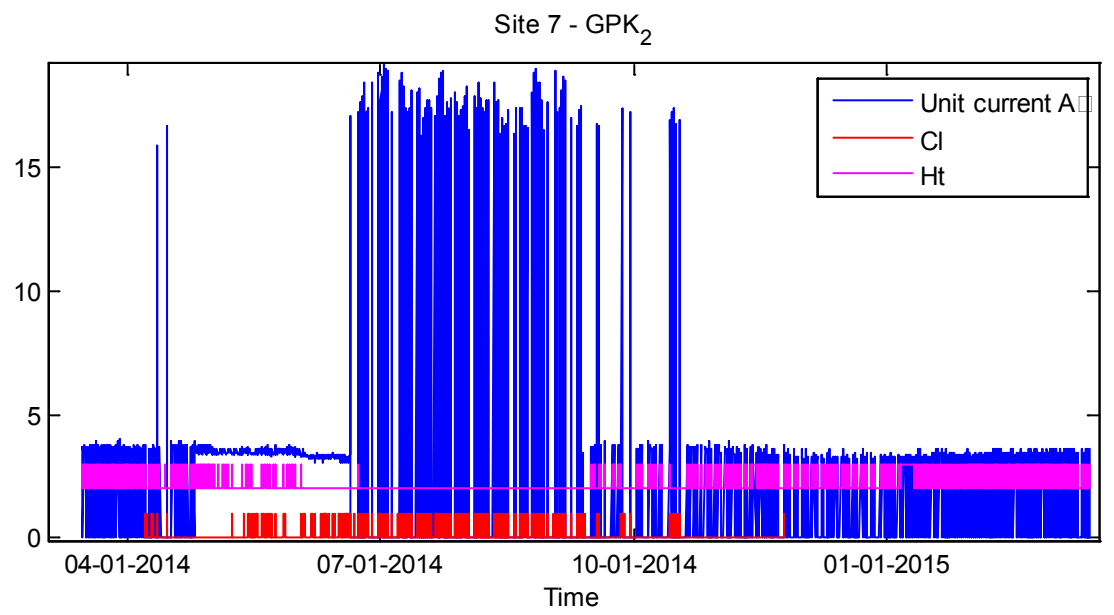

Figure B-4. Time plot of operation data of GPK_2 serving Site 7 


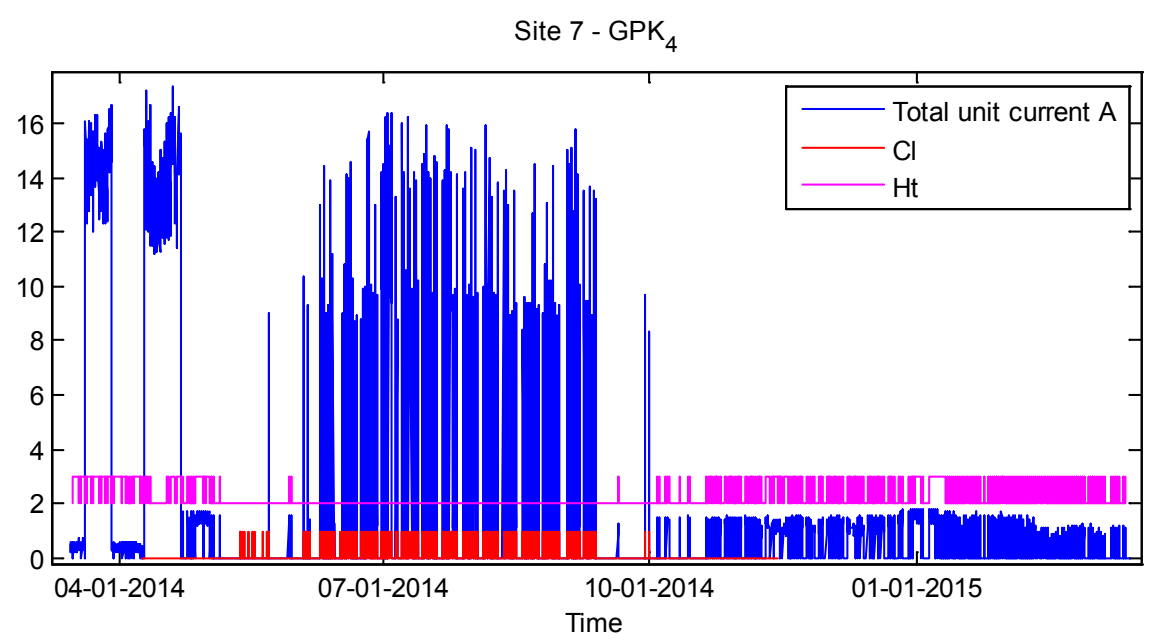

Figure B-5. Time plot of operation data of GPK_4 serving Site 7

\section{B.8 Site 8}

Site 8 has three packaged HPs identified as PHP_1 to PHP_3. This site is the most problematic, with missing equipment tech sheets and abnormal electricity bills. As explained in Appendix A, the team was able to find the tech sheets according to the model numbers extracted from the inventory database, but the unit operation observed in the EMS data does not match the tech sheet description for any of the three units, possibly due to outdated inventory records. This site has constant but near-zero gas use. The little gas consumed is believed to be for domestic hot water. The billed electricity uses are flat throughout the whole year, although there is significant cooling electricity use, as will be explained in Appendix C. Besides, there is zero energy use for space heating, indicating possible existence of self-heating devices in the building that were not metered.

\section{B.9 Site 10}

Site 10 has three packaged rooftop units with gas heat. Two units, GPK_1 and GPK_2, have cooling capacities of 12.5 tons and feature two stages of cooling. The third unit, GPK_ 3 is a 6ton unit and has only one stage of cooling. Gas baseload use is nonzero for this site but is still negligible compared to the heating gas use.

\section{B.10 Site 11}

Site 11 has four packaged rooftop units with electric heat, identified as PAC_1 to PAC_4. Unit PAC_1 is a 10-ton cooling system with 2 stages of cooling and 2 stages of electric heating. The other units have smaller cooling capacities and only feature single-stage cooling. This site is cooling-dominant and heating was rarely requested in the whole year's EMS data.

\section{B.11 Site 13}

Site 13 has 3 packaged rooftop units with gas heat, identified as GPK_1 to GPK_3. The project team failed to find the tech sheets for units GPK_1 and GPK_3. Three-phase power was assumed for these two units in the data processing steps and the calculated unit powers show close matches to the nominal powers based on the unit tonnage and a coefficient of performance of 
3.2. Unit GPK_2 was down for the whole year with zero power consumption, although cooling/heating requests were still being made from the thermostat.

\section{B.12 Site 14}

Site 14 has five packaged rooftop units all with gas heat, identified as GPK_1 to GPK_5. The smaller units, GPK_1 and GPK_2, provide single-stage cooling and the 10-ton units, GPK_3 to GPK_5, provide 2 stages of cooling. Unit GPK_3 was down for the whole year with no heating or cooling request and zero power measurement. Unit GPK_4 stopped working in the middle of the year as shown in Figure B-6: heating and cooling requests were still being made from the thermostat but the unit did not respond and consumed zero power.

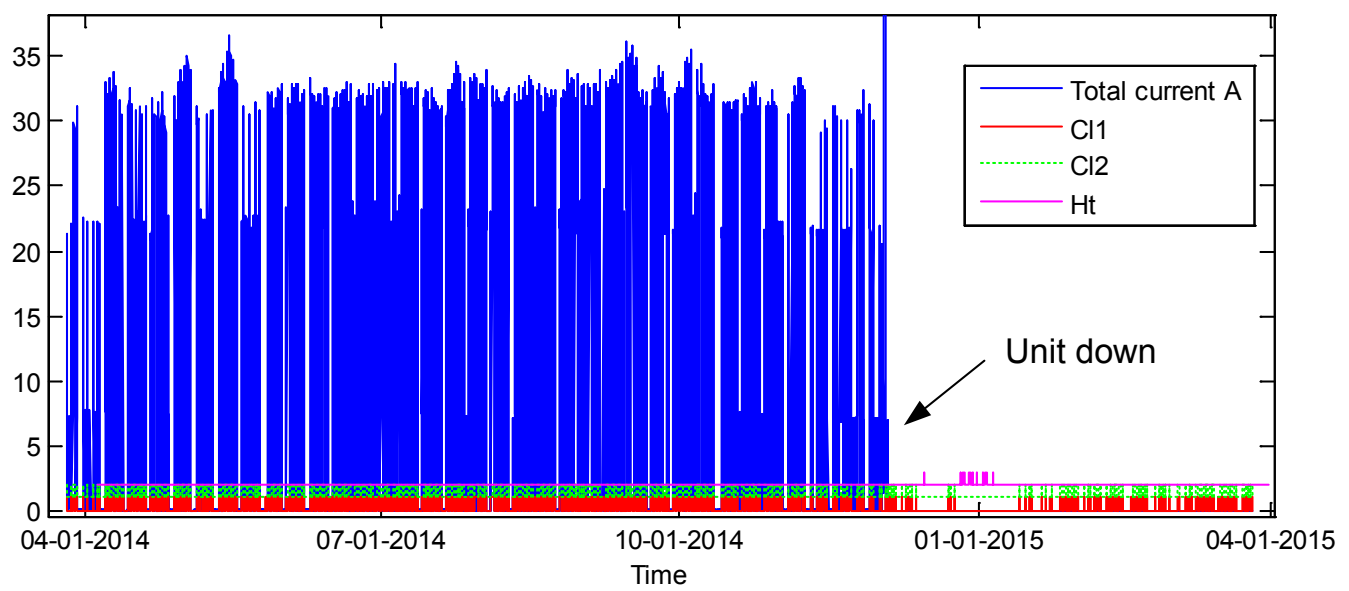

Figure B-6. Time plot of operation data of GPK_4 serving Site 14

\section{B.13 Site 15}

Site 15 has four packaged rooftop units with electric heat, identified as PAC_1 to PAC_4. Model numbers are missing for units $\mathrm{PAC}_{-} 1$ and PAC_4. For the other two units, tech sheets were found online but they indicate the units use gas as the heating source, but this site did not have gas bills at all. In addition, the EMS data shows significant electricity use in heating mode. So there was a potential retrofit for this site as those two units had been installed back in 2005 and the inventory data sheet might not have been kept updated. The EMS data shows that unit PAC_1 has two stages of cooling and two stages of heating and the corresponding powers can be easily identified from the histogram plot shown in Figure B-7. The other three units show one stage of cooling and one stage of heating in the thermostat requests. But the CT readings in units GPK_ 2 and GPK_3 show two levels of heating powers, as can be seen in Figure B-8, indicating a potential stage- -2 heating that was not recorded within the EMS data. 


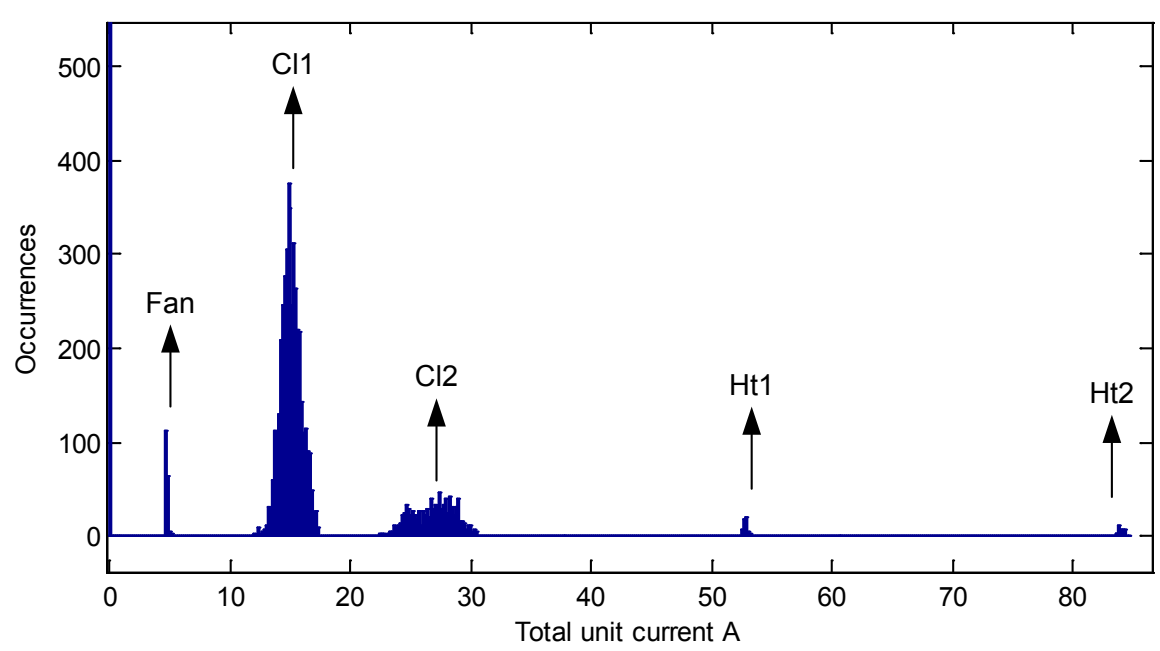

Figure B-7. Histogram plot of the total unit current of PAC_1 serving Site 15

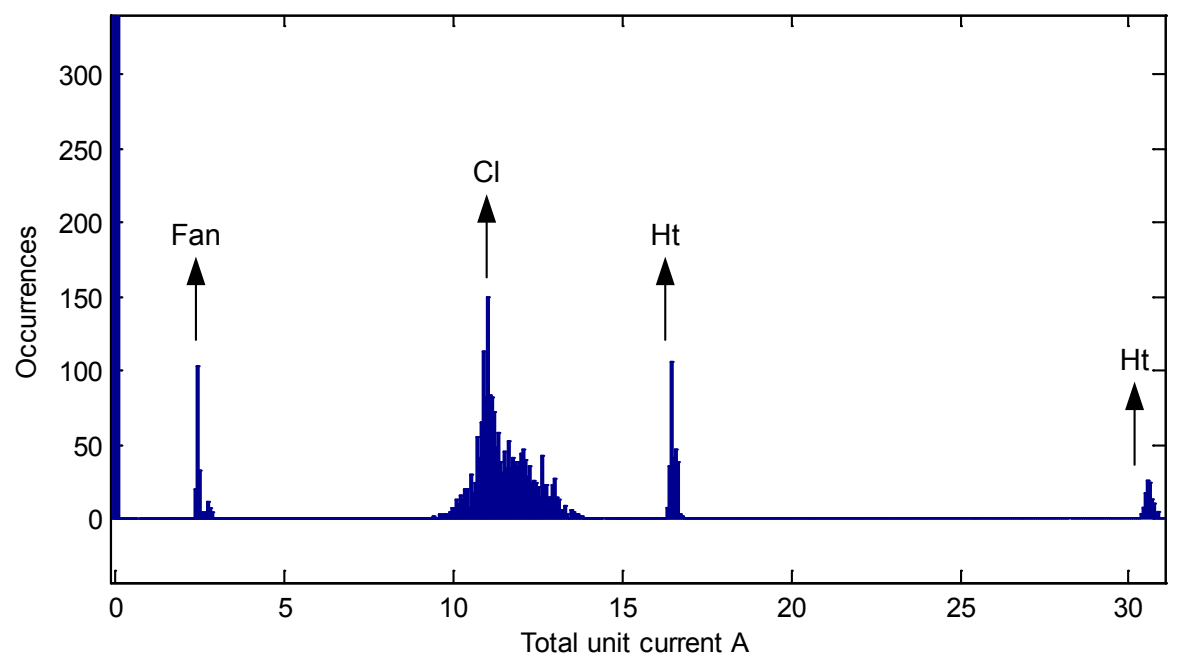

Figure B-8. Histogram plot of the total unit current of PAC_2 serving Site 15

\section{B.14 Site 16}

Site 16 has four split cooling systems with gas heat. CT's in the indoor units only captured the supply fan power and the current measurements in the outdoor units were integrated through each billing cycle to determine the cooling electricity uses. All four units for this site used singlephase power, so a power phase correction factor of 1 was used in the power calculation. 


\section{Appendix C}

Section 4 presented Site 1 validation results as a demonstration case. This appendix documents the detailed validation results for all other test sites.

\section{C.1 Site 2}

This site is located in Brooklyn, New York, with relatively cold climate, and gas is the primary heating source. No electric heat was present at this site so the heating electricity use is zero. However, the Tool significantly overpredicts both cooling and heating uses. This is because the submetered baseload exhibits a valley shape with temperature dependence on both low and high ends of the plotted temperature range.

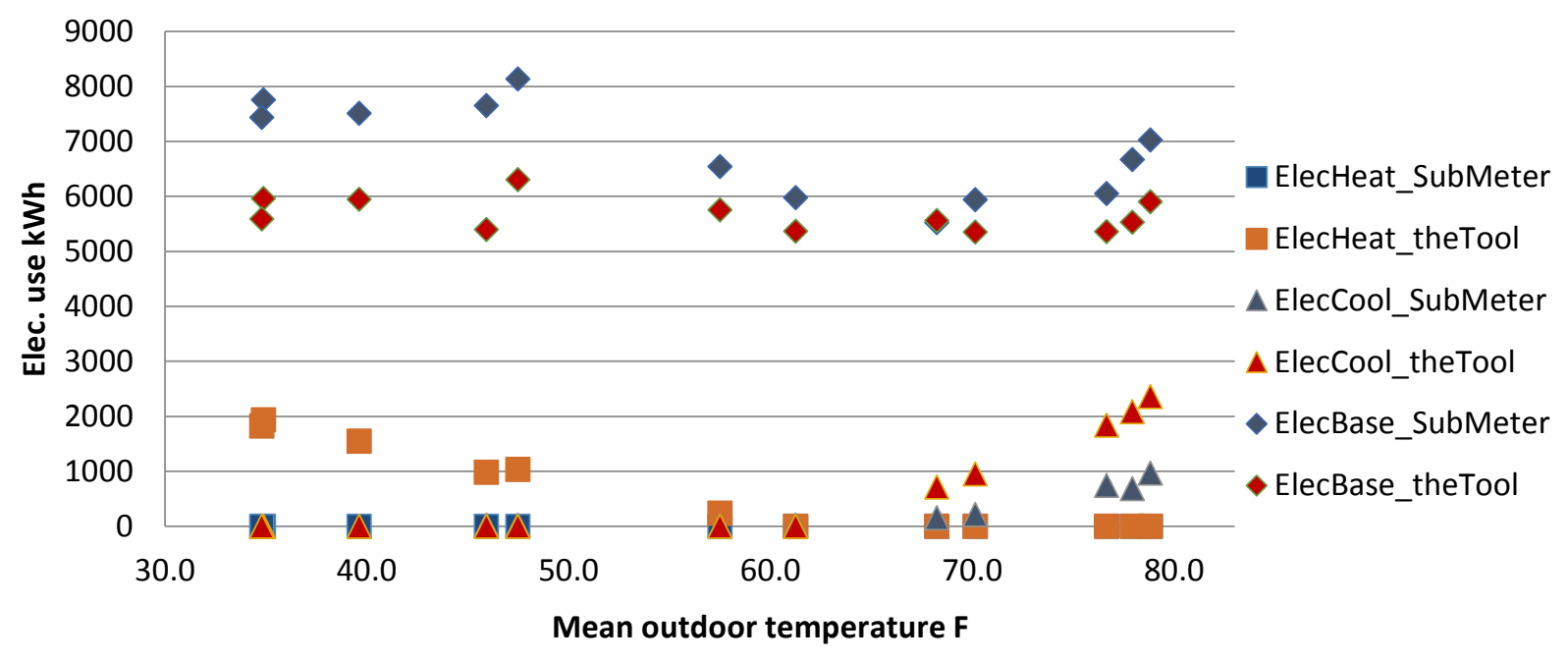

Figure C-1. Electricity end use validation results for Site 2

\section{C.2 Site 3}

This site is located in Seattle, Washington, in the marine climate zone featuring cool summers and warm winters. Heating electricity use is dominant while the cooling demand is relatively low. Reasonable accuracies can be observed for the cooling and heating electricity use estimation. Slight overprediction is present for the heating use at lower outdoor temperatures. Again, this is because the submetered baseload exhibits a consistent negative slope in the heating season and the Tool counted the temperature-dependent energy towards heating use. Note that the submetered cooling electricity use is nonzero in the heating season indicating simultaneous heating and cooling within the building. 


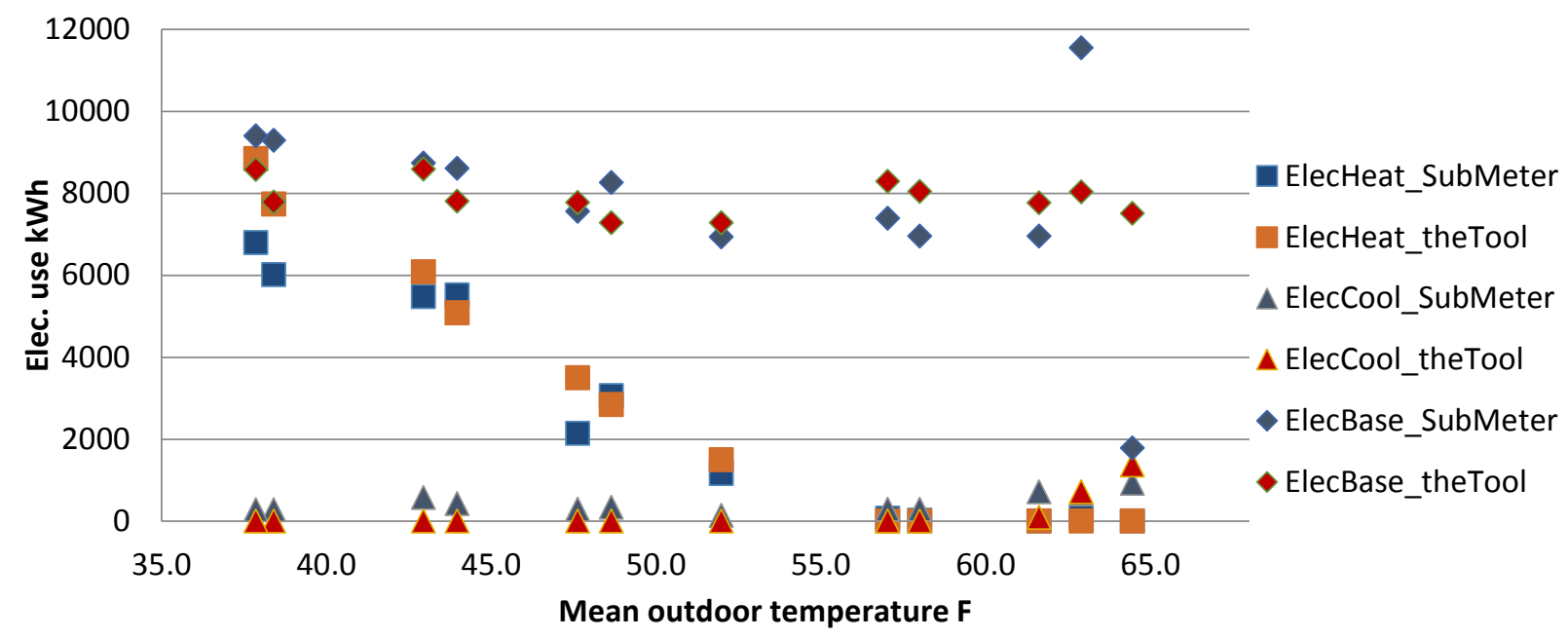

Figure C-2. Electricity end use validation results for Site 3

There are two submetered baseload points that are significantly off the normal baseload level and are far from the Tool's estimate. These two points correspond to the two outlier points in the electricity bill data as shown in Figure C-3 and these two outlier points caused the Tool to output a warning message for this site indicating a poor model fit with an R-squared value of less than 0.85. The outlier points indicate potential meter misreads or irregular activities within those two months that consumed excessive electricity.

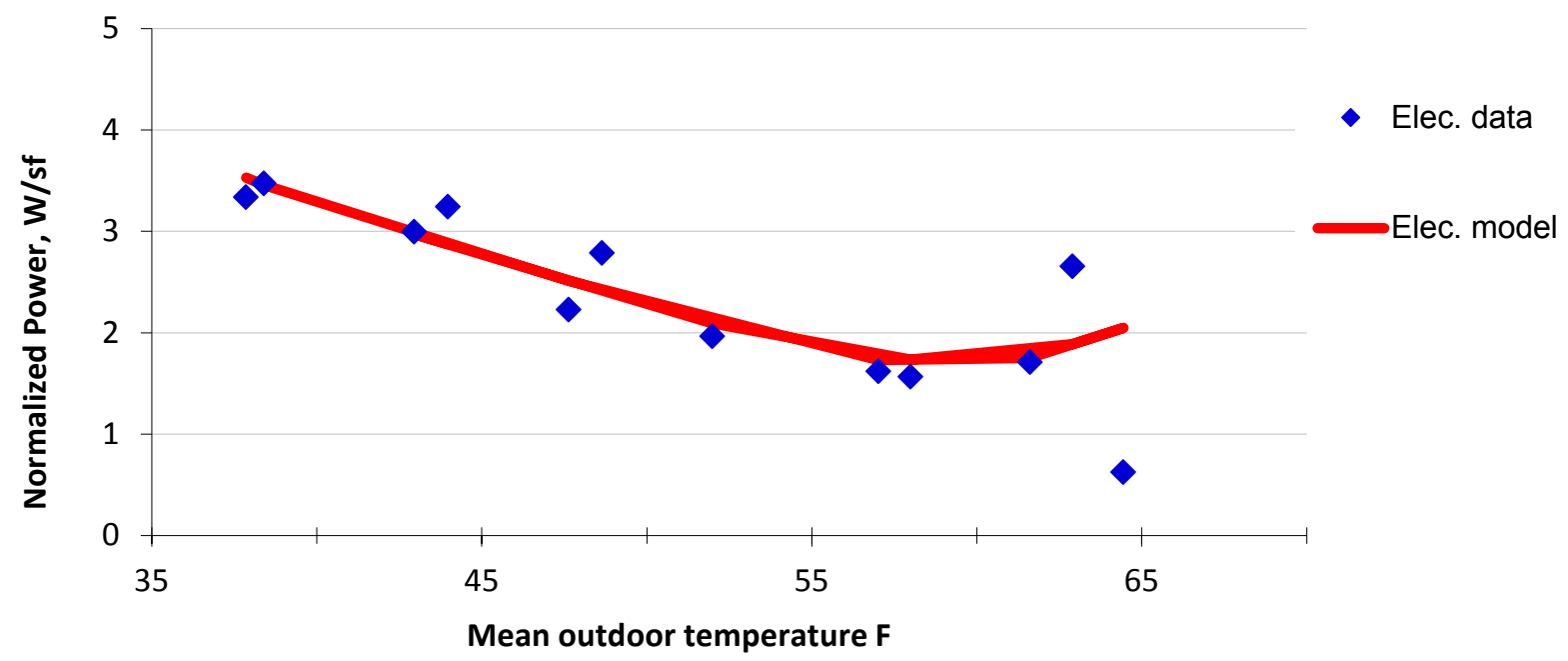

Figure C-3. Electricity signature plot along with the estimated model from the Tool for Site 3

\section{C.3 Site 4}

Similar to Site 2, Site 4, located in Seattle, Washington, in the marine climate zone featuring cool summers and warm winters, used gas as the primary heating source and no electric heat was involved. The Tool outputs nonzero heating electricity use and this is primarily because of the temperature-dependent baseload use at low ambient temperatures and the fact that the Tool counted the temperature-dependent portion of the baseload as space heating use. For cooling use 
estimation, the Tool shows an early cutoff, but because cooling energy use is relatively small compared to the baseload use, the inaccuracy would not affect the overall performance much.

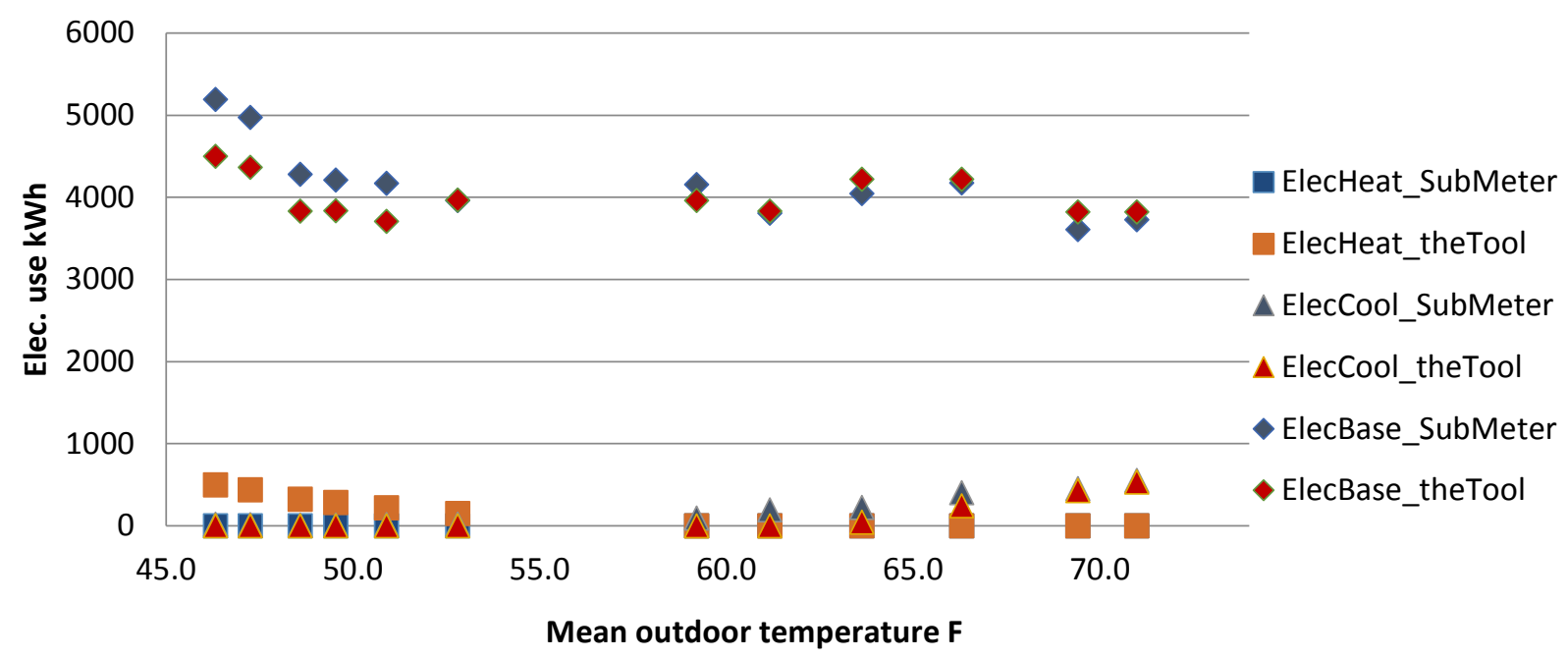

Figure C-4. Electricity end use validation results for Site 4

\section{C.4 Site 5}

Site 5 is located at San Antonio, Texas, in the hot-humid climate zone. Thus, cooling energy use is significant for this site. The Tool consistently overestimates the cooling electricity use and consistently underestimates the heating electricity use. That is because the submetered baseload shows a consistently negative slope with respect to outdoor temperature.

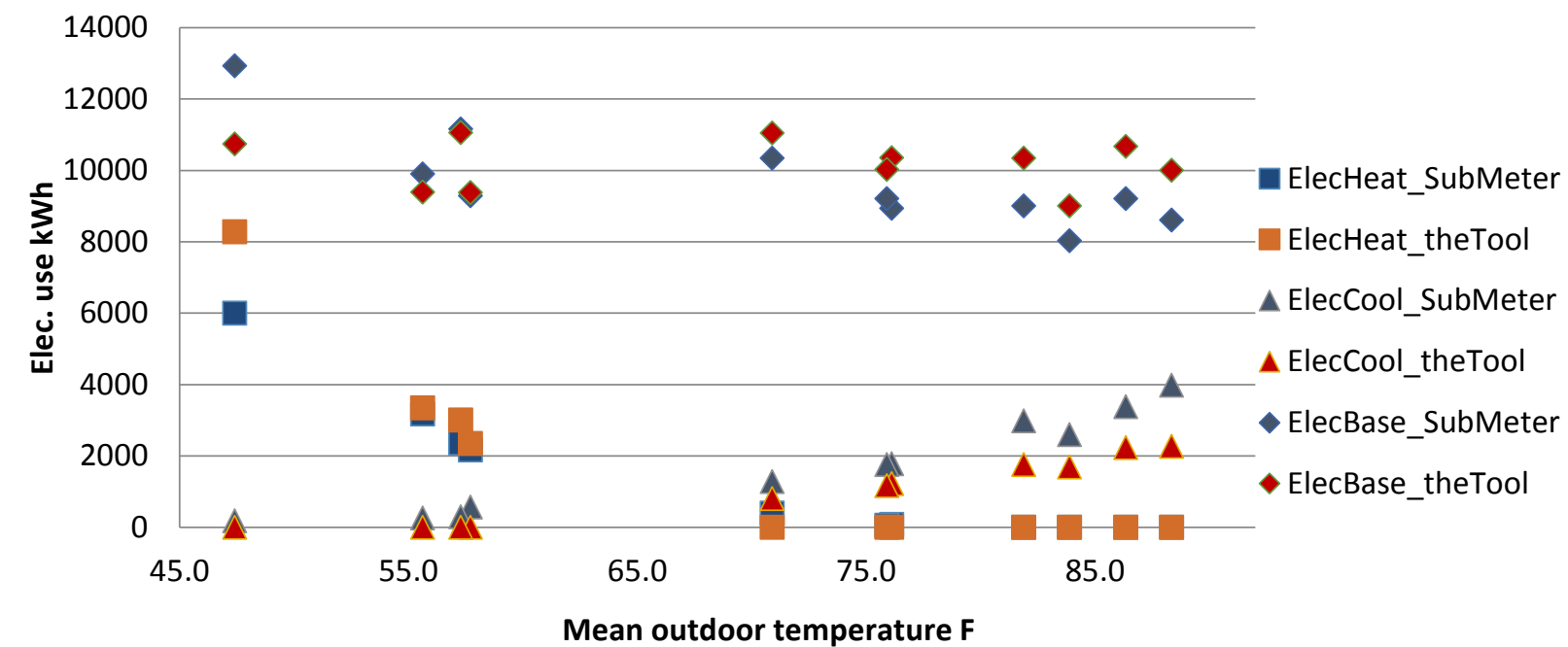

Figure C-5. Electricity end use validation results for Site 5

\section{C.5 Site 6}

Similar to Site 5, Site 6 is also located in Austin, Texas, in the hot-humid climate zone, and there is significant cooling demand. The Tool overestimates both cooling and heating electricity uses as the submetered baseload exhibits a valley shape. 


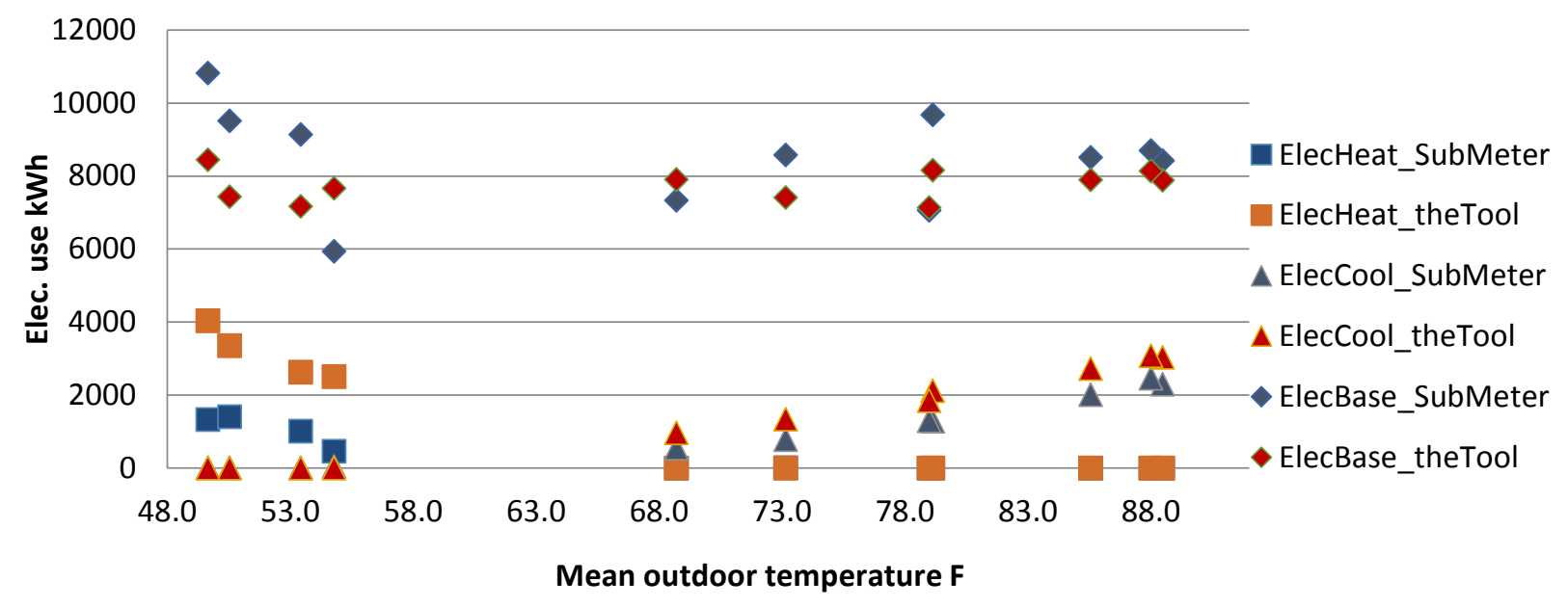

Figure C-6. Electricity end use validation results for Site 6

\section{C.6 Site 7}

Site 7 is located in Newton, Massachusetts, in the cold climate zone and is heating-dominant. This site relied on both electricity and gas for space heating: units GPK-1 to GPK-4 are packaged rooftop units with gas heat and unit SSEL-5 is a split system with an electric heater in the indoor unit. The Tool overestimates both heating and electricity heating uses and the estimation errors are larger for heating electricity use. Tech sheets for three of the units are lacking for this site and assumptions had to be made about the line voltage and number of phases in the power supply, leading to elevated uncertainties.

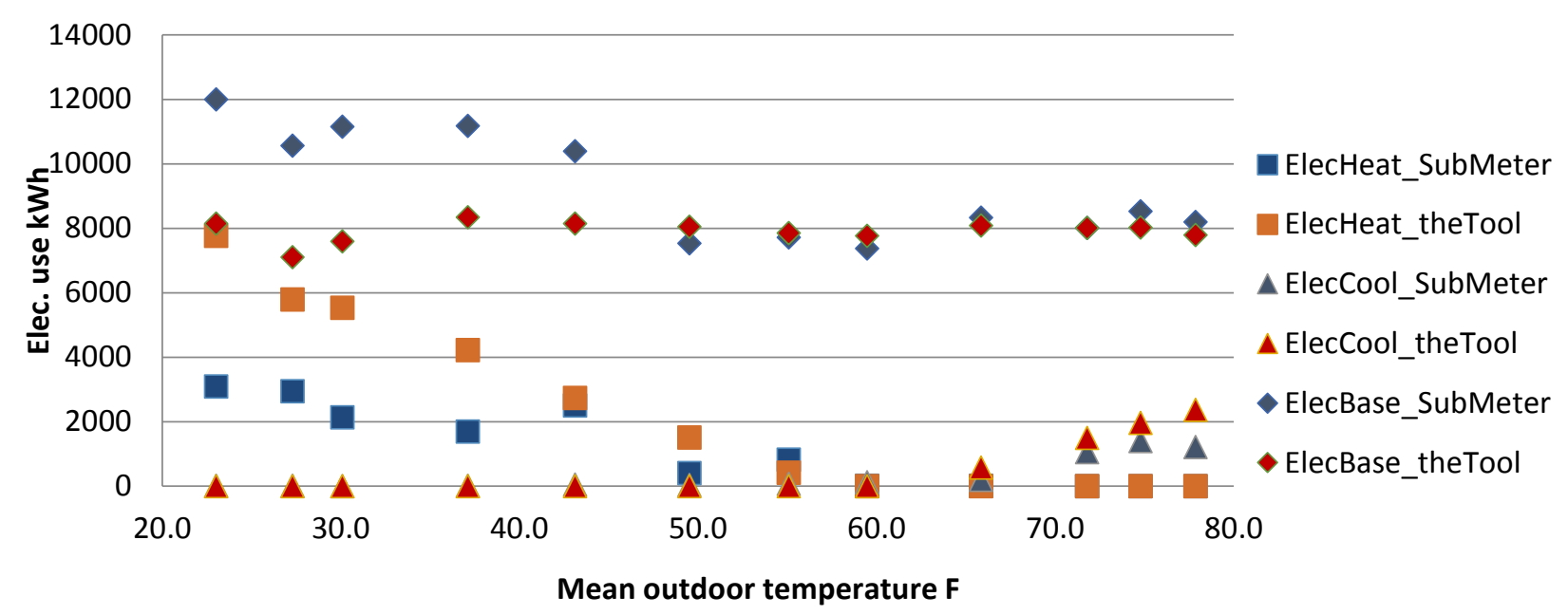

Figure C-7. Electricity end use validation results for Site 7

\section{C.7 Site 8}

Site 8 is located at Los Angeles, California, which has a relatively flat, hot-dry climate. The Tool gives near-zero estimation for both cooling and heating electricity uses but fairly significant cooling existed, as shown in Figure C-8. The large errors are because electricity bills are flat with respect to ambient temperature as shown in the energy signature graph in Figure C-9, but the cooling energy use increases significantly with higher ambient temperature. This discrepancy 
could be due to either meter misreads or decreasing baseload use with higher ambient temperature. Because the estimated cooling energy use is close to zero, the Tool also gives a warning message indicating existence of self-cooling devices in the building that were not metered.

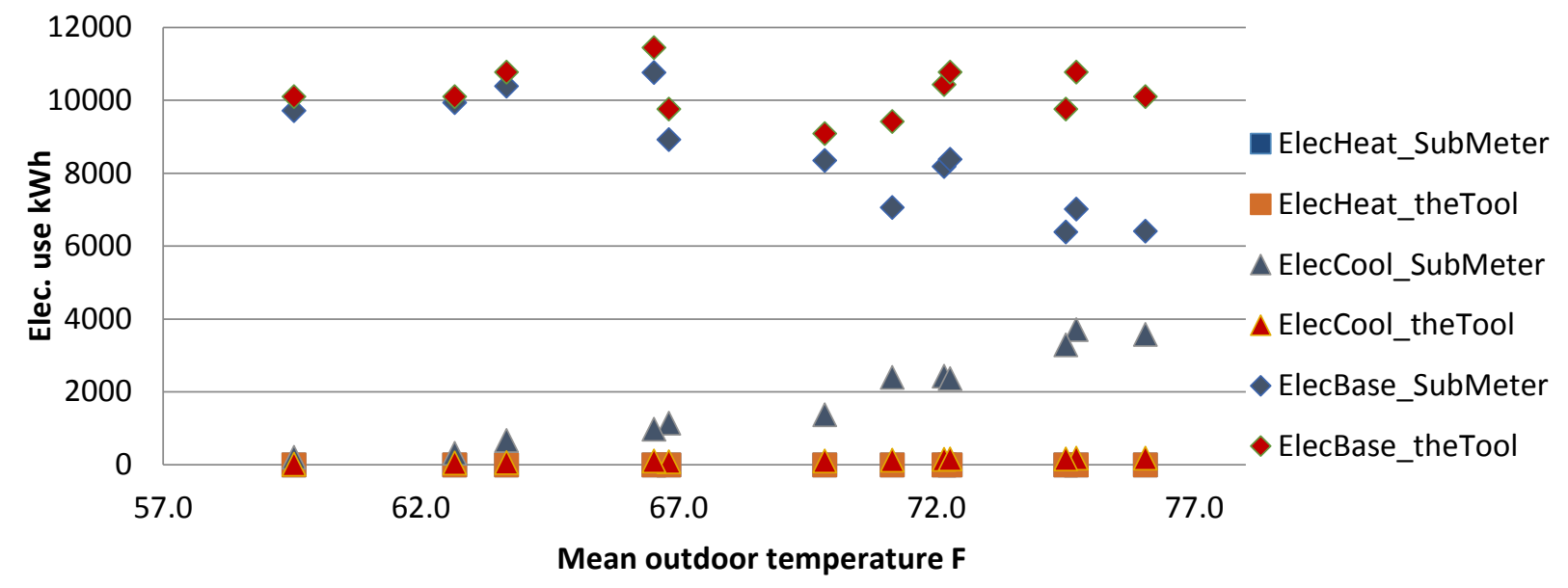

Figure C-8. Electricity end use validation results for Site 8

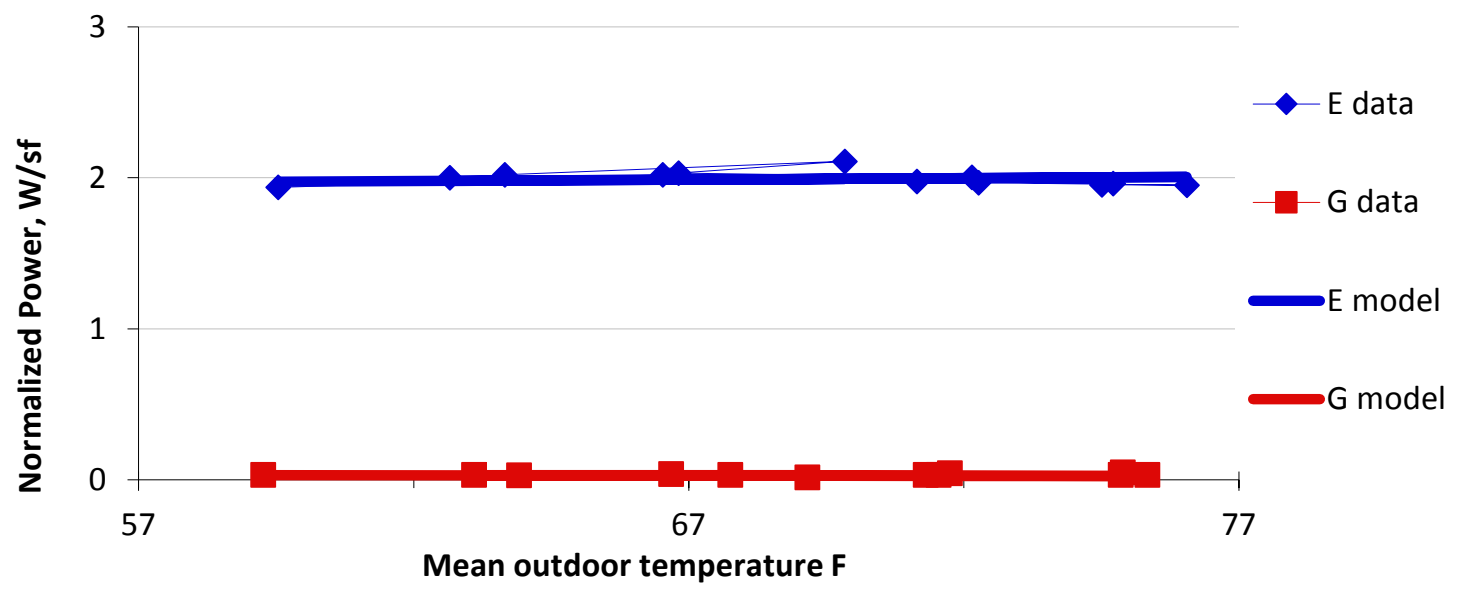

Figure C-9. Energy use signature graph for Site 8

\section{8 Site 10}

This site is located in Norman, Oklahoma, in the mixed-humid climate zone, and the building consumed significant cooling energy. The Tool gives accurate cooling use estimation except for one billing month at the highest ambient temperature as shown in Figure C-10. The submetered cooling use shows a sudden drop for this billing month although the total electricity use for the same billing cycle is comparable to the similar-temperature months. Further investigation into the detailed operational results revealed that thermostats for two of the air-conditioning units, GPK-1 and GPK-3, were malfunctioning for more than 40 days, a period that included the problematic billing month. Figure C-11 shows the operational data plot for unit GPK-1. For the period of mid-August to early October, the thermostat temperature reading was at a constant value of $72^{\circ} \mathrm{F}$ and, as a consequence, no cooling request was made. Unit GPK-3 showed similar 
problems but the down period was different by several days. The issues within the two thermostats prevented the units from turning on and resulted in lower cooling energy use.

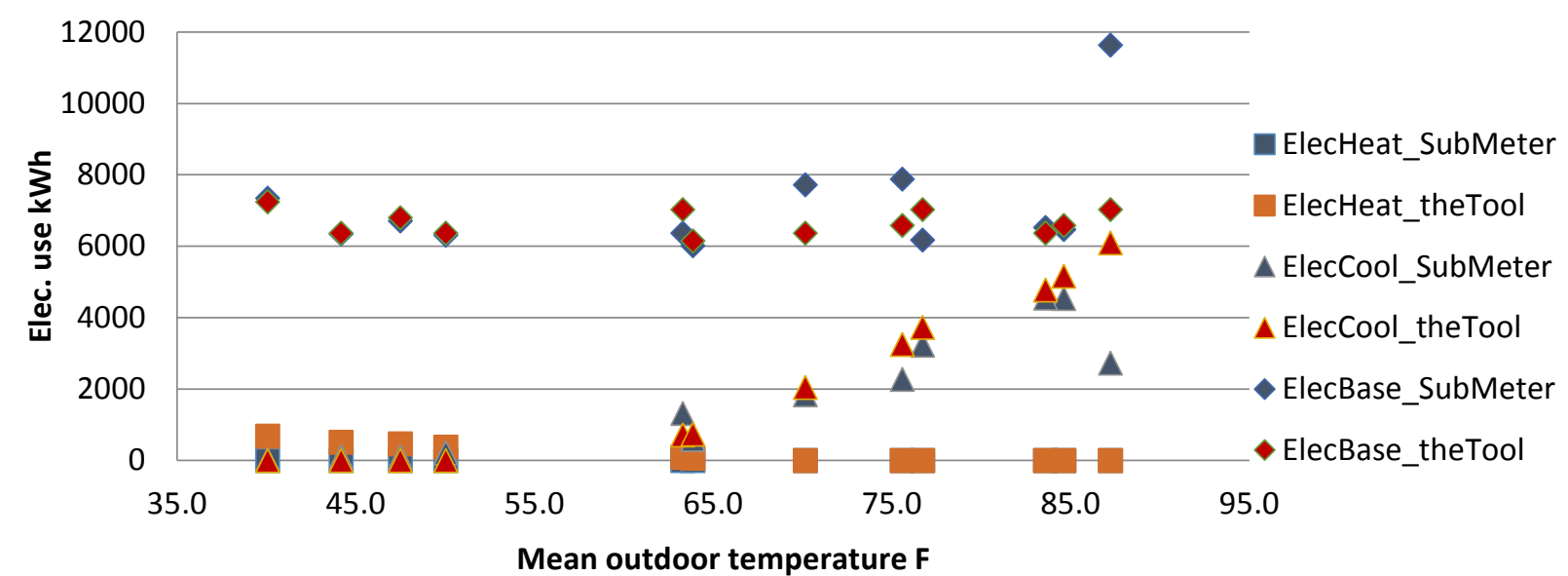

Figure C-10. Electricity end use validation results for Site 10

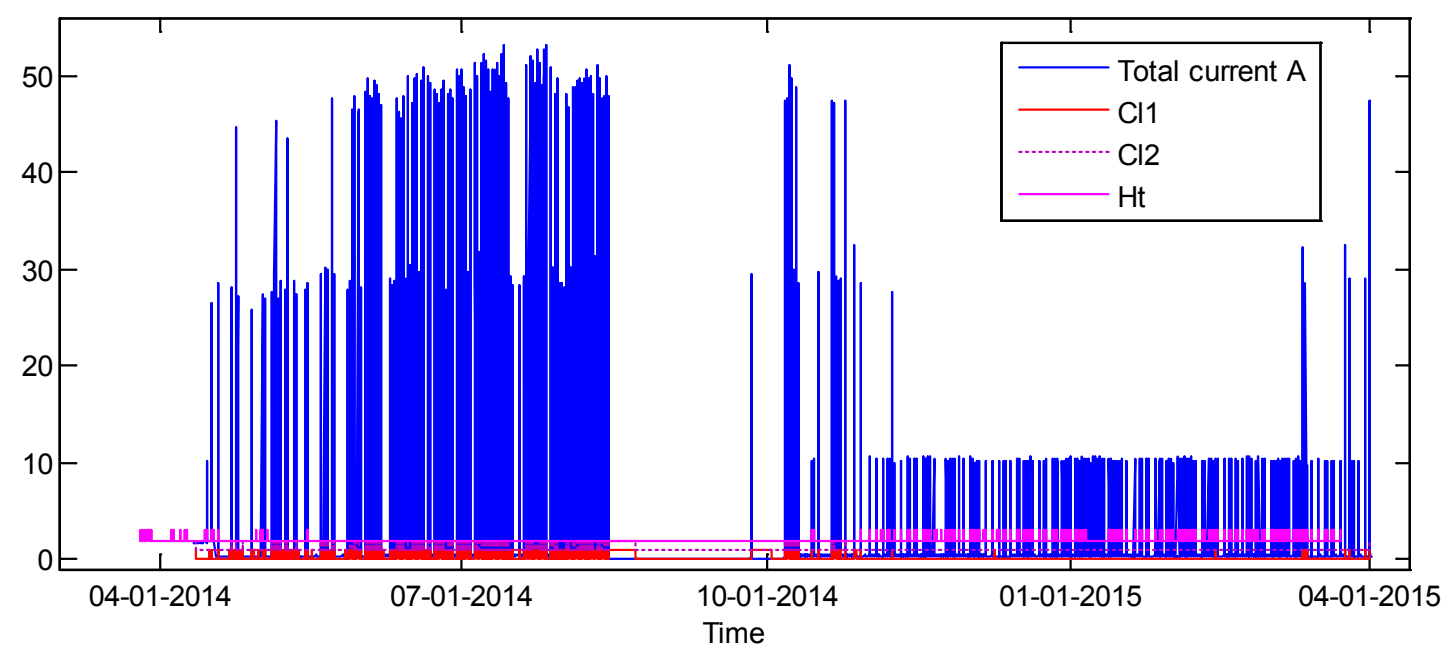

Figure C-11. Unit operation data for GPK-1 at Site 10

\section{C.9 Site 11}

This site is located in San Antonio, Texas, in the hot-humid climate zone and is coolingdominant. The Tool outputs underestimate both cooling and heating electricity uses caused by the negative slope in the submetered baseload with respect to outdoor temperature. However, the estimated baseload also exhibits a negative slope in the lower outdoor temperature range with zero heating electricity use estimation, potentially caused by a numerical failure in the Tool's regression analysis. Because of the zero heating energy estimation, the Tool generates a warning message indicating existence of self-heating devices in the building that were not metered. 


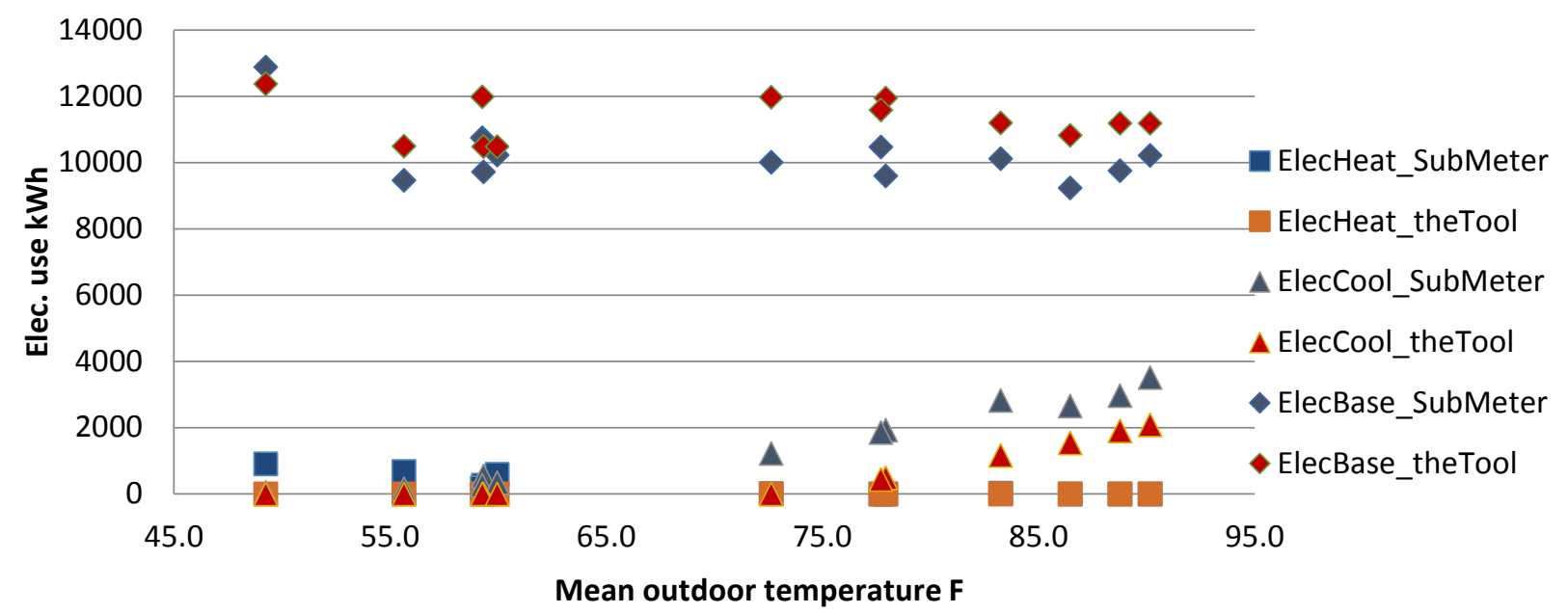

Figure C-12. Electricity end use validation results for Site 11

\section{C.10 Site 13}

This site is located in Los Angeles, California, which has mild and constant hot-dry climate conditions. The tool significantly overestimates the electricity cooling use, as the baseload shows a clear dependence on the outdoor temperature.

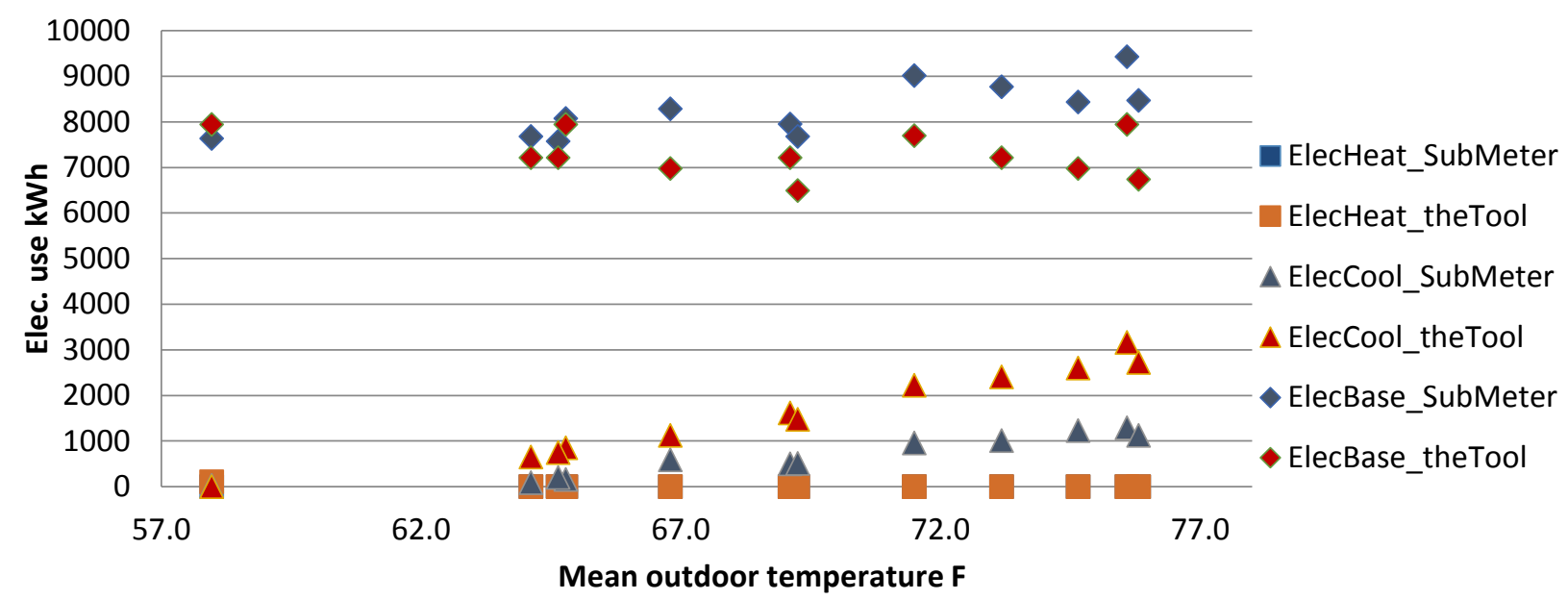

Figure C-13. Electricity end use validation results for Site 13

\section{C.11 Site 14}

Site 14 is also located in Los Angeles, California, with its relatively constant hot-dry climate conditions. The billed electricity use for this site does not vary much with outdoor temperature. Thus, the Tool's estimated cooling electricity use is small, and is significantly lower than the submetered cooling demand, as shown in Figure C-14. This could be caused either by lower baseload electricity use during warmer seasons or meter misreads in the electricity bills. 


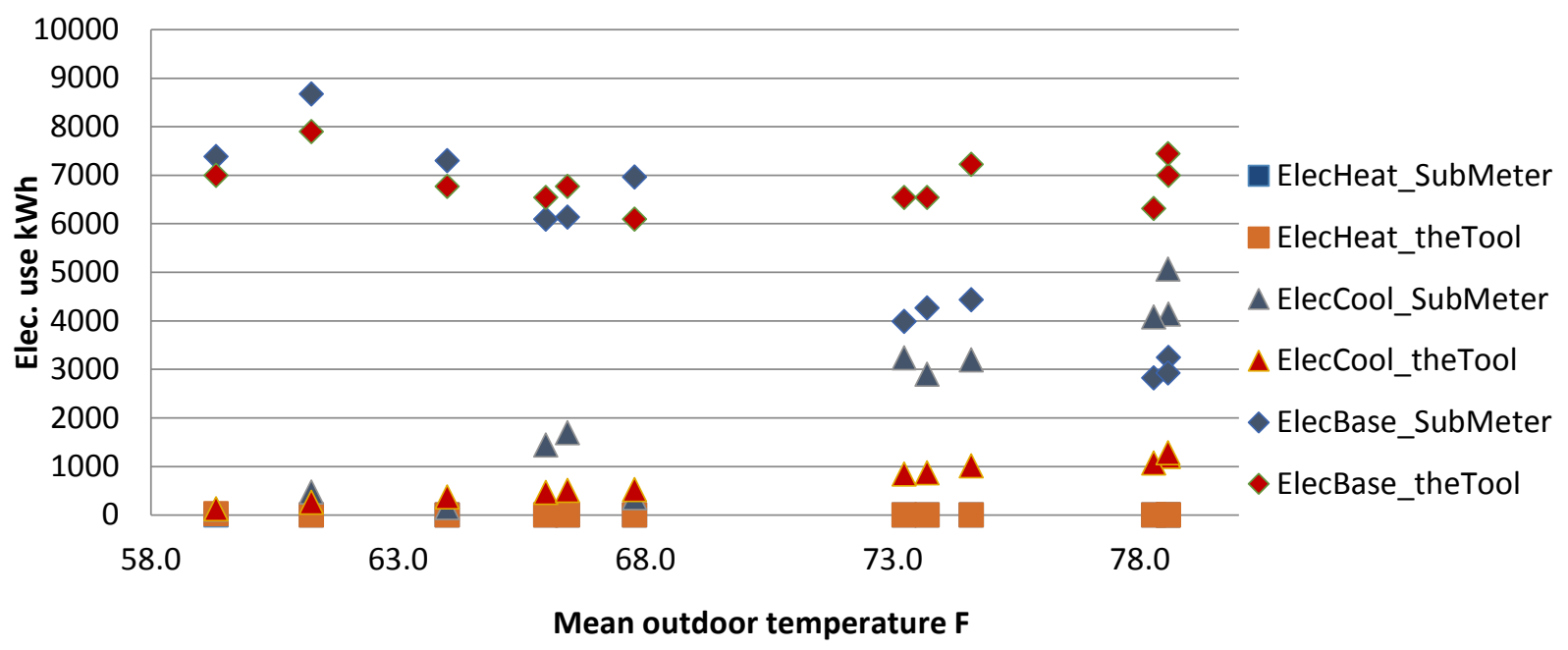

Figure C-14. Electricity end use validation results for Site 14

\section{C.12 Site 15}

This site is located in Austin, Texas, in the hot-humid climate zone and is cooling-dominant. Reasonably good accuracy can be observed in the heating, cooling, and baseload use estimation. Slight underprediction for the cooling electricity use can be seen due to the small variation of the submetered baseload use with outdoor temperature.

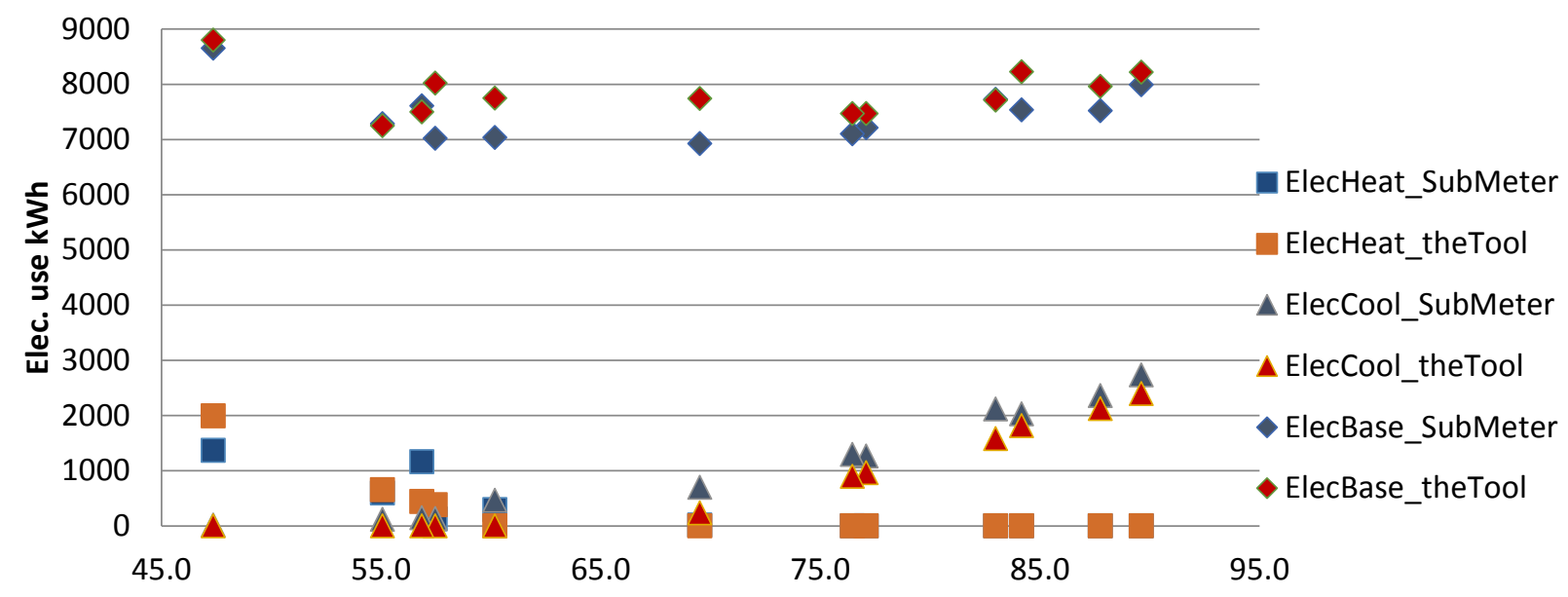

Mean outdoor temperature $F$

Figure C-15. Electricity end use validation results for Site 15

\section{C.13 Site 16}

This site is located in Edmond, Oklahoma, in the mixed-humid climate zone. The Tool provides reasonably accurate estimation of both cooling and heating electricity uses as shown in Figure C16. The good accuracy obtained is due to the relatively flat baseload use profile. 


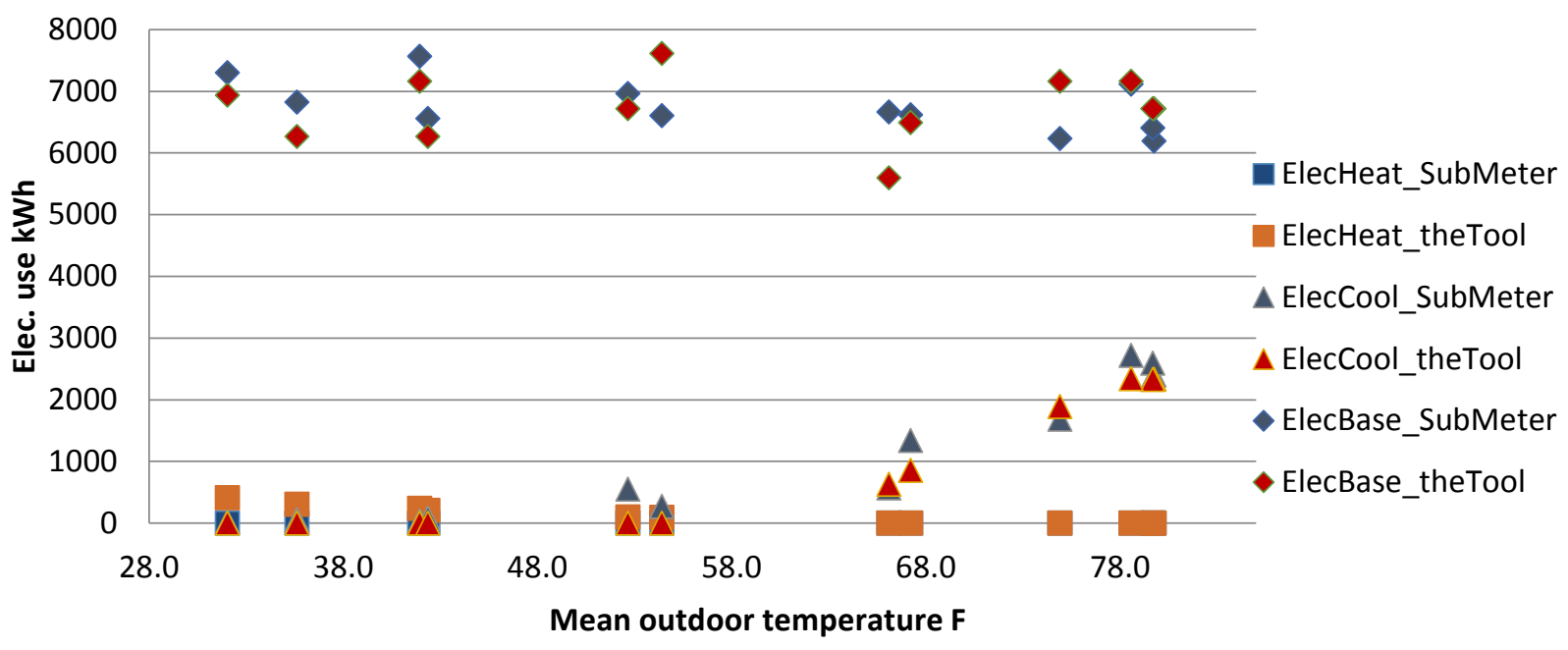

Figure C-16. Electricity end use validation results for Site 16 


\section{Appendix D}

The gas validation step in this study only considered the comparison of the billed and the Tool's estimated total gas uses. Figure D-1 to Figure D-8 show the comparison results for the sites that use gas.

Site 2 has a gas bill with a single-day billing period. Although the single-day bill was removed in running the Tool's regression analysis, the estimated use for this billing period was still provided by the Tool and the overall comparison results for Site 2 are shown in Figure D-1. The Tool provides a significant overestimation of the total gas use in one of the billing periods (the one with an outdoor temperature of $48^{\circ} \mathrm{F}$ in Figure D-1), which indicates a possible operational change leading to less gas consumption for that month.

Site 8 has near-zero gas uses throughout the whole year as shown in the plot of gas bills in Figure C-9. The Tool outputs a warning message indicating that there may be self-heating devices in the building that were not metered.

All sites have zero gas baseload use (inferred by zero gas bills in non-heating season) except for Site 10 . However, the gas baseload use for Site 10 is small and negligible compared to heating use as shown in Figure D-5.

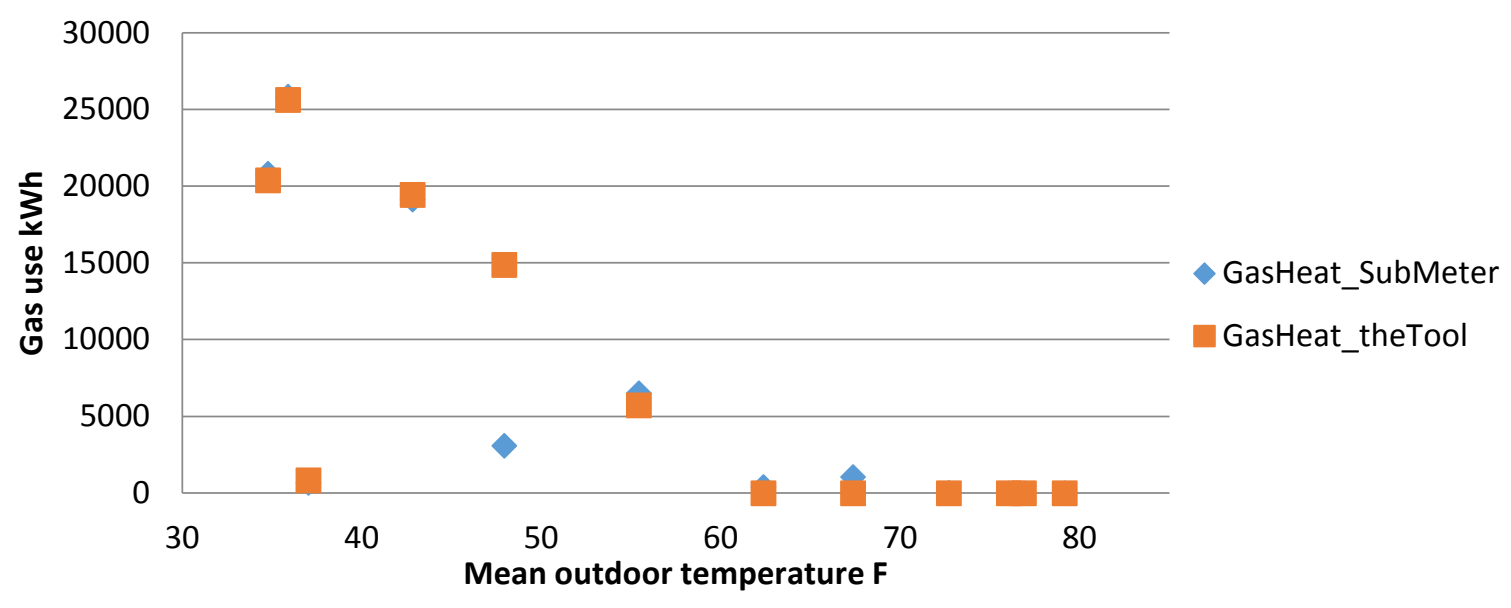

Figure D-1. Gas use validation results for Site 2

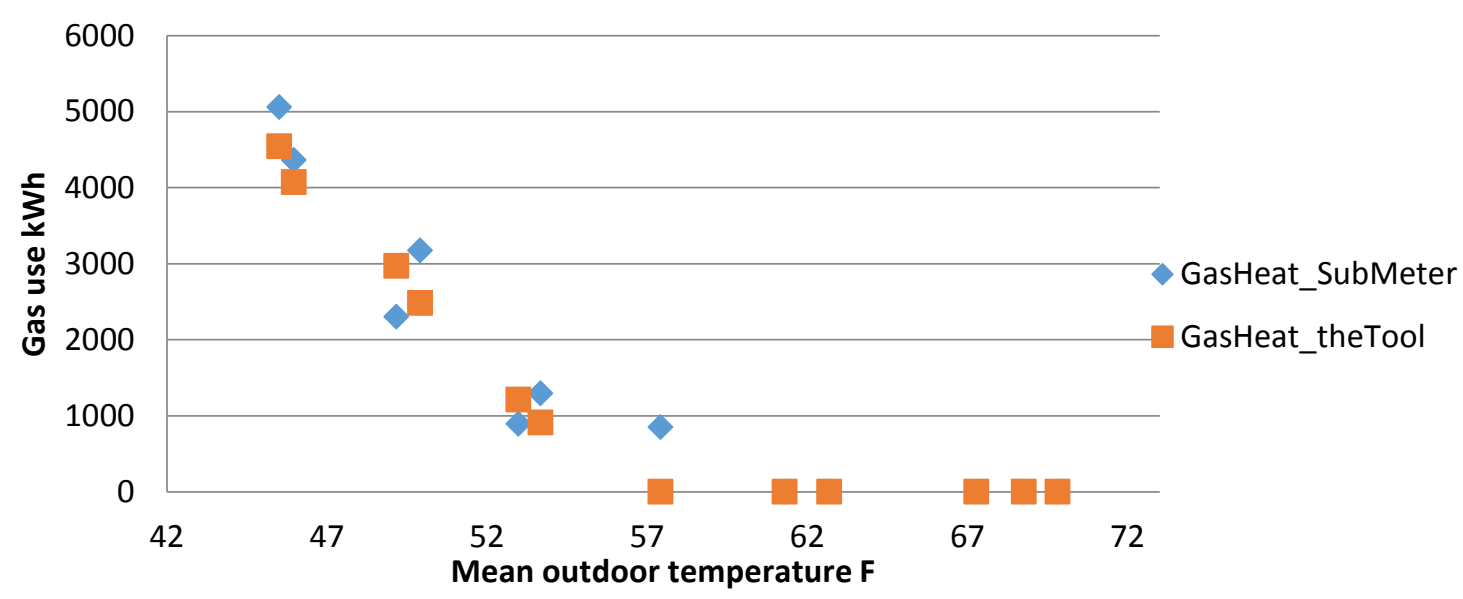

Figure D-2. Gas use validation results for Site 4 


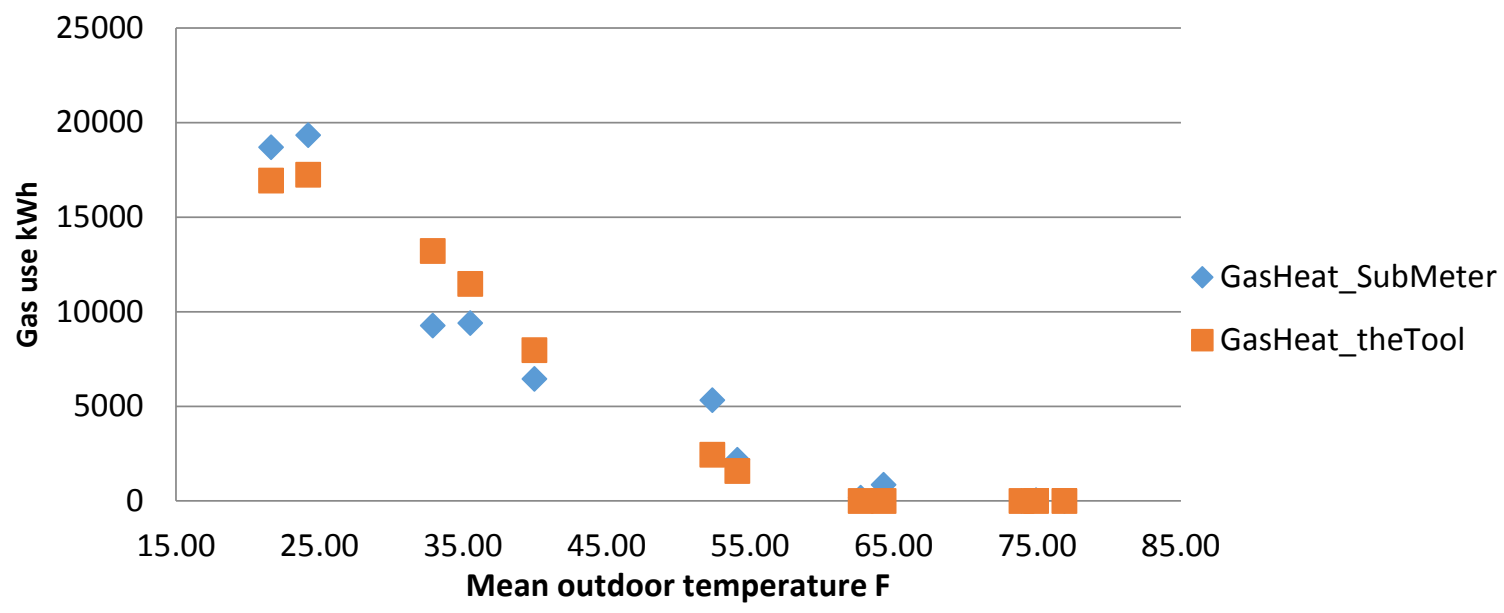

Figure D-3. Gas use validation results for Site 7

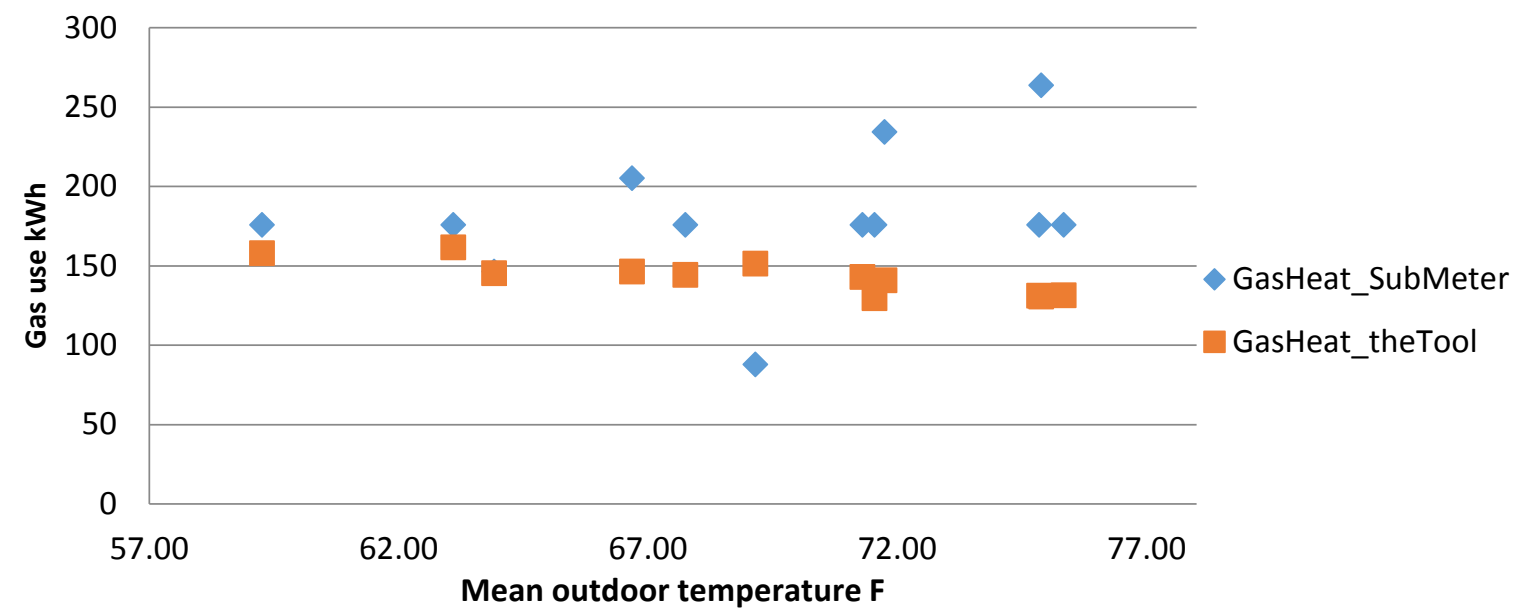

Figure D-4. Gas use validation results for Site 8

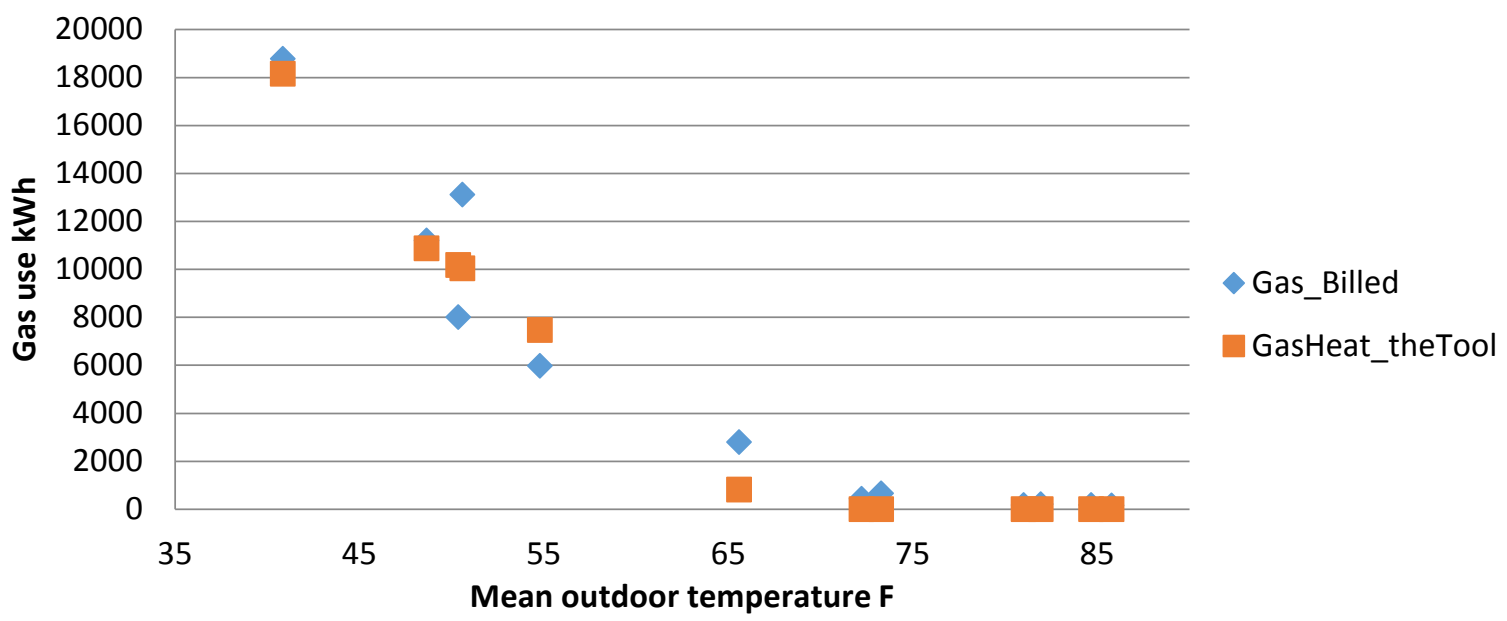

Figure D-5. Gas use validation results for Site 10 


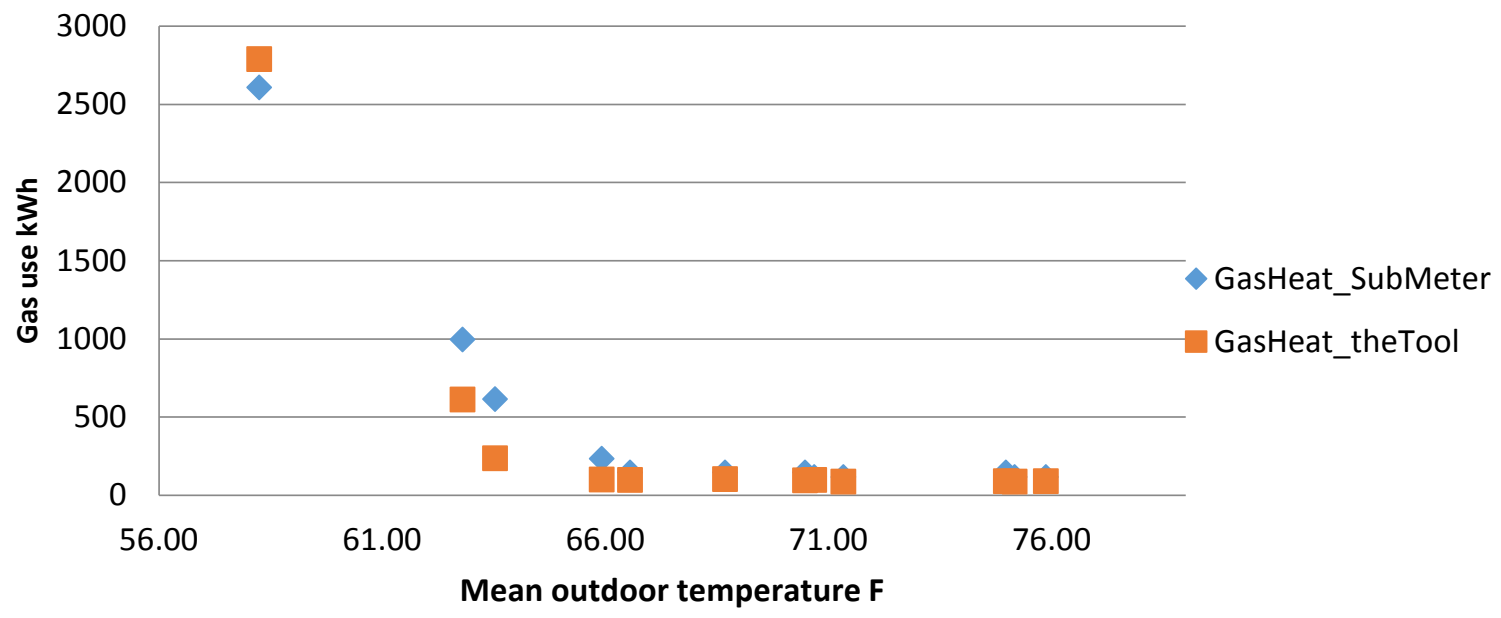

Figure D-6. Gas use validation results for Site 13

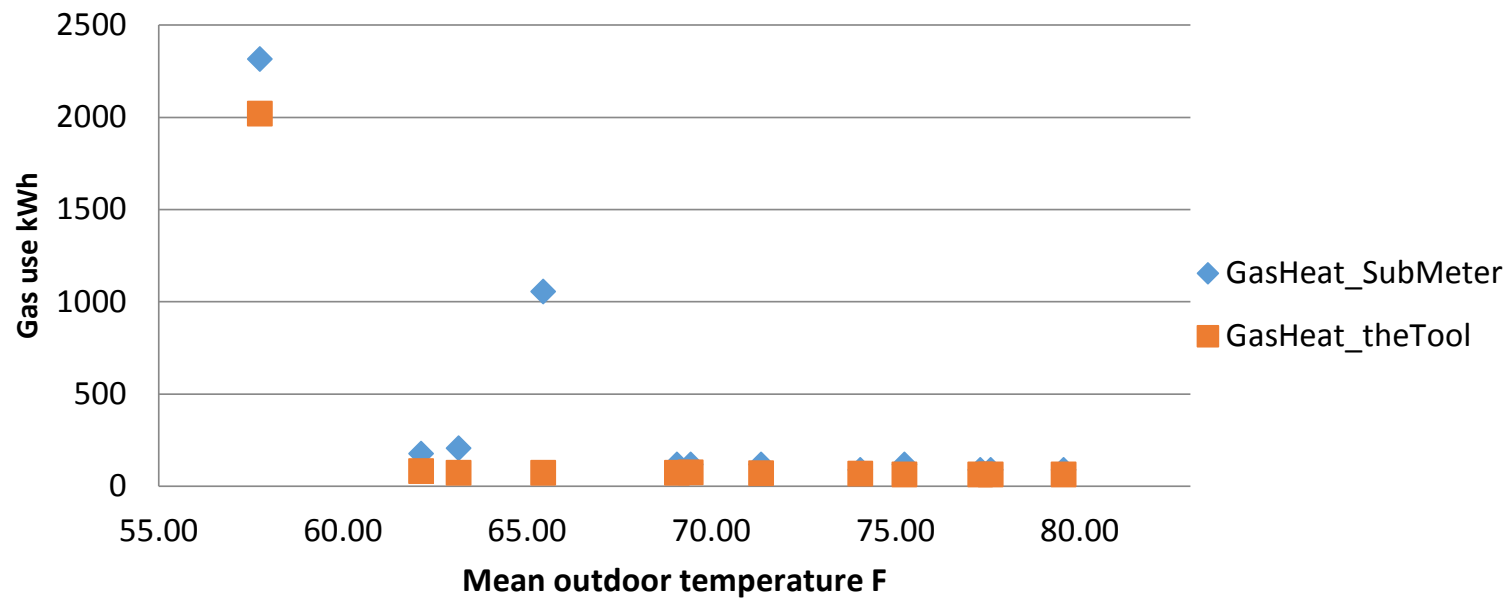

Figure D-7. Gas use validation results for Site 14

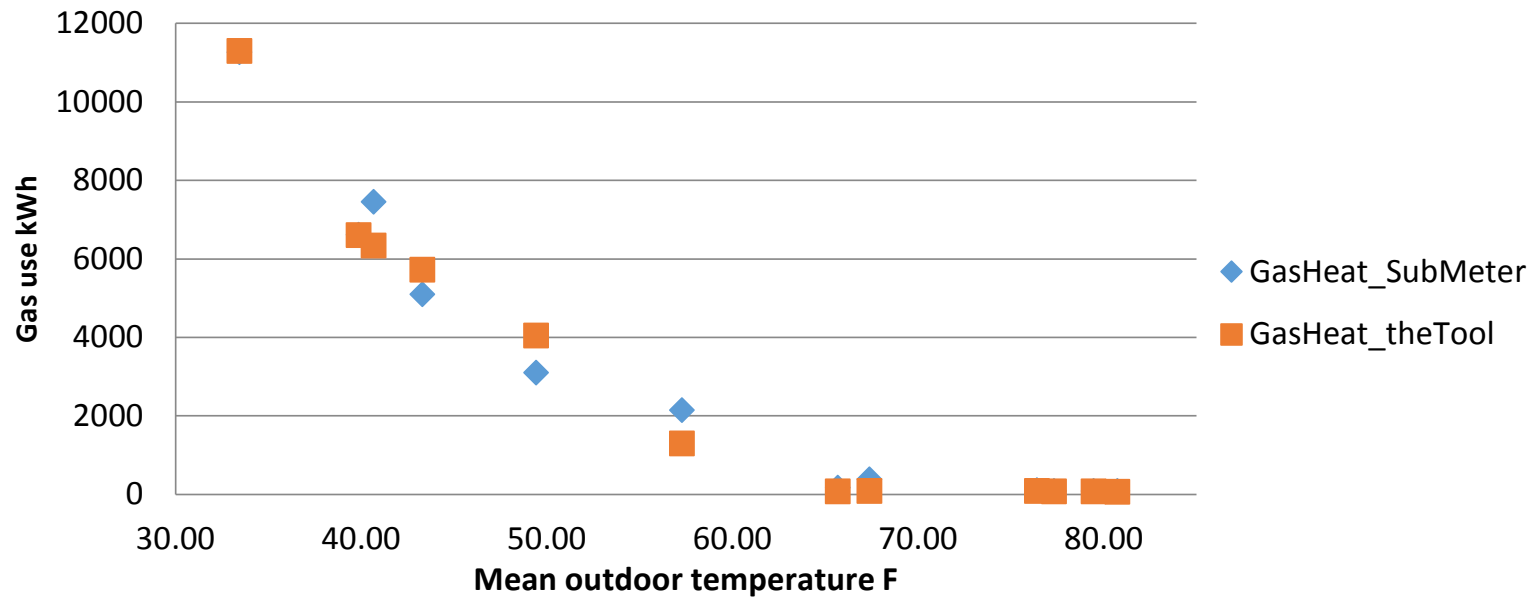

Figure D-8. Gas use validation results for Site 16 